\title{
Floristic study of lagoon areas on the eastern coast in Korean peninsula
}

\author{
Jung-Hyun Kim, Sun-Yu Kim¹, Jeong-Ki Hong², Gi-Heum Nam, Ji-Hong An, \\ Byoung Yoon Lee and Jin-Seok Kim*
}

Plant Resources Division, National Institute of Biological Resources, Incheon 22689, Korea

${ }^{1}$ Exhibition and Education Division, Nakdonggang National Institute of Biological Resources, Sangju 37242, Korea

${ }^{2}$ Freshwater Biodiversity Research Bureau, Nakdonggang National Institute of Biological Resources, Sangju 37242, Korea

(Received 24 November 2016; Revised 12 January 2017; Accepted 25 January 2017)

\section{한반도 동해안 석호의 관속식물상}

\author{
김중현 · 김선유 ${ }^{1}$ · 홍정기 ${ }^{2}$ - 남기흠 · 안지홍 · 이병윤 · 김진석* \\ 국립생물자원관 식물자원과, ${ }^{1}$ 국립낙동강생물자원관 전시교육실, ${ }^{2}$ 국립낙동강생물자원관 담수생물다양성연구실
}

\begin{abstract}
Eastern coastal lagoons are a particular type of estuarine systems where seawater mixes with fresh water from their catchments. With the development of aquatic vegetation, this area shows high level of biodiversity. The purpose of this study is to produce a strategy for the comprehensive conservation of the vegetation of coastal lagoons through studies of the floristics and plant species compositions in 17 eastern coastal lagoons in Korea. Vascular plants were collected 109 times, from June of 2010 to November of 2014. The results showed that there were 720 taxa in total, including 118 families, 378 genera, 655 species, 13 subspecies, 46 varieties, and 6 hybrids. Korean endemic species numbered 11 taxa, and vascular plants listed in the red list according to the International Union for Conservation of Nature (IUCN) numbered 18 taxa. Indicator species of fourth (IV) and fifth (V) degree, as specified by floristic subregions, numbered 23 taxa. Among the species investigated in this survey, there were 4 taxa of plants of southern origin and 8 taxa of plants of northern originin the Korean peninsula. Several rare plants, Thermopsis lupinoides, Ligusticum hultenii, Mitrasacme alsinoides, Utricularia australis, Juncus fauriei, Carex vesicaria, and Puccinellia kurilensis, were distributed in eastern coastal lagoons. In all, 96 alien plants were recorded in the investigated area. The coastal lagoons on the eastern coast of Korea showed high plant diversity with many rare plants and phytogeographically important plants. Conservation strategies to ensure biodiversity and effective management of coastal lagoons are discussed in detail.
\end{abstract}

Keywords: lagoon, flora, rare plant, phytogeography

적 요: 동해안 석호는 해수와 담수가 섞인 독특한 형태의 기수호이며, 수변식생이 발달되어 생물다양성이 풍부한 지역이다. 본 연구는 국내에 분포하는 17 개소의 석호에 대한 식물상과 식물 종조성 등의 조사를 통하 여 석호 식생에 대한 안정적인 보전계획 수립을 위한 기초자료를 제시하고자 한다. 17 개소의 석호에 대한 식 물상 조사결과, 관속식물은 118 과 378 속 655 종 13 아종 46 변종 6 교잡종, 총 720 분류군이 확인되었다. 이중에 서 한반도 고유종이 11 분류군, 멸종우려 식물이 18 분류군, 식물구계학적 특정식물인 IV-V등급 식물이 23 분류 군이었다. 남방계식물은 4 분류군, 북방계식물은 8 분류군으로 조사되었고, 특히 남한 내 희귀식물인 갯활량나물 (Thermopsis lupinoides), 기름당귀(Ligusticum hultenii), 벼룩아재비(Mitrasacme alsinoides), 통발(Utricularia

\footnotetext{
*Author for correspondence: foko@korea.kr
} 
australis), 검정납작골풀(Juncus fauriei), 새방울사초(Carex vesicaria), 천도미꾸리광이(Puccinellia kurilensis) 등이 동해안 석호에서 생육하고 있었다. 외래식물은 96분류군이 발견되었다. 한반도 석호는 식물다양성이 풍 부하고, 희귀식물 및 식물지리학적 중요한 식물이 관찰된다. 석호의 효과적인 관리와 생물다양성 보전을 위 해 체계적인 사항들이 논의되었다.

주요어: 석호, 식물상, 희귀식물, 식물지리

동해안은 한반도 융기축인 함경산맥과 태백산맥이 해 안을 따라 평행하게 뻗어 전체적으로 섬의 수가 적고 해 안선이 단조로운 특징을 보이고 있다(Association for Research on Landscape Ecology, 2001; Lee et al., 2006; Hong, 2011). 바다에 인접하여 돌출된 산지가 많고 이들 사이에는 작은 만(灣)들이 다수 형성되어 있으며, 일반적 으로 만입부에 석호(lagoon)가 분포한다(Association for Research on Landscape Ecology, 2001). 석호는 파도나 해류 의 작용으로 해안선에 생기는 사주, 평행사도 또는 산호 초에 의해 하천의 하구나 만이 막혀서 생성된 연안호소 로 정의되며(Kim et al., 2001; Park, 2006), 일반적으로 해 수와 담수가 섞여 있는 독특한 형태의 기수호(汽水湖)로 분류된다(Park, 2006; Hong, 2011). 호소는 호수(湖)와 늪 (沼)이 합쳐져 만들어진 용어로 수질 및 수생태계 보전에 관한 법률에서는 호소를 만수위(댐의 경우 계획홍수위)
구역 안의 물과 토지로 규정하고 있다. 석호는 조석의 차 이가 적은 해안에서 가장 흔히 발견되고 전 세계 해안선 의 $13 \%$ 를 차지한다(Kjerfve, 1994; Kim et al., 2001). 한반 도의 석호는 총 48 개소이며, 강원도와 함경남도 해안에 서 가장 발달해 있다(Lee et al., 2006). 특히 강원도 강릉원산, 정평-북평 사이의 해안에서 석호의 분포 비율이 가 장 높게 나타나고 있다(Lee et al., 2006). 국내(남한)에서 는 18 개의 석호가 보고되어 있으며(Koo, 2009), 대부분이 강원도 고성군, 속초시, 양양군, 강릉시에 집중적으로 분 포하고 있다(Fig. 1).

지사학적인 석호의 형성 연도는 최후빙하기 이후이며, 형성 이후 수천 년에 걸쳐 지속적으로 매적되는 자연적인 과정을 거쳐 소멸되는 것으로 알려져 있다(Yoon et al., 2008). 석호의 수심, 면적 등의 경관 변화는 하천 유역분지 의 지형을 이루는 기반암의 특성과 관련하여 매립속도의

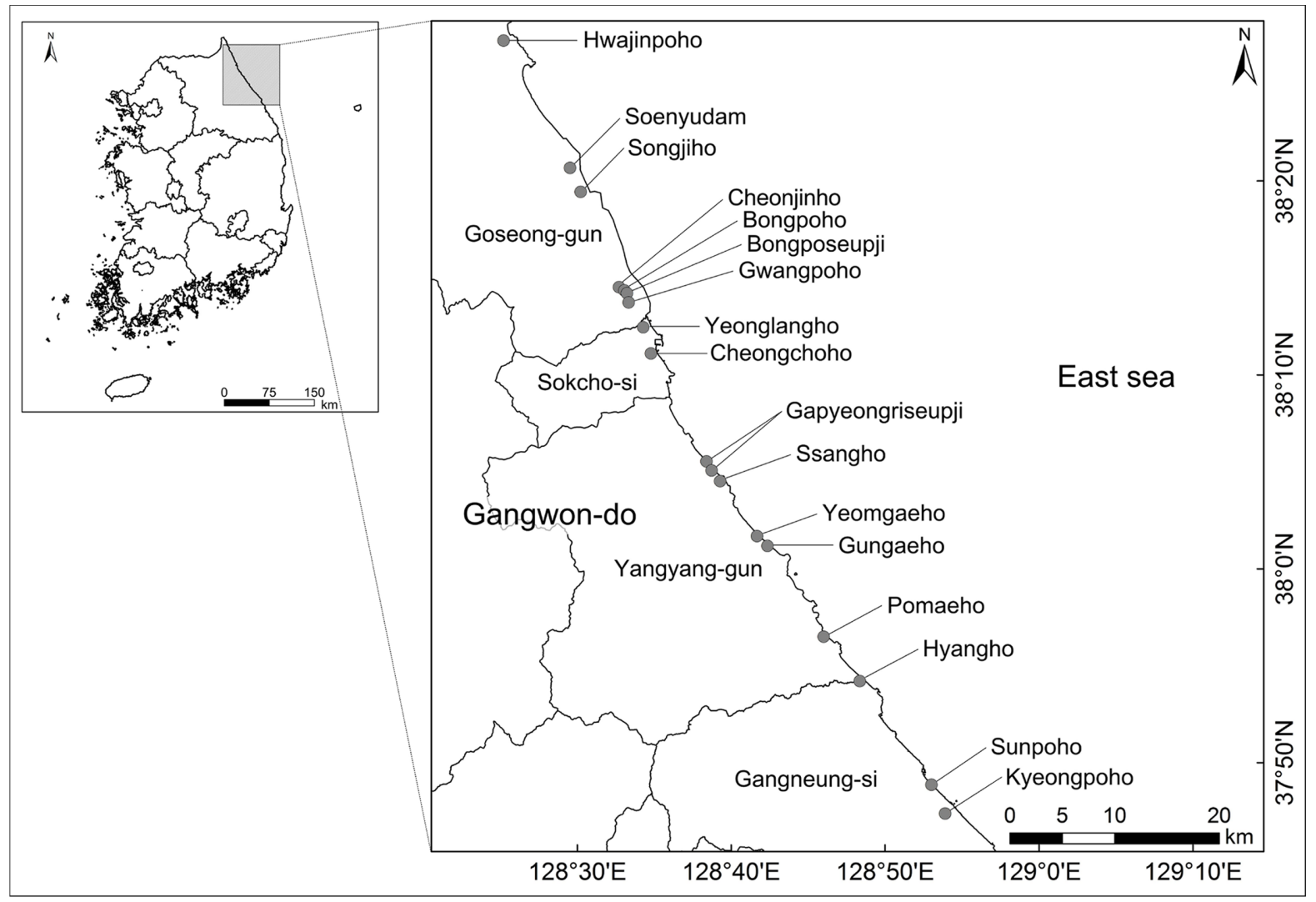

Fig. 1. Distribution map of lagoon areas on the eastern coast in Korea. 
차이가 있으나, 오랜 시간에 걸쳐 진행되는 자연적인 현 상이다(Yoon et al., 2008). 그러나 1960년 이후, 대부분의 석 호는 인위적인 매립, 제방 축조, 관광지 조성 등의 개발 사 업으로 인해 육지화의 진행속도가 가속화되고 있다(Park, 2006). 또한 풍호, 군개호 등의 일부 석호는 완전히 매립되 거나 대부분 소실되어 호소의 형체를 알아보기 힘들고 석 호로서의 기능은 상실된 상태이며, 여기에는 집단시설단 지 및 골프장이 조성되었다.

Ministry of Environment (2008)는 석호에 대한 체계적 인 관리를 위하여 국내 분포하는 18 개 석호를 2 그룹으로 분류하였으며, 석호의 원형이 비교적 잘 보전되어 경관 이 수려하고 문화·자연환경이 우수하여 복원의 가치가 높은 석호(그룹 $\mathrm{A})$ 와 이미 호소의 일부가 매립되어 원형 이 매우 심하게 훼손되었거나 육지화가 진행되고 있는 석호(그룹 B)로 구분하였다. 그룹 $\mathrm{A}$ 에 해당되는 화진포, 송지호, 광포호, 영랑호, 포매호(매호), 향호, 경포호는 비 교적 자연경관이 잘 보전되어 있으나, 그룹 $\mathrm{B}$ 에 속한 쌍 호, 가평리습지, 풍호, 순포호, 군개호, 염개호, 청초호, 천 진호, 봉포호, 봉포습지, 선유담의 석호는 주변 해안과 더 불어 관광지로의 개발과 압력으로 훼손될 위협에 있다 (Yoon et al., 2008).

석호는 수심이 얕고 해수의 영향을 받는 기수호의 특 성을 갖고 있는 것이 많고, 연중 안정된 수위로 인하여 습 지식생이 잘 발달되어 있다(Kim et al., 2010). 석호 수변에
발달된 습지에는 담수, 해양 및 기수성 환경에 적응한 다 양한 동식물이 서식하고 있어 생물다양성이 높은 곳으로 평가되고 있으며(Moon et al., 2007; Kim et al., 2010), 인근 지역의 하구와 구별되는 생태 특성을 지니고 있는 것으 로 알려져 있다(Kwak et al., 2005). 최근 환경부 및 해당 지 방자치단체에서 석호에 대한 보전의 필요성을 인식하고 복원사업을 추진 중에 있으나, 석호의 지형학, 수문학, 수 질에 대한 연구에 치중하여 이루어졌고 이를 바탕으로 일부 석호에 대한 복원사업이 추진되었다(Ministry of Environment, 2008, 2009).

국내의 석호에서는 대표적인 희귀 북방계식물인 각시수 련(Nymphaea minima Nakai), 갯봄맞이꽃(Glaux maritima var. obtusifolia Fernald), 갯활량나물[Thermopsis lupinoides (L.) Link], 조름나물(Menyanthes trifoliata L.), 제비붓꽃(Iris laevigata Fisch. ex Fisch. \& C. A. Mey.) 등의 격리분포 종뿐만 아니라 큰쉽싸리(Lycopus lucidus var. hirtus Regel), 검정납작 골풀(Juncus fauriei H. Lév. \& Vaniot), 나도송이고랭이 [Schoenoplectiella $\times$ trapezoidea (Koidz.) J. Jung \& H.-K. Choi], 천도미꾸리광이[Puccinellia kurilensis (Takeda) Honda] 등 의 미기록/신종이 지속적으로 발견(Jung and Choi, 2011; Kim et al., 2012; Moon et al., 2013; Cho et al., 2016)되고 있 으나, 석호의 동식물상 및 생물지리학 연구 등 체계적인 자연생태계 조사 자료의 부족으로 석호 보전정책 수립에 어려움을 겪고 있다(Ministry of Environment, 2008).

Table 1. The dates and sites of the floristic study of lagoon areas on the eastern coast in Korea.

\begin{tabular}{|c|c|}
\hline Lagoons & Dates \\
\hline Hwajinpoho & 27 May 2011; 5 Jun 2011; 9 Apr 2013; 13 May 2013; 6 Aug 2013; 14 Oct 2013; 29 May 2014 \\
\hline Soenyudam & 18 May 2011; 17 Sep 2011; 7 Oct 2011; 17 May 2012 \\
\hline Songjiho & $\begin{array}{l}20 \text { Jun 2010; } 17 \text { Sep 2010; } 27 \text { May 2011; } 18 \text { Jun 2011; } 17 \text { Sep 2011; } 7 \text { Oct 2011; } 13 \text { Oct 2011; } 7 \text { Sep } 2012 ; 13 \text { May } \\
\text { 2013; } 28 \text { May } 2014\end{array}$ \\
\hline Cheonjinho & 18 Jun 2011; 17 Sep 2011; 6 Oct 2011; 7 Sep 2012 \\
\hline Bongpoho & 17 May 2012; 10 Aug 2012; 5 Sep 2012; 17 Oct 2012; 9 Apr 2013; 28 May 2014 \\
\hline Bongposeupji & 9 Apr 2013; 13 May 2013; 7 Aug 2013; 14 Oct 2013 \\
\hline Gwangpoho & 9 Apr 2013; 14 May 2013; 7 Aug 2013 \\
\hline Yeonglangho & 4 Jun 2013; 18 Apr 2014; 28 May 2014; 1 Jul 2014; 26 Aug 2014; 30 Sep 2014; 5 Nov 2014 \\
\hline Cheongchoho & 4 Jun 2013; 28 May 2014; 2 Jul 2014; 27 Aug 2014; 1 Oct 2014; 4 Nov 2014 \\
\hline Gapyeongriseupji & 11 Apr 2013; 14 May 2013; 7 Aug 2013; 9 Sep 2013; 16 Oct 2013; 27 May 2014 \\
\hline Ssangho & 11 Apr 2013; 2 Jun 2013; 4 Jun 2013; 28 May 2014; 2 Jul 2014; 27 Aug 2014; 1 Oct 2014; 4 Nov 2014 \\
\hline Yeomgaeho & 16 Sep 2011; 2 Jun 2012; 10 Apr 2013; 14 May 2013; 9 Sep 2013; 16 Oct 2013; 27 May 2014 \\
\hline Gungaeho & 31 May 2013; 26 Jun 2013; 16 Oct 2013; 18 Apr 2014; 27 May 2014; 2 Jul 2014; 27 Aug 2014; 1 Oct $2014 ; 4$ Nov 2014 \\
\hline Pomaeho & 16 May 2012; 9 Aug 2012; 5 Sep 2012; 17 Oct 2012; 10 Apr 2013; 26 Jun 2013; 27 May 2014 \\
\hline Hyangho & 10 Apr 2013; 14 May 2013; 8 Aug 2013; 15 Oct 2013; 27 May 2014 \\
\hline Sunpoho & 15 Sep 2011; 16 May 2012; 9 Aug 2012; 5 Sep 2012; 17 Oct 2012; 10 Apr 2013; 27 May 2014 \\
\hline Kyeongpoho & 13 May 2013; 31 May 2013; 15 Oct 2013; 18 Apr 2014; 27 May 2014; 2 Jul 2014; 28 Aug 2014; 2 Oct $2014 ; 3$ Nov 2014 \\
\hline
\end{tabular}


본 연구는 국내의 주요 석호 17 개소에 대한 식물상적 조 사를 바탕으로 종조성의 특징과 식물지리학적 중요성을 밝히고 석호의 체계적인 보전방안 수립을 위한 기초자료 를 제시하고자 한다.

\section{재료 및 방법}

2010년부터 2014년까지, 총 5년간 국내에 분포하는 석 호 17개소(Fig. 1)에 대해 109회의 현지조사를 수행하였으
며(Table 1), 조사지 개황은 Table 2와 같다. 조사범위는 석 호의 만수위 경계선에 해당되는 지역을 포함하여 관속식 물(수생, 육상식물)을 대상으로 실시하였다.

채집된 표본은 대한식물도감(Lee, 1980), 원색한국기준 식물도감(Lee, 1996), 세밀화와 사진으로 보는 한국의 귀 화식물(Park, 2009) 등을 참고하여 동정·분류하였으며, 증 거표본은 고유채집번호를 명기하여 국립생물자원관 관 속식물수장고 $(\mathrm{KB})$ 에 보관하였다. 조사된 관속식물의 목 록은 Cronquist (1981)의 분류체계를 따랐으며, 속이하의

Table 2. Localities and lagoon areas on the eastern coast in Korea.

\begin{tabular}{|c|c|c|c|c|c|c|}
\hline No. & Lagoons & Localities & & $\begin{array}{l}\text { Drainage area } \\
\qquad\left(\mathrm{km}^{2}\right)\end{array}$ & $\begin{array}{c}\text { Water area } \\
\left(\mathrm{km}^{2}\right)\end{array}$ & $\begin{array}{l}\text { Depth } \\
\text { (m) }\end{array}$ \\
\hline 1 & Hwajinpoho & Gangwon-do, Goseong-gun & $\begin{array}{c}38^{\circ} 38^{\prime} 20^{\prime \prime} \mathrm{N} \\
128^{\circ} 26^{\prime} 28^{\prime \prime} \mathrm{E}\end{array}$ & 19.94 & 2.305 & 3.6 \\
\hline 2 & Soenyudam & Gangwon-do, Goseong-gun & $\begin{array}{c}38^{\circ} 21^{\prime} 25^{\prime \prime} \mathrm{N} \\
128^{\circ} 30^{\prime} 15^{\prime \prime} \mathrm{E}\end{array}$ & 0.71 & 0.03 & Swamp \\
\hline 3 & Songjiho & Gangwon-do, Goseong-gun & $\begin{array}{c}38^{\circ} 20^{\prime} 09^{\prime \prime} \mathrm{N} \\
128^{\circ} 30^{\prime} 58^{\prime \prime} \mathrm{E}\end{array}$ & 5.4 & 0.495 & 3.8 \\
\hline 4 & Cheonjinho & Gangwon-do, Goseong-gun & $\begin{array}{c}38^{\circ} 15^{\prime} 14^{\prime \prime} \mathrm{N} \\
128^{\circ} 33^{\prime} 22^{\prime \prime} \mathrm{E}\end{array}$ & 0.37 & 0.024 & 1.5 \\
\hline 5 & Bongpoho & Gangwon-do, Goseong-gun & $\begin{array}{c}38^{\circ} 15^{\prime} 03^{\prime \prime} \mathrm{N} \\
128^{\circ} 33^{\prime} 40^{\prime \prime} \mathrm{E}\end{array}$ & 0.2 & 0.025 & 2 \\
\hline 6 & Bongposeupji & Gangwon-do, Goseong-gun & $\begin{array}{c}38^{\circ} 14^{\prime} 54^{\prime \prime} \mathrm{N} \\
128^{\circ} 33^{\prime} 50^{\prime \prime} \mathrm{E}\end{array}$ & 0.03 & 0.01 & 0.1 \\
\hline 7 & Gwangpoho & Gangwon-do, Sokcho-si & $\begin{array}{c}38^{\circ} 14^{\prime} 05^{\prime \prime} \mathrm{N} \\
128^{\circ} 34^{\prime} 02^{\prime \prime} \mathrm{E}\end{array}$ & 3.29 & 0.07 & 0.7 \\
\hline 8 & Yeonglangho & Gangwon-do, Sokcho-si & $\begin{array}{c}38^{\circ} 13^{\prime} 05^{\prime \prime} \mathrm{N} \\
128^{\circ} 34^{\prime} 59^{\prime \prime} \mathrm{E}\end{array}$ & 10.28 & 1.024 & 8 \\
\hline 9 & Cheongchoho & Gangwon-do, Sokcho-si & $\begin{array}{c}38^{\circ} 11^{\prime} 45^{\prime \prime} \mathrm{N} \\
128^{\circ} 35^{\prime} 20^{\prime \prime} \mathrm{E}\end{array}$ & 25.6 & 1.4 & 7 \\
\hline 10 & Gapyeongriseupji & Gangwon-do, Yangyang-gun & $\begin{array}{c}38^{\circ} 06^{\prime} 09^{\prime \prime} \mathrm{N} \\
128^{\circ} 38^{\prime} 51^{\prime \prime} \mathrm{E} \\
38^{\circ} 05^{\prime} 41^{\prime \prime} \mathrm{N} \\
128^{\circ} 39^{\prime} 10^{\prime \prime} \mathrm{E}\end{array}$ & 0.006 & 0.001 & 1.5 \\
\hline 11 & Ssangho & Gangwon-do, Yangyang-gun & $\begin{array}{c}38^{\circ} 05^{\prime} 07^{\prime \prime} \mathrm{N} \\
128^{\circ} 39^{\prime} 43^{\prime \prime} \mathrm{E}\end{array}$ & 45.15 & 0.004 & $\begin{array}{c}1.0 \\
\text { Swamp }\end{array}$ \\
\hline 12 & Yeomgaeho & Gangwon-do, Yangyang-gun & $\begin{array}{c}38^{\circ} 02^{\prime} 15^{\prime \prime} \mathrm{N} \\
128^{\circ} 42^{\prime} 03^{\prime \prime} \mathrm{E}\end{array}$ & 0.005 & - & 1.0 \\
\hline 13 & Gungaeho & Gangwon-do, Yangyang-gun & $\begin{array}{c}38^{\circ} 01^{\prime} 44^{\prime \prime} \mathrm{N} \\
128^{\circ} 42^{\prime} 43^{\prime \prime} \mathrm{E}\end{array}$ & - & 0.026 & - \\
\hline 14 & Pomaeho & Gangwon-do, Yangyang-gun & $\begin{array}{c}37^{\circ} 57^{\prime} 00^{\prime \prime} \mathrm{N} \\
128^{\circ} 46^{\prime} 17^{\prime \prime} \mathrm{E}\end{array}$ & 9.6 & 0.234 & 3 \\
\hline 15 & Hyangho & Gangwon-do, Gangneung-si & $\begin{array}{c}37^{\circ} 54^{\prime} 40^{\prime \prime} \mathrm{N} \\
128^{\circ} 48^{\prime} 36^{\prime \prime} \mathrm{E}\end{array}$ & 8.06 & 0.345 & 15 \\
\hline 16 & Sunpoho & Gangwon-do, Gangneung-si & $\begin{array}{c}37^{\circ} 49^{\prime} 15^{\prime \prime} \mathrm{N} \\
128^{\circ} 53^{\prime} 06^{\prime \prime} \mathrm{E}\end{array}$ & 1.32 & 0.026 & 0.3 \\
\hline 17 & Kyeongpoho & Gangwon-do, Gangneung-si & $\begin{array}{c}37^{\circ} 47^{\prime} 51^{\prime \prime} \mathrm{N} \\
128^{\circ} 54^{\prime} 15^{\prime \prime} \mathrm{E}\end{array}$ & 36.6 & 0.896 & 1 \\
\hline
\end{tabular}


Table 3. Categorizing vascular plant species by frequency of occurrence in wetlands.

\begin{tabular}{|c|c|c|}
\hline Frequency of occurrence & Abbreviation & Description \\
\hline Obligate wetland plant & OBW & $\begin{array}{l}\text { Occurs almost always in wetlands under natural conditions } \\
\text { (estimated }>98 \% \text { probability in wetlands) }\end{array}$ \\
\hline Facultative wetland plant & FACW & $\begin{array}{l}\text { Usually occurs in wetlands but occasionally found in non-wetlands } \\
\text { (estimated } 71-98 \% \text { probability in wetlands) }\end{array}$ \\
\hline Facultative plant & FAC & $\begin{array}{l}\text { Equally likely to occur in wetlands or non-wetlands } \\
\text { (estimated } 31-70 \% \text { probability in wetlands) }\end{array}$ \\
\hline Facultative upland plant & FACU & $\begin{array}{l}\text { Occasionally occurs in wetlands, but usually occur in non-wetlands } \\
\text { (estimated } 3-30 \% \text { probability in wetlands) }\end{array}$ \\
\hline Obligate upland plant & OBU & $\begin{array}{l}\text { Almost never occurs in wetlands under natural conditions } \\
\text { (estimated }<3 \% \text { probability in wetlands) }\end{array}$ \\
\hline
\end{tabular}

계급은 알파벳순으로 배열하였다(Appendix 1). 학명과 국 명은 국가생물종목록집 관속식물(Lee et al., 2011)을 준하 여 표기하였다. 식물지리학적인 주요종의 선별은 한반도 기후변화 적응 대상식물 300 (Oh et al., 2010), 한국의 멸종 위기 야생동식물 적색자료집 관속식물(National Institute of Biological Resources, 2012), 제4차 전국자연환경조사 지침(National Institute of Environmental Research, 2012)을 참조하여 제시하였다. 한반도 고유종은 식물편(National Institute of Biological Resources, 2013)을 기준으로 하였으 나, 자료가 부족하거나 최근에 보고되어 누락된 종은 논 문과 문헌을 참고하여 추가하였다. 외래식물과 생태계 교란종의 목록 작성은 세밀화와 사진으로 보는 한국의 귀화식물(Park, 2009)과 생태계교란 야생동식물(Kil et al., 2011)을 참조하였다. 관속식물의 유형분류는 식물종이 습지에 출현하는 빈도를 기준으로 다섯 가지 유형(절대 습지식물, 임의습지식물, 양생식물, 절대육상식물 및 임 의육상식물)으로 구분하였다(Choung et al., 2012) (Table 3). 군집 분석은 석호 17 개소에 분포하는 관속식물을 대 상으로 수행하였고, 석호간의 유사도 지수는 MVSP (Multi Variate Statistical Package 3.1-Kovaok Computing Services)의 UPGMA (Unweighted Pair Group Method using Arithmetic algorithm)을 이용하여 분석하였다. Sørensen의 유사도 지수 결과를 토대로 수상도(dendrogram)을 작성 하였다.

\section{결 과}

\section{관속식물 현황}

강원도 동해안 석호 17 개소에 분포하는 관속식물은 식 재수종을 포함하여 118과 378속 655종 13아종 46변종 6교 잡종의 총 720 분류군으로 구성되었다(Table 4, Appendix 1). 이는 우리나라 관속식물 4,338분류군(Lee et al., 2011)의 $16.6 \%$ 이며, 강원도에 분포하는 관속식물 1,465 분류군 $(\mathrm{Oh}$ et al., 2009)의 $49.1 \%$ 에 해당된다. 조사지별 식물다양성이 풍부한 지역은 고성군의 화진포(341분류군)로 나타났으
Table 4. The number of vascular plants surveyed of lagoon areas on the eastern coast in Korea.

\begin{tabular}{lccccccc}
\hline \hline \multicolumn{1}{c}{ Lagoons } & Fam. & Gen. & Sp. & Ssp. & Var. & Hybr. Total \\
\hline Hwajinpoho & 87 & 219 & 306 & 7 & 27 & 1 & 341 \\
Soenyudam & 57 & 126 & 160 & 5 & 11 & - & 176 \\
Songjiho & 75 & 190 & 262 & 6 & 21 & 2 & 291 \\
Cheonjinho & 66 & 149 & 202 & 5 & 9 & 1 & 217 \\
Bongpoho & 57 & 141 & 189 & 4 & 9 & 1 & 203 \\
Bongposeupji & 51 & 102 & 121 & 4 & 8 & - & 133 \\
Gwangpoho & 50 & 119 & 149 & 1 & 8 & 1 & 159 \\
Yeonglangho & 76 & 200 & 285 & 6 & 20 & 1 & 312 \\
Cheongchoho & 49 & 140 & 193 & 1 & 15 & 1 & 210 \\
Gapyeongriseupji & 57 & 150 & 200 & 4 & 14 & 2 & 220 \\
Ssangho & 71 & 179 & 241 & 4 & 18 & 1 & 264 \\
Yeomgaeho & 37 & 101 & 138 & 1 & 7 & - & 146 \\
Gungaeho & 67 & 178 & 238 & 3 & 27 & 1 & 269 \\
Pomaeho & 71 & 181 & 235 & 4 & 18 & 2 & 259 \\
Hyangho & 53 & 135 & 174 & 3 & 12 & 1 & 190 \\
Sunpoho & 69 & 165 & 219 & 2 & 19 & 1 & 241 \\
Kyeongpoho & 63 & 179 & 262 & 2 & 18 & - & 282 \\
\hline \multicolumn{1}{c}{ Total } & 118 & 378 & 655 & 13 & 46 & 6 & 720 \\
\hline
\end{tabular}

며, 속초시 영랑호(312분류군), 고성군 송지호(291분류군), 강릉시 경포호(282분류군), 양양군 군개호(269분류군)의 순으로 분포가 확인되었다(Table 4). 습지식물은 순포호 (80분류군), 천진호(77분류군), 선유담(67분류군), 봉포호 (61분류군), 염개호(54분류군) 등의 순으로 분포가 확인되 었다. 석호의 식물다양성은 전체 유역면적과 가장 밀접한 관계가 있지만, 습지식물은 수 면적과 수심 등 수환경의 물리적 변화에 더 크게 영향을 미치는 것으로 확인되었다.

호소면적 대부분의 우점종은 갈대(Phragmites communis Trin.) 군락이고, 침수성 수생식물이 많이 분포하는 전형 
적인 수생태계의 특징을 잘 보여주고 있다. 그러나 과거 (1910년대)에 비하여, 농경지 및 도로, 매립, 콘도, 아파트, 골프장 건설 등의 인위적인 개발로 석호의 면적이 지속적 으로 감소하고 있는 실정이다(Ministry of Environment, 2008, 2009).

석호는 독특한 기수역 생태계의 특성을 보이며, 수위변 동이 적고 경사가 완만하여 습지식생이 잘 발달할 수 있 는 조건을 갖추고 있다. 이러한 생태, 지리적 특성으로 인 하여 석호는 다양한 동식물의 생물서식공간으로서 중요 한 역할을 하고 있다(Ministry of Environment, 2008, 2009).
그러나 현재에도 육지화가 진행되거나 매립으로 인한 급 격한 생육환경 변화는 식물다양성 감소를 초래할 뿐만 아 니라 종조성이 바뀌고 단순화되며, 그 진행속도는 더욱 가속화될 것으로 생각된다.

\section{한반도 고유종}

석호에서 생육하고 있는 한반도 고유종은 각시수련 (Nymphaea minima Nakai) (Fig. 2B), 금꿩의다리[Thalictrum rochebrunianum var. grandisepalum (H. Lév.) Nakai], 털양지 꽃(Potentilla squamosa Soják.), 큰뚝사초(Carex humbertiana
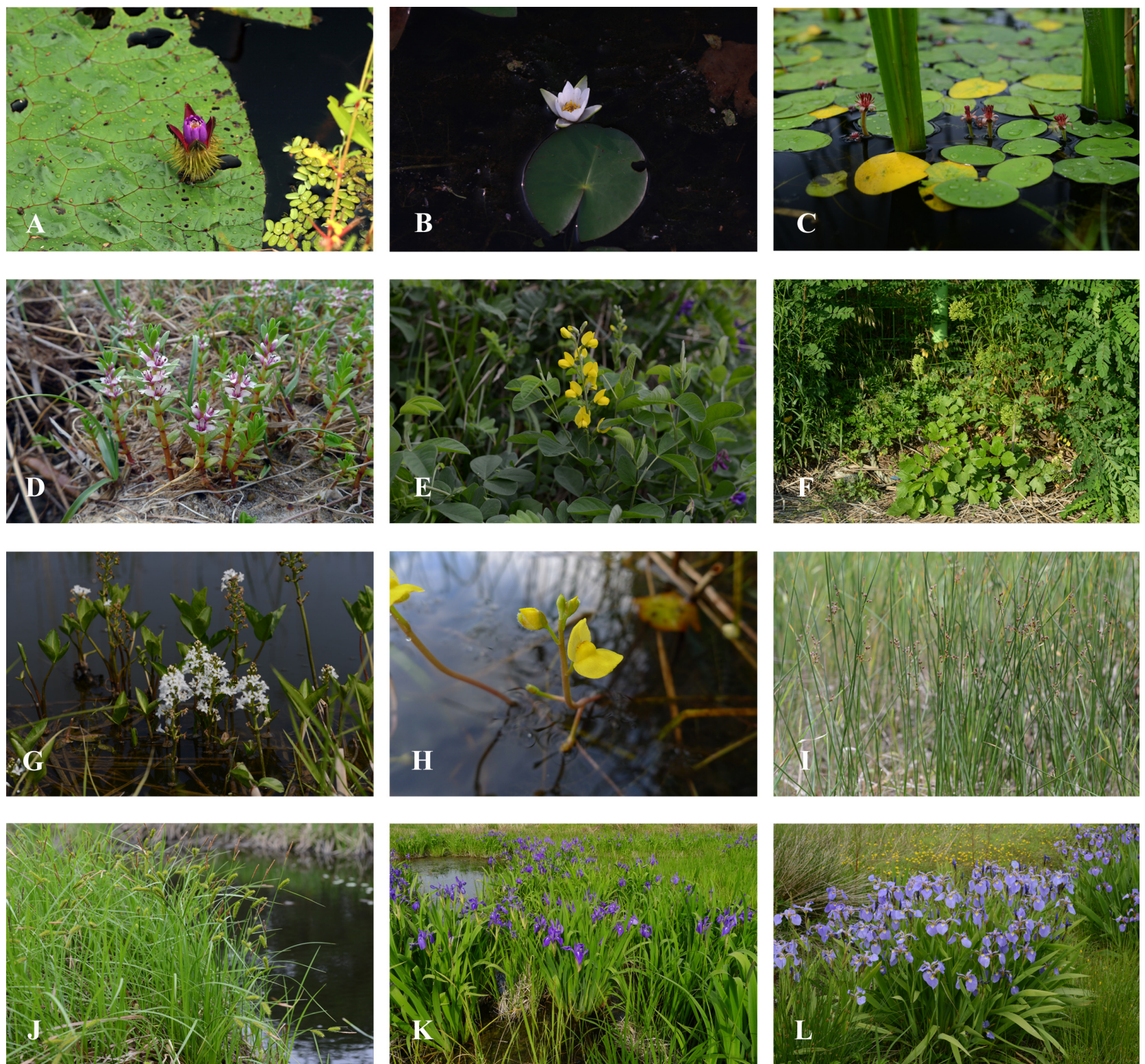

Fig. 2. Some remarkable taxa of lagoon areas on the eastern coast in Korea. A. Euryale ferox Salisb. B. Nymphaea minima Nakai. C. Brasenia schreberi J. F. Gmel. D. Glaux maritima var. obtusifolia Fernald. E. Thermopsis lupinoides (L.) Link. F. Ligusticum hultenii Fernald. G. Menyanthes trifoliata L. H. Utricularia pilosa (Makino) Makino. I. Juncus fauriei H. Lév. \& Vaniot. J. Carex vesicaria L. K. Iris laevigata Fisch. ex Fisch. \& C. A. Mey. L. Iris setosa Pall. ex Link. 
Ohwi), 세모부추(Allium deltoidefistulosum S. O. Yu, S. T. Lee \& W. T. Lee) 등 11분류군으로 조사되었다(Table 5).

각시수련은 1929년 황해도 몽금포 지역에서 채집된 표 본(T. Nakai, 12758)을 근거로 신종 발표되었다(National
Institute of Biological Resources, 2013). 강원도와 북한의 제 한된 습지에서만 분포하며, 농지 확장과 매립 등에 의한 생육환경 변화와 타 수생식물과의 세력경쟁에 의해 도태 할 위험에 처해 있다(National Institute of Biological

Table 5. The list of the endemic plants of lagoon areas on the eastern coast in Korea.

\begin{tabular}{llc}
\hline \hline Family & \multicolumn{1}{c}{ Taxa } & Sites $^{\mathrm{a}}$ \\
\hline Nymphaeaceae & Nymphaea minima Nakai 각시수련 & 2,4 \\
Ranunculaceae & Cimicifuga heracleifolia var. bifida Nakai 세 잎승마 & 1 \\
Ranunculaceae & Thalictrum rochebrunianum var. grandisepalum (H. Lév.) Nakai 금꿩의다리 & 1 \\
Violaceae & Viola seoulensis Nakai 서울제비꽃 & 1,7 \\
Salicaceae & Populus $\times$ tomentiglandulosa T. B. Lee 은사시나무(식재) & $1,3,5,7,8,10,14,15,16$ \\
Salicaceae & Salix koriyanagi Kimura ex Goerz 키버들 & $1,4,6,7,8,9,10,11,14$, \\
Rosaceae & Potentilla squamosa Soják. 털양지꽃 & $15,16,17$ \\
Oleaceae & Forsythia koreana (Rehder) Nakai 개나리(식재) & $1,3,15$ \\
Asteraceae & Aster koraiensis Nakai 벌개미취(식재) & $9,12,15,17$ \\
Cyperaceae & Carex humbertiana Ohwi 큰뚝사초 & 8,17 \\
Liliaceae & Allium deltoidefistulosum S. O. Yu, S. T. Lee \& W. T. Lee 세모부추 & $1,3,4,5,7,8,10,11,12$, \\
aSites: numbers are the same as numbers in Table 2. & $13,14,15,16,17$
\end{tabular}

Table 6. The list of the endangered plants (grade II) and threatened vascular plants of lagoon areas on the eastern coast in Korea.

\begin{tabular}{|c|c|c|c|c|}
\hline Family & Taxa & Grade & Criteria & Sites $^{\mathrm{a}}$ \\
\hline Cupressaceae & Juniperus chinensis L. 향나무(식재) & - & VU & 15 \\
\hline Nymphaeaceae & Euryale ferox Salisb. 가시연 & II & VU & 17 \\
\hline Nymphaeaceae & Nuphar pumila (Timm) DC. 왜개연 & - & VU & 4 \\
\hline Nymphaeaceae & Nymphaea minima Nakai 각시수련 & II & $\mathrm{CR}$ & 2,4 \\
\hline Cabombaceae & Brasenia schreberi J. F. Gmel. 순채 & II & VU & 4 \\
\hline Primulaceae & Glaux maritima var. obtusifolia Fernald 갯봄맞이꽃 & II & VU & 3,14 \\
\hline Crassulaceae & Tillaea aquatica L. 대구돌나물 & - & VU & 13 \\
\hline Menyanthaceae & Menyanthes trifoliata L. 조름나물 & II & VU & 2,5 \\
\hline Menyanthaceae & Nymphoides coreana (H. Lév.) H. Hara 애기어리연 & - & EN & $10,11,12$ \\
\hline Lentibulariaceae & Utricularia pilosa (Makino) Makino 들통발 & - & $\mathrm{VU}$ & $4,5,10,16$ \\
\hline Hydrocharitaceae & Blyxa japonica (Miq.) Maxim. ex Asch. \& Gürke 올챙이솔 & - & NT & 2,5 \\
\hline Potamogetonaceae & Potamogeton pectinatus L. 솔잎가래 & - & $\mathrm{VU}$ & 12 \\
\hline Zosteraceae & Zostera japonica Asch. \& Graebn. 애기거머리말 & - & $\mathrm{VU}$ & 1,3 \\
\hline Cyperaceae & Scirpus nipponicus Makino 물고랭이 & - & NT & 4 \\
\hline Sparganiaceae & Sparganium erectum L. 흑삼릉 & - & NT & $11,13,14$ \\
\hline Sparganiaceae & Sparganium japonicum Rothert 긴흑삼릉 & - & NT & 4,6 \\
\hline Iridaceae & Iris laevigata Fisch. ex Fisch. \& C. A. Mey. 제비붓꽃 & II & $\mathrm{VU}$ & 2,5 \\
\hline Iridaceae & Iris setosa Pall. ex Link 부채붓꽃 & - & EN & $\begin{array}{c}1,3,7,8,10,11 \\
14,15\end{array}$ \\
\hline
\end{tabular}

Sites: numbers are the same as numbers in Table 2. 
Resources, 2012). 고성군에 위치한 선유담과 천진호에서 소수 개체가 확인되었다. 금뀡의다리는 중부 이북지역의 산지 숲 속 사면 및 계곡 주변에 분포하는 한반도 고유종 이다(National Institute of Biological Resources, 2013). 고성군 의 화진포 산지와 인접한 수변부에서만 소수의 개체가 관 찰되었다. 큰뚝사초는 북부지역의 산지 습한 곳에 분포하 는 북방계 다년생식물이다(National Institute of Biological Resources, 2013). 화진포를 포함하여 송지호, 봉포호, 향호, 순포호 등 14 개소의 수변부에 널리 분포하고 개체수도 풍 부한 편이다.

\section{멸종위기 아생식물 및 적색자료집 관속식물}

석호에서 생육이 확인된 관속식물 중 한국의 멸종위기 야생동식물 적색자료집(National Institute of Biological Resources, 2012)에서 멸종우려(CR, EN, VU)와 준위협 (NT)로 평가된 분류군은 가시연(Euryale ferox Salisb.) (Fig. 2A), 순채(Brasenia schreberi J. F. Gmel.) (Fig. 2C), 조름나물 (Menyanthes trifoliata L.) (Fig. 2G), 제비붓꽃(Iris laevigata
Fisch. ex Fisch. \& C. A. Mey.) (Fig. 2K), 부채붓꽃(Iris setosa Pall. ex Link) (Fig. 2L) 등 18분류군이다(Table 6).

가시연, 각시수련, 순채, 갯봄맞이꽃(Fig. 2D), 조름나물, 제비붓꽃은 환경부 지정 멸종위기종 II급에도 해당된다. 가시연은 강릉시의 경포호에서만 생육이 확인되며, 순채 는 고성군의 천진호에서, 갯봄맞이꽃은 고성군의 송지호 와 양양군의 포매호에서, 조름나물과 제비붓꽃은 고성군 의 선유담, 봉포호에서 각각 조사되었다. 경포호의 가시 연습지는 1960년대 농경지로 개간되었다가 2012년에 습 지로 복원되었고, 그 과정에서 가시연 매토종자(buried seed)가 자연 발아되었다는 설과 습지복원 중에 이식했다 는 이견이 있으므로 추후 확인이 필요하다(Noh et al., 2014). 갯봄맞이꽃은 기수역의 축축한 모래땅에 자라는 북방계 희귀식물로 국내에서는 울산, 포항 등을 포함하여 동해안을 따라 국소적으로 분포하고 북한, 일본, 중국, 러 시아의 극동지방에도 자란다(National Institute of Biological Resources, 2012). 국내에서는 드물게 분포하지 만, 국외의 경우는 개체수도 많고 분포역도 넓은 편이다

Table 7. The list of floristic regional indicator plants (grade VI-V) of lagoon areas on the eastern coast in Korea.

\begin{tabular}{|c|c|c|c|}
\hline Family & Taxa & Grade & Sites $^{\mathrm{a}}$ \\
\hline Nymphaeaceae & Nymphaea minima Nakai 각시수련 & \multirow{11}{*}{$\mathrm{V}$} & 2,4 \\
\hline Cabombaceae & Brasenia schreberi J. F. Gmel. 순채 & & 4 \\
\hline Ranunculaceae & Cimicifuga heracleifolia var. bifida Nakai 세 잎승마 & & 1 \\
\hline Berberidaceae & Epimedium koreanum Nakai 삼지구엽초 & & 1 \\
\hline Crassulaceae & Tillaea aquatica L. 대구돌나물 & & 13 \\
\hline Menyanthaceae & Menyanthes trifoliata L. 조름나물 & & 2,5 \\
\hline Menyanthaceae & Nymphoides coreana (H. Lév.) H. Hara 애기어리연 & & $10,11,12$ \\
\hline Lentibulariaceae & Utricularia japonica Makino 통발 & & $2,3,4,10,12,13,14,17$ \\
\hline Lentibulariaceae & Utricularia pilosa (Makino) Makino 들통발 & & $4,5,10,16$ \\
\hline Sparganiaceae & Sparganium erectum L. 흑삼릉 & & $11,13,14$ \\
\hline Iridaceae & Iris laevigata Fisch. ex Fisch. \& C. A. Mey. 제비붓꽃 & & 2,5 \\
\hline Cupressaceae & Platycladus orientalis (L.) Franco 측백나무(식재) & \multirow{12}{*}{ VI } & 15 \\
\hline Nymphaeaceae & Euryale ferox Salisb. 가시연 & & 17 \\
\hline Droseraceae & Drosera rotundifolia L. 끈끈이주걱 & & 4 \\
\hline Brassicaceae & Arabidopsis thaliana (L.) Heynh. 애기장대 & & 9 \\
\hline Rosaceae & Potentilla anserina $\mathrm{L}$. 눈양지꽃 & & $1,3,10,12,14,17$ \\
\hline Fabaceae & Thermopsis lupinoides (L.) Link 갯활량나물 & & 1 \\
\hline Fabaceae & Vicia bungei Ohwi 들완두 & & 16 \\
\hline Fabaceae & Wisteria floribunda (Willd.) DC. 등(식재) & & 9,15 \\
\hline Asteraceae & Aster pseudoglehnii Y. S. Lim, Hyun \& H. Shin 섬쑥부쟁이 & & 8 \\
\hline Cyperaceae & Carex arenicola F. Schmidt 진퍼리사초 & & $1,3,5,7,8,10,12,13,14$ \\
\hline Sparganiaceae & Sparganium japonicum Rothert 긴흑삼릉 & & 4,6 \\
\hline Iridaceae & Iris setosa Pall. ex Link 부채붓꽃 & & $1,3,7,8,10,11,14,15$ \\
\hline
\end{tabular}

${ }^{a}$ Sites: numbers are the same as numbers in Table 2. 
(National Institute of Biological Resources, 2012). 조름나물은 정수성 수생식물로서 대암산, 울진, 태백 등 경북과 강원 일부 지역의 습지에서만 발견되는 북방계 희귀식물이다 (Oh et al., 2010; National Institute of Biological Resources, 2012). 고성군의 선유담, 봉포호 2 개소에서 소수의 개체가 생육하고 있다. 봉포호 자생지 주변은 낚시꾼들에 의한 답 압과 수초 제거 등의 직접적인 피해가 일부 나타났으나, 2014년부터 수질 및 수생태계 보존 법률에 따라 낚시금지 구역으로 지정되어 보호되고 있다.

\section{식물구계학적 특정식물}

국내에서 일부 지역에만 제한적으로 분포하여 식물지 리학적 가치가 높은 것으로 평가되는 식물구계학적 특정 식물 $\mathrm{V}$ 등급과 $\mathrm{IV}$ 등급은 총 23 분류군이 조사되었다(Table 7). V등급은 각시수련, 세잎승마(Cimicifuga heracleifolia var. bifida Nakai), 삼지구엽초(Epimedium koreanum Nakai), 애기어리연[Nymphoides coreana (H. Lév.) H. Hara], 들통발 [Utricularia pilosa (Makino) Makino] (Fig. 2H) 등 11분류군 이며, IV등급은 가시연, 끈끈이주걱(Drosera rotundifolia L.), 애기장대[Arabidopsis thaliana (L.) Heynh.], 갯활량나물 (Fig. 2E), 긴흑삼릉 (Sparganium japonicum Rothert) 등 12분 류군이다. 그 외에 III등급은 왜개연[Nuphar pumila (Timm) DC.], 솔잎가래(Potamogeton pectinatus L.), 새방울사초 (Carex vesicaria L.) (Fig. 2J) 등 21분류군, II등급은 여우버 들(Salix xerophila Flod.), 물질경이[Ottelia alismoides (L.) Pers.], 꽃창포[Iris ensata var. spontanea (Makino) Nakai] 등 12 분류군, I등급은 가는오이풀(Sanguisorba tenuifolia Fisch. ex Link), 가는가래(Potamogeton cristatus Regel \& Maack), 왕미꾸리광이(Glyceria leptolepis Ohwi) 등 29분류 군이다.
들통발은 국내의 강원, 경남, 경북 등 3 개 지역 습지에 분포하는 것으로 알려지고 있으며, 적색자료집에서 취약 종으로 분류되고 있는 식충식물이다(National Institute of Biological Resources, 2012). 고성군의 천진호, 봉포호, 양양 군의 가평리습지, 강릉시의 순포호 등 4 개소에서 생육이 확인되었다. 최근에는 인천시 도서지역인 교동도, 백령도 에서 자생지가 발견되어 보고된 바 있다(Kim et al., 2013a, 2015). 새방울사초는 한반도 북부지역에서만 생육이 확인 되는 북방계식물이며(Oh, 2007), 남한에서의 분포는 알려 져 있지 않다. 국내에서는 처음으로 양양군의 가평리습지 에서 생육이 확인되었으며, 수백 개체가 집단으로 분포하 였다. 갯활량나물은 양양군의 낙산사에서 채집된 후 그간 분포 기록이 없던 희귀식물이다(National Institute of Biological Resources, 2012). 고성군의 화진포에서 5개체 정 도가 확인되었으나, 대부분의 개체가 불량한 생육 상태를 보이고 있어 개체수 감소로 이어질 가능성이 크다.

\section{남방계 및 북방계 식물}

기후변화 적응 대상식물(Oh et al., 2010) 중 북위 $35^{\circ}$ 또 는 $36^{\circ}$ 이남인 중국과 일본 남부, 한반도 중부 이남에 주로 분포하는 남방계식물과 극동러시아, 중국 동북부, 일본 북 부 및 한반도 중부 이북에 주로 분포하는 북방계식물 다수 가 석호에서 확인되었다. 기후변화에 민감한 남방계식물 은 자주괴불주머니[Corydalis incisa (Thunb.) Pers.], 여우팥 [Dunbaria villosa (Thunb.) Makino], 모래지치[Argusia sibirica (L.) Dandy] 등 4분류군이 조사되었으며, 기후변화에 취약 한 북방계식물은 삼지구엽초, 조선현호색(Corydalis turtschaninovii Besser), 야광나무[Malus baccata (L.) Borkh], 애기앉은부채(Symplocarpus nipponicus Makino) 등 8분류군 이 확인되었다(Table 8).

Table 8. The list of northern and southern plants lineages adapted to climate change of lagoon areas on the eastern coast in Korea.

\begin{tabular}{|c|c|c|c|}
\hline Family & Taxa & Part & Sites $^{\mathrm{a}}$ \\
\hline Berberidaceae & Epimedium koreanum Nakai 삼지구엽초 & \multirow{8}{*}{$\mathrm{N}$} & 1 \\
\hline Fumariaceae & Corydalis turtschaninovii Besser 조선현호색 & & 1 \\
\hline Rosaceae & Malus baccata (L.) Borkh. 야광나무 & & 1 \\
\hline Menyanthaceae & Menyanthes trifoliata $\mathrm{L}$. 조름나물 & & 2,5 \\
\hline Scrophulariaceae & Melampyrum setaceum (Maxim. ex Palib.) Nakai 애기며느리밥풀 & & 3,10 \\
\hline Asteraceae & Artemisia codonocephala Diels 참쑥 & & 13,17 \\
\hline Asteraceae & Cirsium pendulum Fisch. ex DC. 큰엉겅퀴 & & $5,10,11,17$ \\
\hline Araceae & Symplocarpus nipponicus Makino 애기앉은부채 & & 1 \\
\hline Fumariaceae & Corydalis incisa (Thunb.) Pers. 자주괴불주머니 & \multirow{4}{*}{ S } & 8 \\
\hline Fabaceae & Dunbaria villosa (Thunb.) Makino 여우팥 & & 3 \\
\hline Apiaceae & Cnidium japonicum Miq. 갯사상자 & & 8,14 \\
\hline Boraginaceae & Argusia sibirica (L.) Dandy 모래지치 & & 16 \\
\hline
\end{tabular}

${ }^{a}$ Sites: numbers are the same as numbers in Table 2. 
그 외 국내 내륙에서 분포역이 좁은 남방계식물에 개미 탑[Haloragis micrantha (Thunb.) R. Br], 벼룩아재비 (Mitrasacme alsinoides R. Br.), 모기방동산이(Cyperus haspan L.) 등과 세잎승마, 여우버들, 갯봄맞이꽃, 눈양지 꽃(Potentilla anserina L.), 털연리초[Lathyrus palustris ssp. pilosus (Cham.) Hultén], 갯활량나물, 기름당귀(Ligusticum hultenii Fernald) (Fig. 2F), 큰쉽싸리, 검정납작골풀(Fig. 2I), 까락사초(Carex pallida C. A. Mey.), 새방울사초, 도루박이 (Scirpus radicans Schkuhr), 천도미꾸리광이 등의 북방계 희귀식물도 석호에서 생육하고 있다.

벼룩아재비는 중국(남부), 일본, 동남아시아, 인도, 스리 랑카, 오스트레일리아 등 열대 및 아열대지역에 분포하는 남방계식물이며, 국내에서는 경남 및 전남지역의 낮은 지 대 습지에 분포하는 일년생 초본이다(Kim et al., 2013b). 고 성군의 송지호와 양양군의 염개호 2 개소에서 관찰되며, 수변부 모래땅에 수십 개체가 불연속적으로 생육하고 있 다. 이 일대가 벼룩아재비 분포역의 최북단지역으로 추정 된다. 검정납작골풀과 큰쉽싸리는 최근 석호에서 발견되 어 국내의 분포가 학계에 보고된 종이다(Kim et al., 2012; Moon et al., 2013). 특히 검정납작골풀은 최초 보고된 하조 대 해안가 사구 습지 이외의 지역으로는 처음으로 염개호
의 수변부에서 소수 개체군의 생육을 확인하였다. 큰쉽싸 리는 그간 종에 대한 인식부족으로 쉽싸리에 오동정되어 왔으나, 보고된 이후 석호에 널리 분포하는 것으로 조사 되었다. 이 외에도 갯활량나물, 기름당귀, 새방울사초, 천 도미꾸리광이 등의 북방계 희귀식물은 남한지역에서는 동해안 석호에만 자생하며, 소수의 개체군이 분포하므로 적극적인 보호조치가 요구된다.

조사된 식물목록을 바탕으로 본 강원도 석호는 남방계 및 북방계식물이 공존하는 종조성의 특징을 보이고 있다. 두 식물군의 공존은 비교적 따뜻한 동절기 기온의 영향으 로 남방계식물들의 생육이 가능하며, 고위도 지역에 형성 된 기수호라는 특수한 환경으로 다수의 북방계식물들이 분포하는 것으로 판단된다(Kim et al., 2013b).

\section{외래식물 및 생태계 교란식물}

석호 17 개소에서 관찰된 외래식물은 큰석류풀(Mollugo verticillata L.), 서양갯냉이[Cakile edentula (Bigelow) Hook.], 선토끼풀(Trifolium hybridum L.), 능수참새그령 [Eragrostis curvula (Schrad.) Nees] 등 22과 96분류군이 확인 되었으며(Table 9), 이는 석호에 분포하는 720 분류군 중 $13.3 \%$ 에 해당하는 수치이다. 외래식물은 도로와 인접한

Table 9. The list of alien plants of lagoon areas on the eastern coast in Korea.

\begin{tabular}{|c|c|c|}
\hline Family & Taxa & Sites $^{\mathrm{a}}$ \\
\hline Papaveraceae & Papaver rhoeas L. 개양귀비 & 8,17 \\
\hline Phytolaccaceae & Phytolacca americana L. 미국자리공 & $3,7,8,10,11,13,15,17$ \\
\hline Chenopodicaceae & Chenopodium album L. 흰명아주 & $8,9,11,13,16,17$ \\
\hline Chenopodicaceae & Chenopodium ficifolium $\mathrm{Sm}$. 좀명아주 & $1,3,4,5,7,8,9,11,13,17$ \\
\hline Chenopodicaceae & Chenopodium glaucum L. 취명아주 & $1,5,8,9$ \\
\hline Amaranthaceae & Amaranthus hybridus L. 긴털비름 & 8 \\
\hline Amaranthaceae & Amaranthus lividus L. 개비름 & 16 \\
\hline Amaranthaceae & Amaranthus retroflexus L. 털비름 & $1,2,7,8,13,15$ \\
\hline Molluginaceae & Mollugo verticillata $\mathrm{L}$. 큰석류풀 & 8 \\
\hline Caryophyllaceae & Silene armeria L. 끈끈이대나물 & $5,6,11,13,16,17$ \\
\hline Caryophyllaceae & Spergularia rubra J. Presl \& C. Presl 유럽개미자리 & $3,8,9,13$ \\
\hline Caryophyllaceae & Vaccaria hispanica (Mill.) Rauschert 말뱅이나물 & 11 \\
\hline Polygonaceae & Fallopia dumetorum (L.) Holub 닭의 덩굴 & $3,8,9,14$ \\
\hline Polygonaceae & Rumex acetosella L. 애기수영 & All \\
\hline Polygonaceae & Rumex crispus L. 소리쟁이 & $2,3,4,5,8,9,10,11,12,13,14,15,16,17$ \\
\hline Polygonaceae & Rumex obtusifolius L. 돌소리쟁이 & 13,16 \\
\hline Cucurbitaceae & Sicyos angulatus L. 가시박 & 6,7 \\
\hline Brassicaceae & Barbarea vulgaris W. T. Aiton 유럽나도냉이 & $1,7,9,10,15$ \\
\hline Brassicaceae & Brassica juncea (L.) Czern. 갓 & 15,17 \\
\hline Brassicaceae & Cakile edentula (Bigelow) Hook. 서양갯냉이 & 13,14 \\
\hline Brassicaceae & Lepidium apetalum Willd. 다닥냉이 & $1,3,4,8,9,10,12,13,14,15,16$ \\
\hline
\end{tabular}


Table 9. Continued.

\begin{tabular}{|c|c|c|}
\hline Family & Taxa & Sites $^{\mathrm{a}}$ \\
\hline Brassicaceae & Lepidium virginicum $\mathrm{L}$. 콩다닥냉이 & $5,7,8,9,10,11,13,14,15,16,17$ \\
\hline Brassicaceae & Rorippa sylvestris (L.) Besser 가새잎개갓냉이 & 9 \\
\hline Brassicaceae & Thlaspi arvense L. 말냉이 & 17 \\
\hline Rosaceae & Potentilla supina L. 개소시랑개비 & $5,7,8,9,12,13,15,17$ \\
\hline Rosaceae & Rubus fruticosus L. 서양산딸기 & 4,16 \\
\hline Fabaceae & Amorpha fruticosa L. 족제비싸리 & $1,3,4,7,8,9,10,11,12,13,14,15,16,17$ \\
\hline Fabaceae & Lespedeza lichiyuniae T. Nemoto, H. Ohashi \& T. Itoh 자주비수리 & 8,17 \\
\hline Fabaceae & Lespedeza thunbergii ssp. formosa (Vogel) H.Ohashi 중국풀싸리 & 8 \\
\hline Fabaceae & Lotus corniculatus L. 서양벌노랑이 & 8,17 \\
\hline Fabaceae & Medicago lupulina L. 잔개자리 & 8 \\
\hline Fabaceae & Medicago sativa L. 자주개자리 & 17 \\
\hline Fabaceae & Robinia pseudoacacia L. 아까시나무 & $1,2,3,4,5,6,7,8,9,10,11,13,14,16,17$ \\
\hline Fabaceae & Trifolium hybridum L. 선토끼풀 & 17 \\
\hline Fabaceae & Trifolium pratense L. 붉은토끼풀 & $1,3,8,11,15,17$ \\
\hline Fabaceae & Trifolium repens L. 토끼풀 & $1,3,4,6,7,8,9,10,11,12,13,14,15,16,17$ \\
\hline Onagraceae & Oenothera biennis L. 달맞이꽃 & $1,3,4,5,6,7,8,9,10,11,12,13,14,15,16,17$ \\
\hline Euphorbiaceae & Euphorbia supina Raf. 애기땅빈대 & $1,8,9,11,17$ \\
\hline Simaroubaceae & Ailanthus altissima (Mill.) Swingle 가중나무 & $1,3,5,11,17$ \\
\hline Oxalidaceae & Oxalis dillenii Jacq. 들괭이밥 & 11,17 \\
\hline Solanaceae & Datura tatula L. 독말풀 & 8,13 \\
\hline Solanaceae & Physalis wrightii A. Gray 노란꽃땅꽈리 & 10 \\
\hline Solanaceae & Solanum americanum Mill. 미국까마중 & 10 \\
\hline Convolvulaceae & Cuscuta pentagona Engelm. 미국실새삼 & $4,5,6,8,10,13,14,15,16$ \\
\hline Convolvulaceae & Ipomoea hederacea Jacq. 미국나팔꽃 & $4,7,16,17$ \\
\hline Convolvulaceae & Ipomoea hederacea var. integriuscula A. Gray 둥근잎미국나팔꽃 & 9,13 \\
\hline Convolvulaceae & Ipomoea purpurea (L.) Roth 둥근잎나팔꽃 & $9,10,13$ \\
\hline Plantaginaceae & Plantago lanceolata $\mathrm{L}$. 창질경이 & 8 \\
\hline Scrophulariaceae & Lindernia dubia (L.) Pennell 미국외풀 & 11 \\
\hline Scrophulariaceae & Veronica arvensis L. 선개불알풀 & $1,5,7,8,9,11,14,16,17$ \\
\hline Scrophulariaceae & Veronica persica Poir. 큰개불알풀 & $7,9,15,17$ \\
\hline Rubiaceae & Diodia teres Walter 백령풀 & $5,7,11,12,13$ \\
\hline Asteraceae & Achillea millefolium L. 서양톱풀 & 8 \\
\hline Asteraceae & Ambrosia artemisiifolia L. 돼지풀 & $1,2,3,4,5,7,8,9,10,11,12,13,14,15,16,17$ \\
\hline Asteraceae & Ambrosia trifida L. 단풍잎돼지풀 & 6,9 \\
\hline Asteraceae & Aster novibelgii L. 우선국 & 17 \\
\hline Asteraceae & Aster pilosus Willd. 미국쑥부쟁이 & $1,3,4,5,8,9,10,11,12,13,14,15,16,17$ \\
\hline Asteraceae & Aster subulatus var. sandwicensis (A. Gray) A. G. Jones 큰비짜루국화 & $3,5,8,9,10,13,14,15,16,17$ \\
\hline Asteraceae & Bidens frondosa L. 미국가막사리 & $1,2,3,4,5,6,8,9,10,11,12,13,14,15,16,17$ \\
\hline Asteraceae & Bidens pilosa L. 울산도깨비바늘 & $2,13,14,16,17$ \\
\hline Asteraceae & Centaurea cyanus L. 수레국화 & 17 \\
\hline
\end{tabular}


Table 9. Continued.

\begin{tabular}{|c|c|c|}
\hline Family & Taxa & Sites $^{\mathrm{a}}$ \\
\hline Asteraceae & Chrysanthemum leucanthemum L. 불란서국화 & 17 \\
\hline Asteraceae & Conyza bonariensis (L.) Cronquist 실망초 & 17 \\
\hline Asteraceae & Conyza canadensis (L.) Cronquist 망초 & $1,2,3,4,5,7,8,9,10,11,12,13,14,15,16,17$ \\
\hline Asteraceae & Coreopsis lanceolata $\mathrm{L}$. 큰금계국 & $3,5,7,9,11,12,13,15,17$ \\
\hline Asteraceae & Cosmos bipinnatus Cav. 코스모스 & $4,10,11,13,14,17$ \\
\hline Asteraceae & Cosmos sulphureus Cav. 노랑코스모스 & 17 \\
\hline Asteraceae & Erechtites hieracifolia (L.) Raf. ex DC. 붉은서나물 & $4,5,8,9,10,11,12,13,14,15,16$ \\
\hline Asteraceae & Erigeron annuus (L.) Pers. 개망초 & $1,3,4,5,6,7,8,9,10,11,12,13,14,15,16,17$ \\
\hline Asteraceae & Erigeron strigosus Muhl. ex Willd. 주걱개망초 & $8,9,12$ \\
\hline Asteraceae & Galinsoga ciliata (Raf.) S. F. Blake 털별 꽃아재비 & $1,2,4,6,7,8,9,10,16,17$ \\
\hline Asteraceae & Galinsoga parviflora Cav. 별꽃아재비 & 1 \\
\hline Asteraceae & Helianthus tuberosus L. 뚱딴지 & $10,13,14,17$ \\
\hline Asteraceae & Matricaria matricarioides (Less.) Porter ex Britton 족제비쑥 & 9,14 \\
\hline Asteraceae & Rudbeckia laciniata var. hortensia L. H. Bailey 겹삼잎국화 & 13 \\
\hline Asteraceae & Senecio vulgaris L. 개쑥갓 & $5,8,9,13,17$ \\
\hline Asteraceae & Solidago gigantea ssp. serotina (Aiton) McNeill 미국미역취 & 6 \\
\hline Asteraceae & Sonchus asper (L.) Hill 큰방가지똥 & $8,9,13,15,17$ \\
\hline Asteraceae & Sonchus oleraceus L. 방가지똥 & $8,9,17$ \\
\hline Asteraceae & Tagetes minuta L. 만수국아재비 & 17 \\
\hline Asteraceae & Taraxacum laevigatum (Willd.) DC. 붉은씨서양민들레 & 1,9 \\
\hline Asteraceae & Taraxacum officinale F. H. Wigg. 서양민들레 & $1,2,4,6,7,8,9,10,11,15,16,17$ \\
\hline Asteraceae & Xanthium strumarium L. 도꼬마리 & 10 \\
\hline Poaceae & Agropyron repens (L.) P. Beauv. 구주개밀 & 9,17 \\
\hline Poaceae & Bromus tectorum L. 털빕새귀리 & $1,9,12,13,15,17$ \\
\hline Poaceae & Bromus unioloides Kunth 큰이삭풀 & 17 \\
\hline Poaceae & Dactylis glomerata L. 오리새 & $1,2,3,6,7,8,9,10,11,13,14,15,16,17$ \\
\hline Poaceae & Eragrostis curvula (Schrad.) Nees 능수참새그령 & 8,13 \\
\hline Poaceae & Festuca arundinacea Schreb. 큰김의털 & $1,3,8,9,10,11,12,13,14,15,16,17$ \\
\hline Poaceae & Festuca myuros L. 들묵새 & $3,5,8,9,11,13,17$ \\
\hline Poaceae & Leptochloa malabarica (L.) Veldkamp 갯드렁새 & 14 \\
\hline Poaceae & Lolium multiflorum Lam. 쥐보리 & 17 \\
\hline Poaceae & Lolium perenne L. 호밀풀 & 8,17 \\
\hline Poaceae & Panicum dichotomiflorum Michx. 미국개기장 & $1,2,3,4,8,9,10,11,12,13,14,15,16,17$ \\
\hline Poaceae & Poa pratensis L. 왕포아풀 & $1,3,5,6,7,8,9,10,11,12,13,14,15,16,17$ \\
\hline Poaceae & Puccinellia distans (Jacq.) Parl. 처진미꾸리광이 & 17 \\
\hline
\end{tabular}

${ }^{a}$ Sites: numbers are the same as numbers in Table 2.

수변부의 가장자리에 집중적으로 분포하는 양상을 보였 다. 외래식물의 출현 비율은 속초시 청초호에서 $21.4 \%$ 로 가장 높았고, 경포호(20.6\%), 영랑호(16.0\%), 군개호 $(16.0 \%)$ 등의 순으로 나타났다(Fig. 3). 생태계 교란식물은
애기수영(Rumex acetosella L.), 가시박(Sicyos angulatus L.), 돼지풀(Ambrosia artemisiifolia L.), 단풍잎돼지풀(Ambrosia trifida L.), 미국쑥부쟁이(Aster pilosus Willd.) 등이 관찰되 었으며, 이 중 애기수영은 모든 석호에서 확인되었다. 


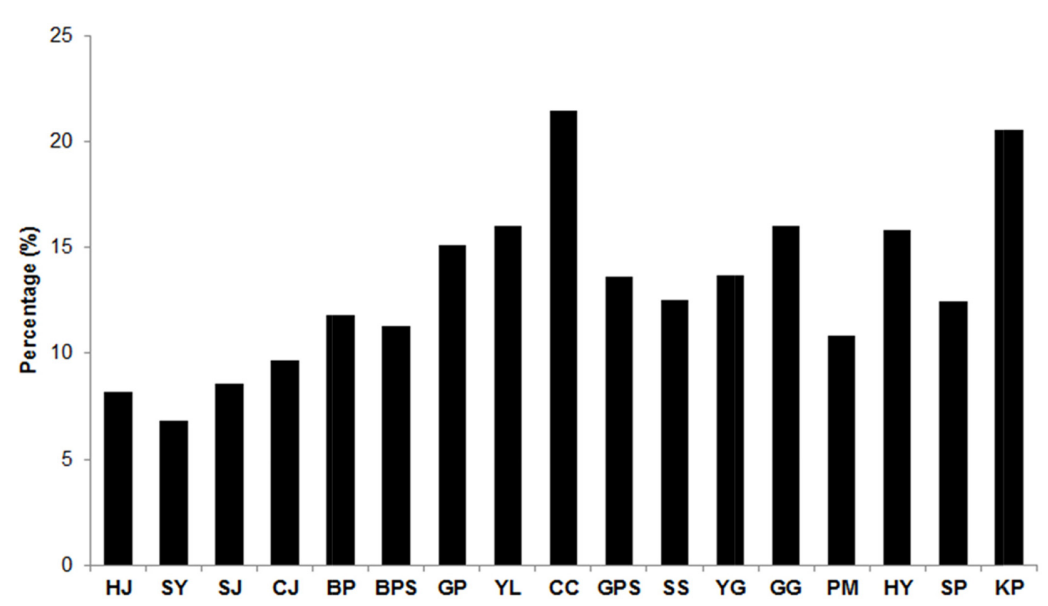

Fig. 3. Changes and percentage of alien plants of lagoon areas on the eastern coast in Korea. HJ, Hwajinpoho; SY, Soenyudam; SJ, Songjiho; CJ, Cheonjinho; BP, Bongpoho; BPS, Bongposeupji; GP, Gwangpoho; YL, Yeonglangho; CC, Cheongchoho; GPS, Gapyeongriseupji; SS, Ssangho; YG, Yeomgaeho; GG, Gungaeho; PM, Pomaeho; HY, Hyangho; SP, Sunpoho; KP, Kyeongpoho.

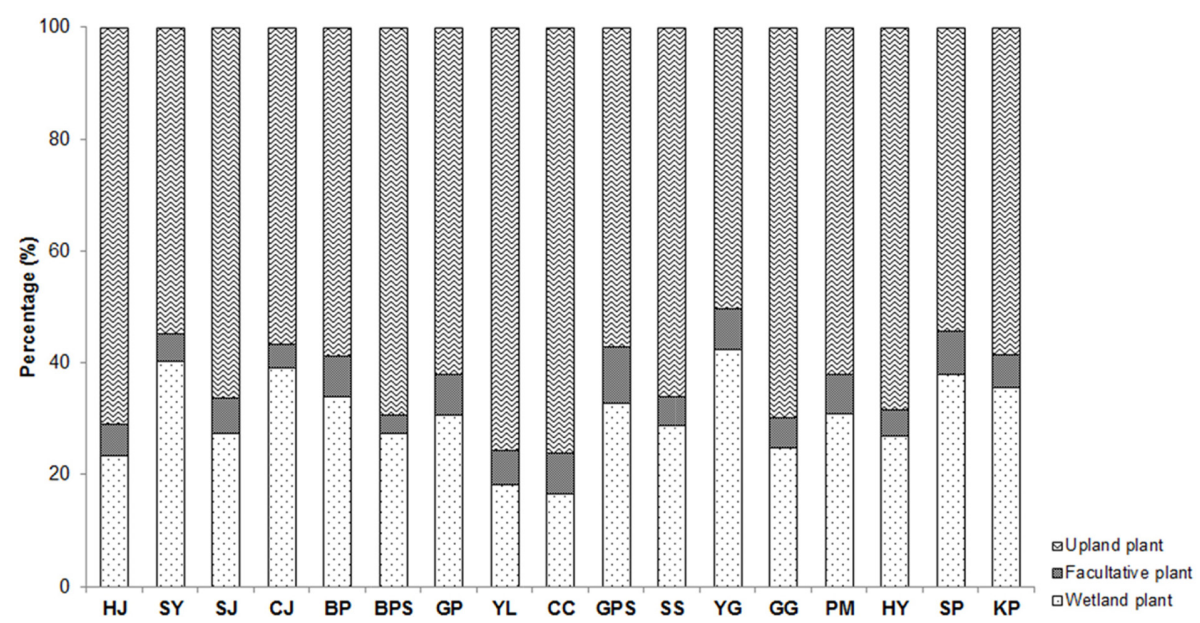

Fig. 4. Changes and percentage of categorizing vascular plants of lagoon areas on the eastern coast in Korea. HJ, Hwajinpoho; SY, Soenyudam; SJ, Songjiho; CJ, Cheonjinho; BP, Bongpoho; BPS, Bongposeupji; GP, Gwangpoho; YL, Yeonglangho; CC, Cheongchoho; GPS, Gapyeongriseupji; SS, Ssangho; YG, Yeomgaeho; GG, Gungaeho; PM, Pomaeho; HY, Hyangho; SP, Sunpoho; KP, Kyeongpoho.

\section{유형분류}

동해안 석호 17 개소에 분포하는 관속식물(외래식물과 재배종 제외)을 5 개 유형으로 구분한 결과, 습지식물(절대 습지식물, 임의습지식물)의 비율은 염개호에서 $42.4 \%$ 로 가장 높았고, 선유담(40.2\%), 천진호(39.2\%), 순포호 $(38.0 \%)$ 등의 순으로 나타났다. 양생식물의 비율은 가평 리습지에서 $10.1 \%$ 로 가장 높았고, 순포호(7.7\%), 광포호 (7.5\%), 청초호(7.4\%) 등의 순으로 나타났다. 육상식물(절 대육상식물, 임의육상식물)의 비율은 청초호에서 $76.1 \%$ 로 가장 높았고, 영랑호(75.6\%), 화진포호(71.0\%), 군개호 (70.0\%) 등의 순으로 나타났다(Fig. 4).

육상식물의 출현비율은 최소 $50 \%$ 에서 최대 $76 \%$ 까지 나타나, 모든 석호의 육상식물 출현비율이 습지식물보
다 더 높게 나타났다(Fig. 4). 육상식물의 출현비율이 높 은 석호에서 외래식물의 출현비율도 높은 것으로 확인 되었다.

\section{유사도 분석}

식물을 이용하여 각 석호간의 유사성을 추정하기 위해 Sørensen의 유사도 지수를 분석한 결과를 Figs. 5와 6에 나 타내었다. 군집 간에 유사도 지수가 $20 \%$ 미만일 때 서로 이질적인 집단이고, $80 \%$ 이상일 때 서로 동질적인 집단으 로서(Whittaker, 1956), 생태적으로 유사한 집단일수록 유 사도 지수는 높게 나타난다(Cox, 1976).

17 개 석호에 출현하는 전체 식물을 대상(외래식물과 재 배종 제외)으로 한 유사도 분석결과, 쌍호와 경포호 사이 


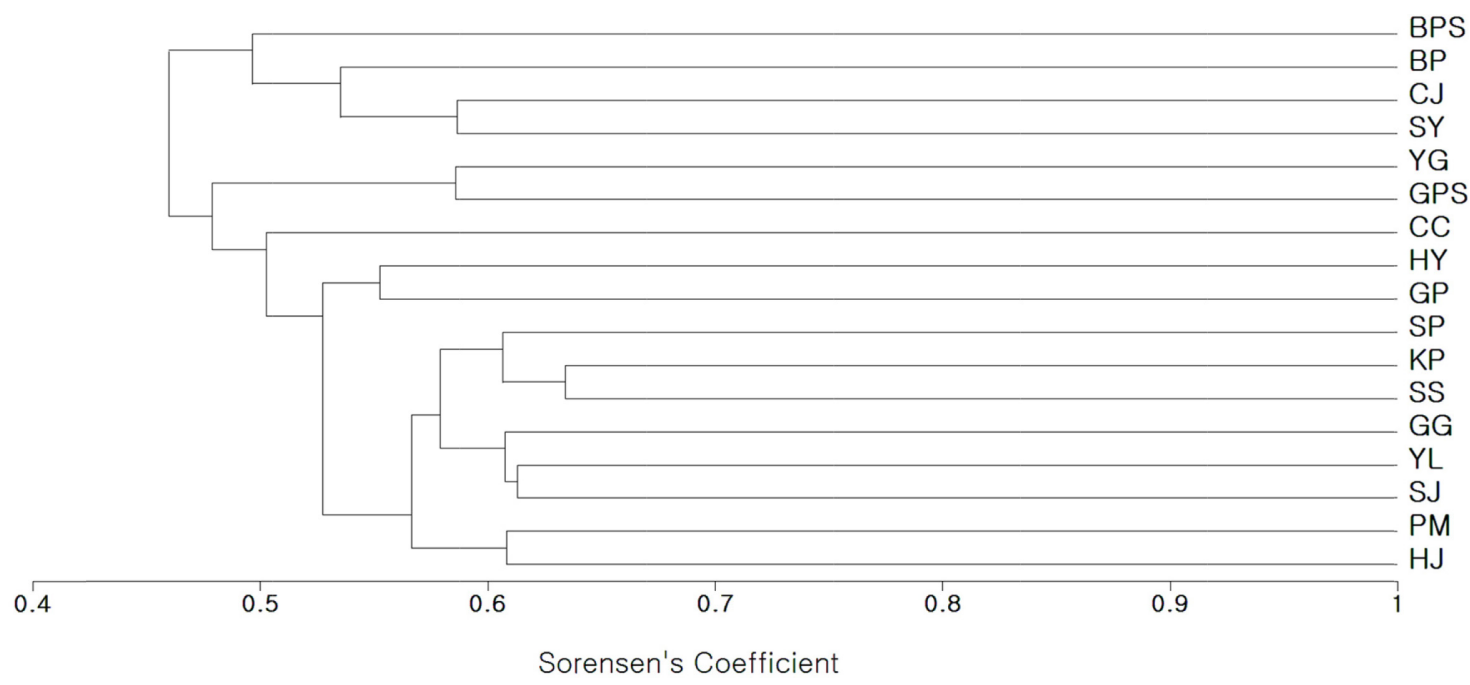

Fig. 5. Dendrogram showing the degree of Sørensen similarity based on vascular flora data of lagoon areas on the eastern coast in Korea. BPS, Bongposeupji; BP, Bongpoho; CJ, Cheonjinho; SY, Soenyudam; YG, Yeomgaeho; GPS, Gapyeongriseupji; CC, Cheongchoho; HY, Hyangho; GP, Gwangpoho; SP, Sunpoho; KP, Kyeongpoho; SS, Ssangho; GG, Gungaeho; YL, Yeonglangho; SJ, Songjiho; PM, Pomaeho; HJ, Hwajinpoho.

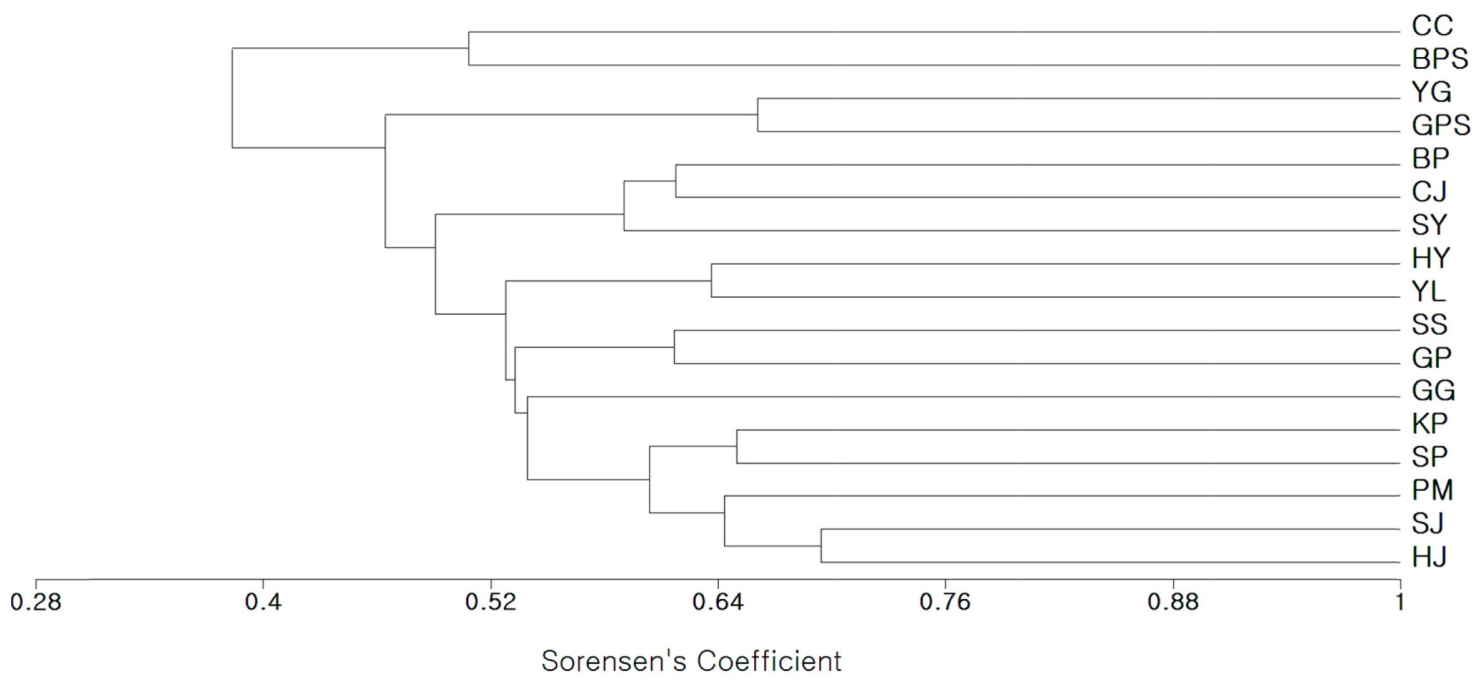

Fig. 6. Dendrogram showing the degree of Sørensen similarity based on hydrophyte data of lagoon areas on the eastern coast in Korea. CC, Cheongchoho; BPS, Bongposeupji; YG, Yeomgaeho; GPS, Gapyeongriseupji; BP, Bongpoho; CJ, Cheonjinho; SY, Soenyudam; HY, Hyangho; YL, Yeonglangho; SS, Ssangho; GP, Gwangpoho; GG, Gungaeho; KP, Kyeongpoho; SP, Sunpoho; PM, Pomaeho; SJ, Songjiho; HJ, Hwajinpoho.

의 유사도가 $63.4 \%$ 로 가장 높게 나타났다. 송지호와 영랑 호(node 2) 사이의 유사도가 $61.3 \%$, 화진포와 포매호가 $60.8 \%$, node 2 와 군개호가 $60.8 \%$ 등의 순으로 나타났다 (Fig. 5).

Choung et al. (2012) 기준에 따라 습지식물(절대습지식 물, 임의습지식물)만을 이용한 유사도 분석결과는 화진 포와 송지호 사이의 유사도(node 1)가 69.4\%로 가장 높 게 나타났다. 가평리습지와 염개호 사이의 유사도가
$66.1 \%$, 순포호와 경포호가 $65.0 \%$, node 1 과 포매호가 $64.3 \%$ 등의 순으로 나타났다(Fig. 6). 이러한 결과는 전체 출현종을 이용하여 분석한 유사도 지수보다 높게 나타 났고, 지역적으로 인접해 있는 석호간의 유사도 지수도 높게 나타났다(Figs. 5, 6). 이는 육지화가 진행됨에 따라 습지식물보다는 육상식물의 출현비율이 높게 나타나 각 석호만의 지역 특이성과 다양성이 반영되지 못한 것으 로 판단된다. 


\section{고 찰}

본 연구의 조사결과, 동해안 석호에서 확인된 관속식물 은 118 과 378 속 655 종 13 아종 46변종 6교잡종, 총 720 분류 군이 확인되었다. 각시수련, 털양지꽃, 큰뚝사초 등 한반 도 고유종이 11 분류군이고, 가시연, 순채, 조름나물, 제비 붓꽃 등 멸종위기 및 우려종이 18 분류군이다. 세잎승마, 삼지구엽초, 애기어리연, 끈끈이주걱, 긴흑삼릉 등 식물 지리학적 주요종으로 평가되는 식물구계학적 특정식물 $\mathrm{IV}-\mathrm{V}$ 등급 식물이 23분류군이다. 또한 각시수련, 갯활량 나물, 기름당귀, 큰쉽싸리, 통발, 검정납작골풀, 새방울사 초, 나도송이고랭이, 천도미꾸리광이 등은 남한 내에서 석호에서만 관찰되는 종이며, 대구돌나물, 선물수세미, 벼룩아재비, 섬쑥부쟁이(Aster pseudoglehnii Y. S. Lim, Hyun \& H. Shin), 올챙이솔[Blyxa japonica (Miq.) Maxim. ex Asch. \& Gürke], 애기거머리말(Zostera japonica Asch. \& Graebn.), 긴흑삼릉 등은 자생지가 2-3곳에 불과한 희귀식 물로서 이들에 대한 적극적인 보호가 필요한 생태적 중요 종이다.

식물의 분포는 수계의 물리적, 화학적 및 생물학적 변화 에 민감하게 반응하며, 특히 퇴적물의 축적, 부영양화, 수 문학적 변화에 민감한 것으로 알려져 있고(Miller et al., 2006), 지질이나 지하수, 토양 등의 차이를 설명하는 주요 지표로서 활용되고 있다(U. S. Environmetal Protection Agency, 1998; Gernes and Helgen, 1999; Nichols et al., 2000; Herman et al., 2001; Miller et al., 2006; Rothrock et al., 2008). 그 중 출현종의 총 분류군 수, 습지식물이나 수생식물 같 은 특정 식물종의 수, 멸종위기종의 수, 고유종의 수, 외래 종의 수 등은 호수의 건강성을 평가하기 위한 지표로 사 용한다(Choung and Lee, 2013). 이에 기초하여 일부 석호의 특징을 살펴보면, 염개호와 선유담은 습지식물의 출현 비 율이 높고, 육상식물과 외래식물의 출현 비율이 낮게 나 타났다. 염개호의 경우 내륙 쪽의 작은 웅덩이 부분과 배 후습지대가 남아있고, 해안사구가 거의 온전히 보전되고 있으며(Ministry of Environment, 2009), 선유담호는 수역이 좁고 swamp 상태이기 때문일 것으로 판단된다. 반면에 청 초호와 영랑호는 육상식물과 외래식물의 출현 비율이 높 고, 습지식물의 출현 비율이 낮게 나타났다. 청초호의 주 변 지역은 도시화 지역으로 인간의 간섭이 매우 크고 주 변의 농경지 등에서 비점오염 물질과 생활하수가 그대로 유입되고 있으며(Ministry of Environment, 2009), 영랑호의 경우 둘레길 설치로 인한 수변의 인공화와 획일화된 수변 관리에 의한 것으로 판단된다.

석호는 유역 산림이나 농경지로부터의 토사유입과 매 립, 수변식물의 번성 등에 의한 육지화 과정을 거쳐 왔고, 그로 인해 그 면적이 점차 축소되고 있다. 그에 따라 환경 부 및 해당 지방자체단체에서 일부 석호에 대한 복원사업 이 추진되고 있다(Ministry of Environment, 2008, 2009). 이
처럼 문제가 있는 대상을 복원하기 위해서는 그 대상에 대한 모니터링과 진단평가가 이루어져야 한다. 그 결과에 근거한 문제의 정도를 인식하여 훼손 정도에 따라 최적의 복원경로를 추적하면 비용의 낭비를 막을 수 있고, 복원 이 추구하는 지역 특이성과 다양성이 살아나 보다 나은 복원 효과도 거둘 수 있다(Lee, 2007; Lee et al., 2011). 또한 습지식물의 종다양성이나 분포는 수리적 조건에 큰 영향 을 받기 때문에(Raulings et al., 2010), 출현종과 외래종에 대한 지속적인 모니터링은 석호의 구조와 기능 변화를 파 악하기 위해 필수적이다(Kim and Myung, 2008).

습생 천이가 진행됨에 따라 유기물과 토양 침전물의 퇴 적, 지하수위 감소 등으로 습지식물이 육상식물로 점차 대체되고 잠식하게 된다(Cronk and Fennessy, 2001). 영양 염류 흡수능, 수질 정화능, 서식처로서의 역할 등 정착된 식생이 발휘하는 본래의 기능을 지속적으로 유지하기 위 해서는 수심 관리와 토양 수분 보유능이 균등히 유지되어 수습생식물이 생육할 수 있도록 해야 한다(Son et al., 2015). 석호의 식물 및 식생은 생산자로서의 역할과 다른 생물의 서식처 및 은신처 기능을 수행함으로서 다른 생물 군과의 연계성을 고려한 복원이 필요하다(Ministry of Environment, 2008, 2009).

본 연구는 총 5 년간 국내에 분포하는 석호 17 개소에 대 해 식물상적 현황 조사와 지속적인 모니터링을 수행한 결 과로서, 석호가 지닌 식물지리학적 중요성과 보존의 시급 성을 강조하고자 하였다. 최근 석호의 중요성을 인식하여 복원을 추진하고 있는 상황에서 식물다양성 보전정책 및 복원방안을 수립하기 위한 기초자료와 합리적인 관리방 안의 정보제공 등에 활용될 것으로 기대한다.

\section{Acknowlegments}

This work was supported by a grant from the National Institute of Biological Resources (NIBR), funded by the Ministry of Environment (MOE) of the Republic of Korea (NIBR201201018, 201301046, 201401104).

\section{Literature Cited}

Association for Research on Landscape Ecology. 2001. Landscape Ecology. Donghwa Technology Publishing Co., Seoul. Pp. 185-220. (in Korean)

Cho, Y. H., J. H. Kim and S. H. Park. 2016. Grasses and Sedges in South Korea. Geobook, Seoul, 527 pp. (in Korean)

Choung, Y. S., W. T. Lee, K. H. Cho, K. Y. Joo, B. M. Min, J. O. Hyun and K. S. Lee. 2012. Categorizing Vascular Plant Species Occurring in Wetland Ecosystems of the Korean Peninsula. Center for Aquatic Ecosystem Restoration, Chuncheon, 243 pp. (in Korean) 
Choung, Y. and K. Lee. 2013. Review of a plant-based health assessment methods for lake ecosystems. Korean Journal of Ecology and Environment 46: 145-153. (in Korean)

Cox, G. W. 1976. Laboratory Manual of General Ecology. 3rd ed. Wm. C. Brown Company, Dubuque, IA, 232 pp.

Cronk, J. K. and M. S. Fennessy. 2001. Wetland Plants: Biology and Ecology. CRC Press, Boca Raton, FL, 482 pp.

Cronquist, A. 1981. An Integrated System of Classification of Flowering Plants. Columbia University Press, New York, $1262 \mathrm{pp}$.

Gernes, M. C. and J. C. Helgen. 1999. Indexes of Biotic Integrity (IBI) for Wetlands: Vegetation and Invertebrate IMI's. Final Report to U.S. EPA, Assistance Number CD 995525-01. Minnesota Pollution Control Agency, St. Paul, MN.

Herman, K. D., L. A. Masters, M. R. Penskar, A. A. Reznicek, G. S. Wilhelm, W. W. Brodovich and K. P. Gardiner. 2001. Floristic Quality Assessment with Wetland Categories and Examples of Computer Applications for the State of MichiganRevised. 2nd ed. Michigan Department of Natural Resources, Wildlife Division, Natural Heritage Program, Lansing, MI, 19 pp.

Hong, M. P. 2011. Plants of lagoons on the eastern coast in Korea. Nature Conservation 155: 13-20. (in Korean)

Jung, J. and H.-K. Choi. 2011. Taxonomic study of Korean Scirpus L. s.l. (Cyperaceae) I. Morphology of Bolboschoenus (Asch.) Palla, Schoenoplectus (Rchb.) Palla, Schoenoplectiella Lye, Scirpus L., and Trichophorum Pers. Korean Journal Plant Taxonomy 41: 16-34. (in Korean)

Kil, J., Y. Kim, H. Kim, D. Lee, C. Lee, S. Hwang, D. Kim and M. Kim. 2011. Monitoring of Invasive Alien Species Designated by the Wildlife Protection Act (V). National Institute of Environmental Research, Incheon, 196 pp. (in Korean)

Kim, C.-H. and H. Myung. 2008. A 4-year follow-up survey of flora at the human-made wetlands along Boknaecheon of Juam Lake. Journal of the Korean Society for Environmental Restoration and Revegetation Technology 11: 25-37. (in Korean)

Kim, H. Y., M. H. Kim, H. K. Choi, D. Y. Lyang, E.-J. Shin, K. S. Lee and H. Yi. 2010. Changes of vegetation structure according to the hydro-seral stages in the east coastal lagoons, Korea. Journal of Wetlands Research 12: 129-144. (in Korean)

Kim, J.-H., G.-H. Nam, S.-Y. Kim, J.-S. Kim, J.-E. Choi and B. Y. Lee. 2013a. A floristic study of Baengnyeongdo (Isl.) in Korea. Korea Journal Plant Resources 26: 178-213. (in Korean)

Kim, J.-H., S.-Y. Kim, B. Y. Lee and C.-Y. Yoon. 2015. Floristic study of Gyodongdo island in Ganghwa-gun, Korea. Korean Journal Environment and Ecology 29: 105-131.
Kim, J., K.-H. Cho and H.-Y. M. Lee. 2001. Vegetation structure of the Kungae reclaimed wetland in a coastal lagoon of east sea, Korea. Korean Journal of Ecology 24: 27-34. (in Korean)

Kim, J. S., J. H. Kim, S. Y. Kim, G. H. Nam and B. Y. Lee. 2013 b. Flora of Biodiversity Hot-spot in Korea (II). National Institute of Biological Resources. Incheon, 147 pp. (in Korean)

Kim, S., Y. Cho, J. Kim, S. Shim and S. Kim. 2012. Juncus fauriei Lév. \& Vaniot (Juncaceae): a new record in Korea. Korean Journal Plant Taxonomy 42: 330-334. (in Korean)

Kjerfve, B. 1994. Coastal lagoons. In Coastal Lagoon Processes. Kjerfve, B. (ed.), Elsevier Oceanography Series, 60. Elsevier Science Publishers, Amsterdam. Pp. 1-8.

Koo, B. H. 2009. Wetland Ecology. Jogyeong, Paju. Pp. 383-384. (in Korean)

Kwak, S.-J., S.-H. Yoo and J.-I. Chang. 2005. Measuring the conservation value of lagoons: the case of Songji Lagoon. Ocean and Polar Research 27: 161-169. (in Korean)

Lee, B. Y., G. H. Nam, J. Y. Lee, C. H. Park, C. E. Lim, M. H. Kim, S. J. Lee, T. K. Noh, J. A. Lim, J. E. Han and J. H. Kim. 2011. National List of Species of Korea: Vascular Plants. National Institute of Biological Resources, Incheon, 633 pp. (in Korean)

Lee, C. S. 2007. Ecological evaluation on rivers different in restoration methods. In: 2007 Proceeding of Academic Symposium in Riverine Environment. Pp. 113-119.

Lee, C. S., Y. M. Jeong and H. S. Kang. 2011. Concept, direction and task of ecological restoration. Journal of Restoration Ecology 2: 59-71. (in Korean)

Lee, M.-B., N.-S. Kim and G.-R. Lee. 2006. The distribution and geomorphic changes of natural lakes in east coast of Korea. Journal of the Korean Association of Regional Geographers 12: 449-460. (in Korean)

Lee, T. B. 1980. Illustrated Flora of Korea. Hyangmunsa, Seoul, 990 pp. (in Korean)

Lee, W. T. 1996. Standard Illustrations of Korean Plants. Academy Press, Seoul, 624 pp. (in Korean)

Miller, S. J., D. H. Wardrop, W. M. Mahaney and R. P. Brooks. 2006. A plant-based index of biological integrity (IBI) for headwater wetland in central Pennsylvania. Ecological Indicators 6: $290-312$.

Ministry of Environment. 2008. A Study of Ecosystem Survey and Management Strategy for Conservation and Restoration on the Eastern Coast Lagoons I. Wonju Regional Environmental Administration, Wonju, 781 pp. (in Korean)

Ministry of Environment. 2009. A Study of Ecosystem Survey and Management Strategy for Conservation and Restoration on the Eastern Coast Lagoons II. Wonju Regional Environmental Administration, Wonju, 978 pp. (in Korean) 
Moon, D. S., H. J. Kim, M. Y. Choi, D. H. Jung and S. W. Lee. 2007. Water quality characteristics of lagoons in the east coast of Korea. In Joint Conference of the Korean Association of Ocean Science and Technology Societies, 2007 May 31-Jun 1, Busan, Korea. Pp. 2388-2393. (in Korean)

Moon, H. K., Y. C. Kim and S. P. Hong. 2013. Diagnostic characters and new populations of Lycopus lucidus var. hirtus (Lamiaceae). Korean Journal Plant Taxonomy 43: 99-102.

National Institute of Biological Resources. 2012. Red Data Book of Endangered Vascular Plants in Korea. Econature, Seoul, 390 pp. (in Korean)

National Institute of Biological Resources. 2013. Endemic Species of Korea: Plantae. National Institute of Biological Resources, Incheon, 912 pp. (in Korean)

National Institute of Environmental Research. 2012. A Guide to the 4th National Natural Environment Research. National Institute of Environmental Research, Incheon. Pp. 173-226. (in Korean)

Nichols, S., S. Weber and B. Shaw. 2000. A proposed aquatic plant community biotic index for Wisconsin Lakes. Environmental Management 26: 491-502.

Noh, T. K., J. H. Kim, S. Y. Kim, J. S. Kim, H. Y. Lee, C. H. Park, H. K. Oh, B. Y. Lee, K. S. Jeong, W. Lee and D. H. Jang. 2014. Flora of Biodiversity Hot-spot in Korea (III). National Institute of Biological Resources. Incheon, 131 pp. (in Korean)

Oh, B. U., D. G. Jo, S. C. Ko, H. T. Im, W. K. Paik, G. Y. Chung, C. Y. Yoon, K. O. Yoo, C. G. Jang and S. H. Kang. 2009. Distribution Maps of Vascular Plants of Korean Peninsula, VI. Central Province (Gangwon-do). Korea Forest Service, Daejeon, 793 pp. (in Korean)

Oh, B. U., D. G. Jo, S. C. Ko, B. H. Choi, W. K. Paik, G. Y. Chung, Y. M. Lee and C. G. Jang. 2010. 300 Target Plants Adaptable to Climate Change in the Korean Peninsula. Korea National Arboretum, Pocheon, 492 pp. (in Korean)

Oh, Y. C. 2007. Cyperaceae Juss. In The Genera of Vascular Plants of Korea. Flora of Korea Editorial Committee (ed.), Academy Publishing Co., Seoul. Pp. 1113-1181.

Park, C. G. 2006. Status and conservation counterplan on the eastern coast lagoons. Journal of Wetlands Research 8: 21-31. (in Korean)

Park, S. H. 2009. New Illustrations and Photographs of Naturalized Plants of Korea. Ilchokak, Seoul, 575 pp. (in Korean)

Raulings, E. J., K. Morris, M. C. Roache and P. I. Boon. 2010. The importance of water regimes operating at small spatial scales for the diversity and structure of wetland vegetation. Freshwater Biology 55: 701-715.

Rothrock, P. E., T. P. Simon and P. M. Stewart. 2008. Development, calibration, and validation of a littoral zone plant index of biotic integrity (PIBI) for lacustrine wetlands. Ecological Indicators 8: 79-88.

Son, D., H. Lee, E. J. Lee, K.-H. Cho and D. Kwon. 2015. Flora and vegetation structure in a 15-year-old artificial wetland. Ecology and Resilient Infrastructure 2: 54-63. (in Korean)

U. S. Environmetal Protection Agency. 1998. Lake and Reservoir Bioassessment and Biocriteria. Technical Guidance Document EPA 841-B-98-007. U. S. Environmetal Protection Agency, Washington, DC, 118 pp.

Whittaker, R. H. 1956. Vegetation of the Great Smoky Mountains. Ecological Monographs 26: 1-80.

Yoon, S.-O., S. Hwang, C.-S. Park, H.-S. Kim and Y.-R. Moon. 2008. Landscape changes of coastal lagoons during the 20th century in the middle east coast, South Korea. Journal of the Korean Geographical Association 43: 449-465. (in Korean) 
Appendix 1. The list of vascular plants surveyed in lagoon areas on the Korean peninsula.

Taxa/Collection numbers (NIBRVP0000-) $\quad \frac{\text { Collection sites }^{\mathrm{a}}}{$\cline { 3 - 3 }}

\section{Equisetaceae 속새과}

Equisetum arvense L. 쇠뜨기; 364260, 364439, 364609, 364677, 410257, 427822, 427874, $427891,427905,427921,456053,456199,456627,456742,456950,539431$

\section{Osmundaceae 고비과}

Osmunda cinnamomea L. 뀡고비; 364231

Osmunda japonica Thunb. 고비; 399647, 539468

\section{Salviniaceae 생이가래과}

Salvinia natans All. 생이가래; 399276, 489233

Dennstaedtiaceae 잔고사리과

Dennstaedtia wilfordii (T. Moore) H. Christ 황고사리; 457630

Pteridium aquilinum var. latiusculum (Desv.) Underw. ex A. Heller 고사리; 410541, 486923

Aspleniaceae 꼬리고사리과

Asplenium incisum Thunb. 꼬리고사리; 156170, 410220, 427833, 488943, 489526

Onocleaceae 야산고비과

Onoclea sensibilis L. 야산고비; 364310, 410348, 437329, 457618, 486772

Pentarhizidium orientale (Hook.) Hayata 개면마; 457625

\section{Athyriaceae 개고사리과}

Athyrium sinense Rupr. 참새발고사리; 457889

Athyrium yokoscense (Franch. \& Sav.) H. Christ 뱀고사리; 364230, 399630, 399687, 456377, $457615,479580,488487$

Deparia $\times$ angustata (Nakai) Nakaike 개좀진고사리; 479577, 489015

Deparia pycnosora (H. Christ) M. Kato 털고사리; 457862, 456280

\section{Thelypteridaceae 처녀고사리과}

Thelypteris palustris (Salisb.) Schott 처녀고사리; 399353, 399453, 410510, 410630, 437436, 456643, 457310, 479239, 488551

\section{Dryopteridaceae 관중과}

Dryopteris chinensis (Baker) Koidz. 가는잎족제비고사리; 156179, 364229, 456370

Dryopteris crassirhizoma Nakai 관중; 437472, 456358

Polystichum ovato-paleaceum var. coraiense (H. Christ) Sa. Kurata 참나도히초미;457620

\section{Pinaceae 소나무과}

Pinus densiflora Siebold \& Zucc. 소나무; 410237, 427906, 427954, 437397, 437869, 489706 Pinus rigida Mill. 리기다소나무(식재); 410695, 427855, 427918, 456611, 486753

Pinus thunbergii Parl. 곰솔; 307143, 427635, 427907, 427953, 462907, 486824, 489094, 489769

\section{Cupressaceae 측백나무과}

Juniperus chinensis L. 향나무(식재); 427916

Juniperus rigida Siebold \& Zucc. 노간주나무; 486712

Platycladus orientalis (L.) Franco 측백나무(식재); 427917

\section{Lauraceae 녹나무과}

Lindera obtusiloba Blume 생강나무; 410235, 457631, 479426

Nelumbonaceae 연과 
Appendix 1. Continued.

Taxa/Collection numbers (NIBRVP0000-)

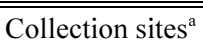

12234556778991011121314151617

Nelumbo nucifera Gaertn. 연; 399203, 489227

Nymphaeaceae 수련과

Euryale ferox Salisb. 가시연; 457009

Nuphar pumila (Timm) DC. 왜개연; 410571

Nymphaea alba L. 흰수련; 410379

Nymphaea minima Nakai 각시수련; 410621, 410840

\section{Cabombaceae 어항마름과}

Brasenia schreberi J. F. Gmel. 순채; 410572

\section{Ceratophyllaceae 붕어마름과}

Ceratophyllum demersum L. 붕어마름; 306358, 399208, 410841, 435074, 479181, 479280, 488858, 489232

\section{Ranunculaceae 미나리아재비과}

Aconitum jaluense Kom. 투구꽃; 457873

Adonis pseudoamurensis W. T. Wang 개복수초; 427848

Cimicifuga heracleifolia var. bifida Nakai 세 잎승마; 457879

Clematis apiifolia DC. 사위질빵; 410652, 410802, 457706, 489000

Ranunculus cantoniensis DC. 털개구리미나리; 410271, 456042, 456576, 456787, 456903, 457226, 457636

Ranunculus chinensis Bunge 젓가락나물; 308912, 456171, 456638, 479210

Ranunculus japonicus Thunb. 미나리아재비; 437413, 479333, 479451, 486857

Ranunculus sceleratus L. 개구리자리; 364240, 364441, 410249, 437401, 437794, 456963, 479405

Thalictrum minus L. 큰꿩의다리(좀꿩의다리); 457735

Thalictrum rochebrunianum var. grandisepalum (H. Lév.) Nakai 금꿩의다리; 457753

\section{Berberidaceae 매자나무과}

Epimedium koreanum Nakai 삼지구엽초; 457892

\section{Menispermaceae 새모래덩굴과}

Cocculus trilobus (Thunb.) DC. 댕댕이덩굴; 151329, 399558, 456298, 456548, 457227, 457684, 462979, 486913, 488823

Menispermum dauricum DC. 새모래덩굴; 306340, 306346, 437469, 488694

Papaveraceae 양귀비과

Chelidonium majus var. asiaticum (H. Hara) Ohwi 애기똥풀; 364249, 364444, 437424, 437826, 456147, 456932, 474874

Papaver rhoeas L. 개양귀비; 456984, 479526

\section{Fumariaceae 현호색과}

Corydalis incisa (Thunb.) Pers. 자주괴불주머니; 456066

Corydalis speciosa Maxim. 산괴불주머니; 456161

Corydalis turtschaninovii Besser 조선현호색; 437458

Ulmaceae 느릅나무과

Celtis jessoensis Koidz. 풍게나무(식재); 489176 
Appendix 1. Continued.

Collection sites $^{\mathrm{a}}$

Taxa/Collection numbers (NIBRVP0000-)

1223456678991011121314151617

Ulmus davidiana var. japonica (Rehder) Nakai 느릅나무; 437412

Ulmus parvifolia Jacq. 참느릅나무; 486883, 489881

$\bigcirc$

\section{Cannabaceae 삼과}

Humulus japonicus Siebold \& Zucc. 환삼덩굴; 399731, 410577, 410821, 456257, 456424, 457057, 457151, 457480, 457881, 488619, 488772, 489046

00000000000000000

\section{Moraceae 뽕나무과}

Morus alba L. 뽕나무; 364234, 364420, 399430, 410526, 437283, 437595, 437653, 437900, $456212,456557,456689,456933,457699,479756$

Morus bombycis Koidz. 산뽕나무; 410268, 437293, 437392, 437654, 456049

$\bigcirc \bigcirc 000000000000$

\section{Urticaceae 쐐기풀과}

Boehmeria spicata (Thunb.) Thunb. 좀깨잎나무; 456051

Boehmeria tricuspis (Hance) Makino 개모시풀(거북꼬리); 456175, 456754

Pilea mongolica Wedd. 모시물통이; 399738, 457858, 456354, 488734, 399644

Juglandaceae 가래나무과

Juglans mandshurica Maxim. 가래나무; 437483, 479461, 489559

\section{Fagaceae 참나무과}

Castanea crenata Siebold \& Zucc. 밤나무(식재); 399519, 410580, 456274, 456684

Quercus aliena Blume 갈참나무; 399543, 437321, 486731, 486816

Quercus dentata Thunb. 떡갈나무; 156183, 156267, 399521, 410481, 437318, 437381, $437628,456129,456655,474862$

Quercus $\times$ dentatomongolica Nakai 떡신갈나무; 399520, 478811

Quercus $\times$ fabri Hance 떡속소리나무; 410479

Quercus $\times$ maccromickii Carruth. 떡갈참나무; 457292

Quercus mongolica Fisch. ex Ledeb. 신갈나무; 437319,437625, 437685, 456656, 486730

Quercus mongolica var. crispula (Blume) H. Ohashi 물참나무; 399411, 399501, 488954

Quercus serrata Murray 졸참나무; 399327, 410285, 410646, 437313, 456150, 456843, 474878

Quercus variabilis Blume 굴참나무; 410518

\section{Betulaceae 자작나무과}

Alnus firma Siebold \& Zucc. 사방오리(식재); 437457, 437823

Alnus hirsuta Turcz. ex Rupr. 물오리나무; 156175, 156657, 399277, 399715, 410604, 427861, 427901, 437289, 437716, 456185, 474884, 479755, 488743

Betula pendula Roth 자작나무(식재); 456080

Carpinus laxiflora (Siebold \& Zucc.) Blume 서어나무; 399499, 456032

Corylus heterophylla Fisch. ex Trautv. 개암나무(난티잎개암나무); 41029, 410813, 456392

\section{Phytolaccaceae 자리공과}

Phytolacca americana L. 미국자리공; 456587; 456799, 457507, 462962, 486958, 488614, 488733, 489174

\section{Chenopodiaceae 명아주과}

Atriplex gmelinii C. A. Mey. ex Bong. 가는갯능쟁이; 489547

Chenopodium album L. 흰명아주; 479398, 488599, 488759, 488944, 489565

$\circ \quad 000$
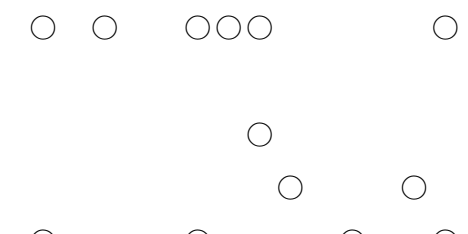

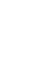

$\bigcirc$

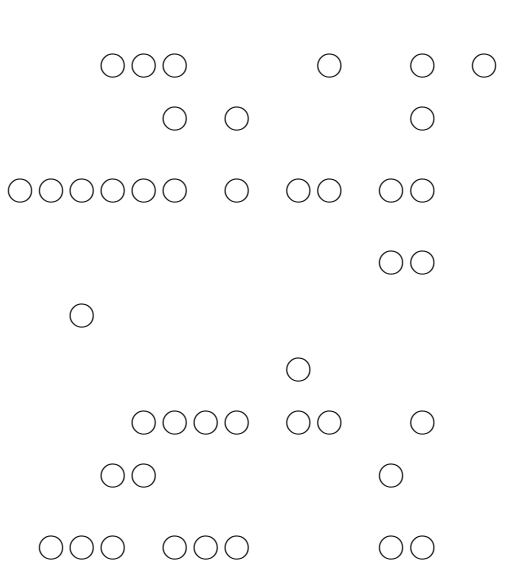

$\bigcirc$

$\bigcirc$

$000000000 \circ 000$

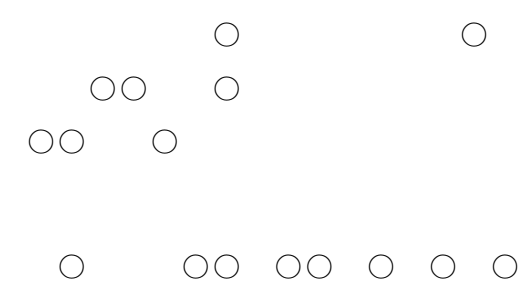


Appendix 1. Continued.

Taxa/Collection numbers (NIBRVP0000-)

Collection sites $^{\mathrm{a}}$

ar. centrorubum Makino 명아주, $399625,399657,410383,410568$,

Chenopodium album var. centrorubum Makino 명아주; 399625, 399657, 410383, 410568, 410750, 456148, 456427, 456762, 457531, 457963, 489215, 489484, 489612, 489960

Chenopodium ficifolium Sm. 좀명아주; 410233, 410368, 437762, 456035, 456145, 456664, 457758, 479313, 479722, 487037

Chenopodium glaucum L. 취명아주; 456077, 457730, 479324, 489938

Corispermum platypterum Kitag. 꼬리호모초; 488966

Salsola komarovii Iljin 수송나물; 457720, 479155, 488720

\section{Amaranthaceae 비름과}

Achyranthes japonica (Miq.) Nakai 쇠무릎; 399250, 399552, 410628, 456288, 456507, 456851, 457746, 488635, 488787, 488935, 489048, 489219

122344556778991011121314151617

Amaranthus hybridus L. 긴털비름; 489486

Amaranthus lividus L. 개비름; 399235

Amaranthus retroflexus L. 털비름; 456468, 456783, 457727,474860, 488969, 539708

Portulacaceae 쇠비름과

Portulaca oleracea L. 쇠비름; 410658, 447996, 456760, 457549, 488664, 488763, 488983

\section{Molluginaceae 석류풀과}

Mollugo verticillata L. 큰석류풀; 488653

\section{Caryophyllaceae 석죽과}

Arenaria serpyllifolia L. 벼룩이자리; 437359, 437704, 437797, 455980, 456158, 456613, 456877, 479213, 486867

Cerastium glomeratum Thuill. 양점나도나물; 364660, 437661, 437814, 437862, 456167, $456610,456979,478803,489030$

Cerastium holosteoides var. hallaisanense (Nakai) M. Mizush. 점나도나물; 364233, 364450, 364621, 410298, 410360, 437356, 437573, 456041, 456698

Dianthus longicalyx Miq. 술패랭이꽃; 213396

Sagina japonica (Sw.) Ohwi 개미자리; 364282, 437362,456009, 456168, 456635, 456938, 462680, 479180, 479274, 489940

Silene armeria L. 끈끈이대나물; 399242, 437340, 456923, 479325, 489875

Silene firma Siebold \& Zucc. 장구채; 399474, 399673, 410406, 410823, 456562, 488605, 488766, 488952, 489043

Spergularia rubra J. Presl \& C. Presl 유럽개미자리; 456011, 456191, 456711, 462679, 479263

Stellaria alsine var. undulata (Thunb.) Ohwi 벼룩나물; 364243, 364454, 364616, 364685, 410275, 410347, 437308, 437421, 437599, 437663, 437821, 456160, 456658, 456896, 478794, 479217

Stellaria aquatica (L.) Scop. 쇠별꽃; 364238, 364443, 410297, 410370, 437559, 437749, 437857, 456063, 456163, 456625, 456954, 479769

Stellaria media (L.) Vill. 별꽃; 364684, 410849, 427862, 427893, 427924, 437304, 437674, 437892, 456165, 478773, 478788, 479729

Vaccaria hispanica (Mill.) Rauschert 말뱅이나물; 488807

\section{Polygonaceae 마디풀과}

Fagopyrum esculentum Moench 메밀; 486796

Fallopia dumetorum (L.) Holub 닭의덩굴; 399551, 488665, 489072

\section{$\bigcirc \bigcirc \bigcirc \bigcirc$}

$\bigcirc \bigcirc \bigcirc \bigcirc \bigcirc \bigcirc \bigcirc$

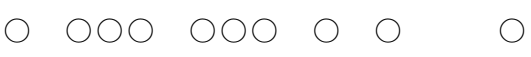

$\bigcirc \quad \bigcirc \bigcirc$

$\bigcirc \quad \bigcirc$

$\bigcirc$

$\bigcirc \bigcirc \bigcirc 0000 \bigcirc 00000$

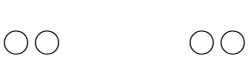

$\bigcirc \bigcirc$

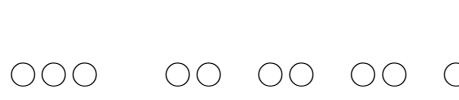

$\bigcirc$

$\bigcirc \bigcirc 0 \bigcirc \bigcirc \bigcirc$

$\bigcirc 00 \bigcirc 0 \bigcirc \bigcirc \bigcirc \bigcirc$

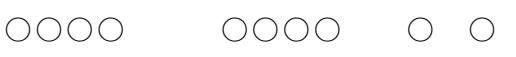

$\bigcirc$

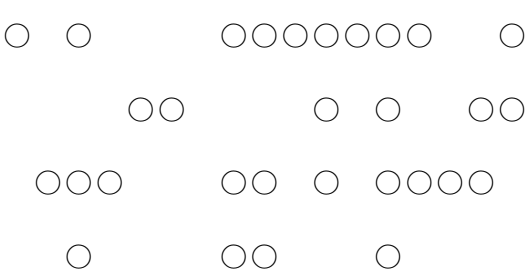

0000000000000000

$000 \quad 00000 \quad 00000$

000000000000

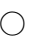

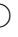

O 
Appendix 1. Continued.

Collection sites ${ }^{\mathrm{a}}$

Taxa/Collection numbers (NIBRVP0000-)

12234456678891011121314151617

Polygonum aviculare L. 마디풀; 399593, 410270, 437730, 456126, 456575, 456673, 456729, $456916,457360,457728,479302,488646$

Polygonum hastatosagittatum Makino 긴미꾸리낚시; 399793, 457528, 489007

Polygonum hydropiper L. 여뀌; 223118, 399789, 410664, 410770, 457012, 457514, 462967, 489003, 489622

Polygonum japonicum Meisn. 흰꽃여뀌; 399231, 456814, 457032, 457483

Polygonum koreense Nakai 대동여뀌; 399531, 410530, 410600, 456826, 457027, 457119, 457453, 457874, 489006

Polygonum lapathifolium L. 흰여뀌; 399458, 399484, 399542, 410401, 456236, 456495, 456797, 457095, 457523, 488725, 488869, 489081, 489210

Polygonum lapathifolium var. salicifolium Sibth. 솜흰여뀌; 486919

Polygonum longisetum Bruijn 개여뀌; 399534, 399729, 410409, 410834, 456502, 457973 , 489062, 489217, 489414, 489608

$0.00000-0=00$

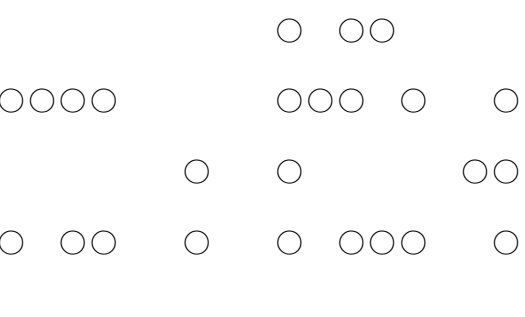

$\bigcirc \bigcirc 00000000000$

Polygonum muricatum Meisn. 넓은잎미꾸리낚시; 399424,399489, 399634, 399758, 410642, 410774, 456252, 456388, 489601

Polygonum nepalense Meisn. 산여뀌; 399480

Polygonum perfoliatum L. 며느리배꼽; 156186, 307184, 399254, 399373, 399437, 410751, 456534, 456766, 457221, 457799, 486756, 486926, 488532, 489153, 489944

Polygonum persicaria L. 봄여뀌; 456454, 486675

Polygonum pubescens Blume 바보여뀌; 399788, 410634,456361, 462960, 462984, 488603

Polygonum sagittatum L. 미꾸리낚시; 399659, 410528, 410595, 410791, 456220, 456798, 457099, 457537, 457805, 489558, 489726

Polygonum senticosum (Meisn.) Franch. \& Sav. 며느리밑씻개; 456571, 457738, 488586, 489167

Polygonum thunbergii Siebold \& Zucc. 고마리; 399533, 399692, 399747, 410643, 410772, $456318,456446,456795,457038,457811,489548,489614,489693,490055$

Polygonum viscoferum Makino 끈끈이여뀌; 410637

Polygonum viscosum Buch.-Ham. ex D. Don 기생여뀌; 410724, 488879

Rumex acetosa L. 수영; 364236, 437488, 456869

Rumex acetosella L. 애기수영; 364281, 364456, 364610, 364682, 410288, 410349, 437339, 437351, 437642, 437697, 437898, 456111, 456637, 456755, 456920, 479171, 486702

Rumex crispus L. 소리쟁이; 156358, 399290, 410359, 456061, 456184, 456889, 457214, 462914, 479158, 479198, 486872

Rumex japonicus Houtt. 참소리쟁이; 399377, 410494, 456558, 457261, 457680, 479493, 486787, 486865, 489179

Rumex obtusifolius L. 돌소리쟁이; 399218, 486946

Actinidiaceae 다래나무과

Actinidia arguta (Siebold \& Zucc.) Planch. ex Miq. 다래; 457748

\section{Elatinaceae 물별과}

Elatine triandra Schkuhr 물별; 456187, 457491

\section{Clusiaceae 물레나물과}

Hypericum ascyron L. 물레나물; 457565

Hypericum erectum Thunb. 고추나물; 399336, 399387, 410599, 414464, 456543, 457670, 488699, 488854 
Appendix 1. Continued.

Hypericum laxum (Blume) Koidz. 좀고추나물; 151385, 399209, 399386, 399539, 410603, 410723, 456293, 457245, 457586, 488850

000000

$\bigcirc \bigcirc \bigcirc \bigcirc$

Triadenum japonicum (Blume) Makino 물고추나물; 399466, 410632, 457302, 462923, 462956, 462990

\section{Malvaceae 아욱과}

Hibiscus mutabilis L. 부용(식재); 457041

\section{Droseraceae 끈끈이귀개과}

Drosera rotundifolia L. 끈끈이주걱; 410376

\section{Violaceae 제비꽃과}

Viola albida var. chaerophylloides (Regel) F. Maek. 남산제비꽃; 437520

Viola lactiflora Nakai 흰젖제비꽃; 364681, 437352, 478776, 478801, 486870, 498608

Viola mandshurica W. Becker 제비꽃; 364266, 364451, 364605, 364680, 410293, 437343, 437389, 437780, 456203, 457422, 478785

Viola orientalis (Maxim.) W. Becker 노랑제비꽃; 427814, 437326, 437760, 458615

Viola seoulensis Nakai 서울제비꽃; 427829, 427875

Viola verecunda A. Gray 콩제비꽃; 364232, 364433, 364606, 364659, 410282, 437300, 437427, 437755, 437792, 456022, 456166, 456746, 479286, 479607

Viola yedoensis Makino 호제비꽃; 427632, 427873, 456634. 456946, 478782, 479721

\section{Cucurbitaceae 박과}

Actinostemma lobatum (Maxim.) Franch. \& Sav. 뚜껑덩굴; 399741, 456556, 456778

Sicyos angulatus L. 가시박; 456371, 456852

\section{Salicaceae 버드나무과}

Populus euramericana Guinier 이태리포푸라(식재); 457712

Populus nigra var. italica Koehne 양버들(식재); 427840

Populus $\times$ tomentiglandulosa T. B. Lee 은사시나무(식재); 364419, 410260, 437411, 437655, 456084, 456559, 457251

Salix babylonica L. 수양버들; 399398, 410325, 410583, 427913, 456068

Salix caprea L. 호랑버들; 462958, 456177, 456567

Salix chaenomeloides Kimura 왕버들; 456069, 456531, 456702, 456907, 479586

Salix gracilistyla Miq. 갯버들; 364421, 364690, 399502, 427937, 456207, 456284, 486886, 488686, 489258

Salix koreensis Andersson 버드나무; 364620, 399751, 410259, 410698, 427629, 427634, $427898,437353,456194,456285,456839,456865,457269,478779,486760,489054$

Salix koriyanagi Kimura ex Goerz 키버들; 410358, 427633, 427638, 427857, 427884, 427888, 427900, 427936, 427955, 456078, 456704, 456900

Salix matsudana var. tortuosa Vilm. 용버들; 427879, 456213, 456866, 479452

Salix siuzevii Seemen 참오글잎버들; 399448, 427641, 427938, 457773, 488649

Salix subfragilis Andersson 선버들; 364313, 399570, 427640, 427880, 427889, 437842, 456198, 456703, 486776, 488602, 489259

Salix xerophila Flod. 여우버들; 437777,478778

\section{Brassicaceae 십자화과}

$\bigcirc$

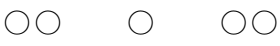

000000

0000<smiles>OOC(O)(O)O</smiles>

00000000000

0000

○ 000

$\bigcirc$

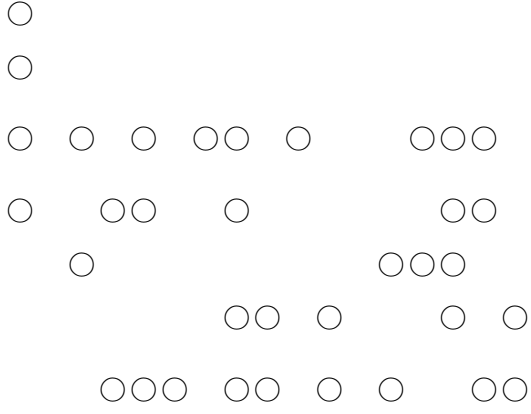

00000000000000000

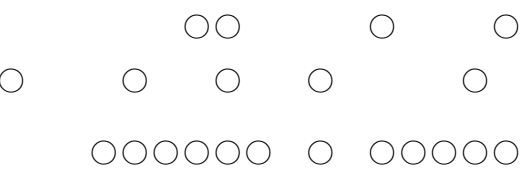

$\bigcirc$

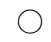


Appendix 1. Continued.

Taxa/Collection numbers (NIBRVP0000-)

Collection sites $^{\mathrm{a}}$

12234456678891011121314151617

Arabis glabra (L.) Bernh. 장대나물; 364292, 437443

$\bigcirc$

Barbarea orthoceras Ledeb. 나도냉이; 364287, 364449, 410315, 437388, 456050, 456652, 456943, 479166, 479237, 479723

Barbarea vulgaris W. T. Aiton 유럽나도냉이; 437468, 437594, 437735, 437783, 479711

Brassica juncea (L.) Czern. 갓; 437804, 487010

Brassica napus L. 유채; 427853

Cakile edentula (Bigelow) Hook. 서양갯냉이; 479145, 488959

Capsella bursa-pastoris (L.) Medik. 냉이; 364279, 364448, 364678, 410287, 427819, 427871, 427911, 437294, 437866, 455976, 456196, 456714, 456959, 479617

Cardamine fallax (O. E. Schulz) Nakai 좁쌀냉이; 427910,427944, 437301, 437376, 437757, 437876, 456089, 478768, 478807, 479610

Cardamine flexuosa With. 황새냉이; 364242, 364432, 364612, 364668, 410316, 427885, 437667, 456668, 456915, 479222, 479459, 479717

Cardamine leucantha (Tausch) O. E. Schulz 미나리냉이; 437473

Draba nemorosa L. 꽃다지; 364293, 364623, 364676, 410294, 427825, 427870, 427886, 427912, 427949, 456159, 456630, 456737, 456917, 478796

Lepidium apetalum Willd. 다닥냉이; 151298, 364291, 410322, 437604, 437782, 437864, 456072, 456146, 456693, 457723, 479121

Lepidium virginicum L. 콩다닥냉이 437557, 437738, 455994, 456886, 478820, 479139, 479142, 479167, 479303, 479656, 489958

Rorippa cantoniensis (Lour.) Ohwi 좀개갓냉이; 456913

Rorippa indica (L.) Hiern 개갓냉이; 410280, 437349, 455974, 456670, 457440, 479724

Rorippa palustris (L.) Besser 속속이풀; 156260, 364241, 399255, 410300, 410765, 437290, 437402, 437676, 437785, 456105, 456660, 456899, 479211, 479294, 479326, 479415, 479700

Rorippa sylvestris (L.) Besser 가새잎개갓냉이; 456738

Thlaspi arvense L. 말냉이; 478769

\section{Ericaceae 진달래과}

Rhododendron mucronulatum Turcz. 진달래; 410223, 427843, 437626, 456391, 486724

Rhododendron schlippenbachii Maxim. 철쭉; 437624, 479612

\section{Pyrolaceae 노루발과}

Chimaphila japonica Miq. 매화노루발; 291829

Pyrola japonica Klenze ex Alef. 노루발; 410286, 457384, 486725

\section{Ebenaceae 감나무과}

Diospyros lotus L. 고욤나무; 410277, 456307, 456683, 456135

\section{Styracaceae 때죽나무과}

Styrax japonicus Siebold \& Zucc. 때죽나무; 364254, 410645, 456710

Styrax obassia Siebold \& Zucc. 쪽동백나무; 410261

\section{Symplocaceae 노린재나무과}

Symplocos sawafutagi Nagam. 노린재나무; 364264, 364666, 410650, 437521, 437291 437723, 437627, 450098

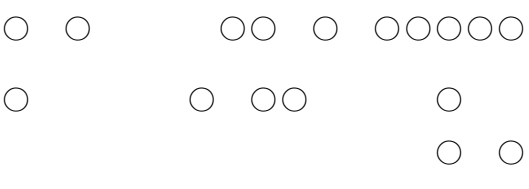

$\bigcirc \bigcirc$

000000000000000

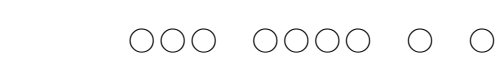

$000000000 \bigcirc \bigcirc \bigcirc \quad 00$

$\bigcirc$

$0000000000 \quad 00000$

$\bigcirc 00 \quad 000 \quad 00000$

0000000000

$\bigcirc \bigcirc \quad \bigcirc \bigcirc \bigcirc \bigcirc$

00000000000000000

Primulaceae 앵초과

Androsace umbellata (Lour.) Merr. 봄맞이꽃; 478792 
Appendix 1. Continued.

Taxa/Collection numbers (NIBRVP0000-)

\begin{tabular}{lllllllll} 
Collection sites $^{\mathrm{a}}$ \\
\hline 122 & 3 & 4 & 5 & 6 & 7 & 8 & 91011121314151617
\end{tabular}

Glaux maritima var. obtusifolia Fernald 갯 봄맞이꽃; 366699, 410241

Lysimachia clethroides Duby 큰까치수염; 456439, 457854, 486710, 486852

Lysimachia davurica Ledeb. 좁쌀풀; 399301, 399404, 410474, 410629, 456278, 456529, 456812, 457589, 486806, 486858, 486969, 487034, 488585 $\bigcirc$

$\bigcirc \quad \bigcirc \quad \bigcirc$ $\bigcirc \bigcirc \bigcirc$

$\bigcirc 0000000$ $\bigcirc \bigcirc 0 \bigcirc \bigcirc \bigcirc \bigcirc$

Lysimachia japonica Thunb. 좀가지풀; 456740

\section{Crassulaceae 돌나물과}

Orostachys japonica (Maxim.) A. Berger 바위솔; 489488

Orostachys malacophylla (Pall.) Fisch. 둥근바위솔; 410506

Sedum bulbiferum Makino 말똥비름; 462913, 479514

Sedum kamtschaticum Fisch. \& C. A. Mey. 기린초; 364245, 462912, 479422, 490014

Sedum polytrichoides Hemsl. 바위채송화; 489488

Sedum sarmentosum Bunge 돌나물; 462909, 462911, 462916, 479697

Tillaea aquatica $\mathrm{L}$. 대구돌나물; 456186

\section{Rosaceae 장미과}

Agrimonia pilosa Ledeb. 짚신나물; 156171, 399370, 457639, 488855, 489151

Duchesnea indica (Andr.) Focke 민뱀딸기; 364263, 410722, 437299, 437543, 437729, 456155, 456580, 479412

Malus baccata (L.) Borkh. 야광나무; 437456

Malus sieboldii (Regel) Rehder 아그배나무; 437801

Potentilla anserina L. 눈양지꽃; 364285, 410242, 437429, 456945, 457174, 479277

Potentilla chinensis Ser. 딱지꽃; 410408

Potentilla fragarioides L. 양지 꽃; 427863, 478767

Potentilla freyniana Bornm. 세잎양지꽃; 364267, 364662, 437320, 437503

Potentilla squamosa Soják. 털양지꽃; 410292, 427831, 437854

Potentilla supina L. 개소시랑개비; 437717, 456019, 456121, 456707, 479169, 479196, 479319, 479369

Prunus armeniaca var. ansu Maxim. 살구나무(식재); 410276

Prunus padus L. 귀룽나무; 410224, 437459

Prunus persica (L.) Batsch 복숭아나무; 410520, 437420, 437798, 456183

Prunus serrulata Lindl. 벚나무; 399419, 437479, 437825, 479558, 456079, 456132, 456905

Pyrus ussuriensis Maxim. 산돌배나무; 292185

Rosa multiflora Thunb. 찔레나무; 399427, 410284, 410831, 456047, 456208, 456688, $456925,457219,457779,479770$

Rosa rugosa Thunb. 해당화; 306330, 410253, 437391, 437611, 437805, 437902, 455975, 456940, 489669

Rubus coreanus Miq. 복분자딸기; 410484

Rubus crataegifolius Bunge 산딸기; 364658, 410222, 410674, 410828, 437408, 437652, 456127, 479665, 488612

Rubus fruticosus L. 서양산딸기; 410581

Rubus oldhamii Miq. 줄딸기; 364312, 410515, 437379, 456616, 456919, 478786, 478816

Rubus parvifolius L. 멍석딸기; 456001, 456204, 456599, 457218 
Appendix 1. Continued.

Taxa/Collection numbers (NIBRVP0000-)

Amorpha fruticosa L. 족제비싸리; 399361, 399745, 410350, 410535, 437790, 456043, 456108, 456811, 456909, 457239, 457716, 479642, 479709

Amphicarpaea bracteata ssp. edgeworthii (Benth.) H. Ohashi 새콩; 399550, 410497, 410626, 456444, 457865, 462985, 489460

Chamaecrista nomame (Siebold) H. Ohashi 차풀; 399295, 399402, 410417, 410700, 456584, 456758, 457145, 457546, 457718, 488703, 488768, 489204, 489542, 490003

Crotalaria sessiliflora L. 활나물; 457383

Desmodium podocarpum DC. 개도둑놈의갈고리; 457886

Desmodium podocarpum ssp. oxyphyllum (DC.) H. Ohashi 도둑놈의갈고리; 457599

Dunbaria villosa (Thunb.) Makino 여우팥; 399518

Glycine soja Siebold \& Zucc. 돌콩; 156283, 399253, 399296, 399416, 410500, 410570, $456417,456833,457025,457602,488611,488800,488908,489052$

Indigofera kirilowii Maxim. ex Palib. 땅비싸리; 364268

Kummerowia stipulacea (Maxim.) Makino 둥근매듭풀; 456810, 488778, 489079

Kummerowia striata (Thunb.) Schindl. 매듭풀; 399317, 399477, 399587, 410449, 410592, 456448, 456824, 457100, 457472, 457677, 488632, 488779, 488993, 489082, 489206

Lathyrus japonicus Willd. 갯완두; 410250, 437396, 437564, 437812, 437887, 456614, 479130, 479144, 479505

Lathyrus palustris ssp. pilosus (Cham.) Hulten 털연리초; 457585

Lespedeza bicolor Turcz. 싸리; 399426, 410560, 488701, 489220

Lespedeza cuneata (Dum. Cours.) G. Don. 비수리; 399457, 399662, 410531, 410591, 456223, 456386, 456418, 457500, 457809, 488669, 488754, 489251, 489581

Lespedeza cyrtobotrya Miq. 참싸리; 399588, 410389, 410576, 410822, 456324, 456416, 456847, 457399, 486859, 487005, 488709, 488789, 488924

Lespedeza davurica (Laxm.) Schindl. 호비수리; 474861

Lespedeza juncea (L. f.) Pers. 땅비수리; 488755

Lespedeza lichiyuniae T. Nemoto, H. Ohashi \& T. Itoh 자주비수리; 489113, 489503

Lespedeza maximowiczii C. K. Schneid. 조록싸리; 399445, 410513, 410651, 410716, 456395, 457698, 486766, 488706

Lespedeza thunbergii (DC.) Nakai 풀싸리; 292178

Lespedeza thunbergii ssp. formosa (Vogel) H. Ohashi 중국풀싸리; 488702

Lespedeza tomentosa (Thunb.) Siebold ex Maxim. 개싸리; 156276, 489844

Lespedeza virgata (Thunb.) DC. 좀싸리; 488753

\section{Collection sites $^{\mathrm{a}}$

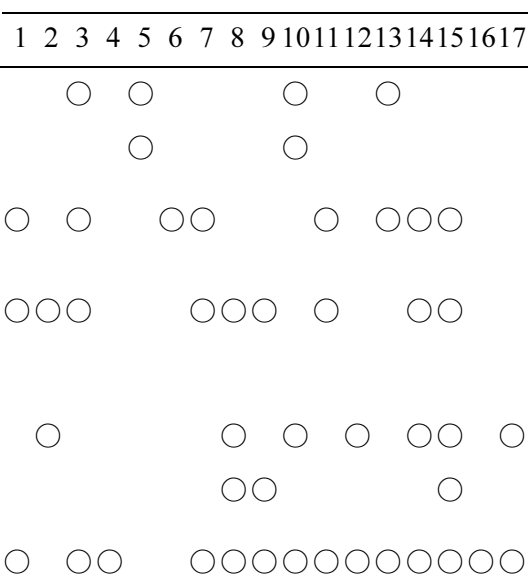 \\ 122334556778891011121314151617}

(

$\bigcirc \bigcirc \bigcirc$

00000000000

$\bigcirc$

$\bigcirc$

$\bigcirc$

000000000000000

$\bigcirc$

$\begin{array}{llll}00 & 0 & 0 & 0 \\ 000 & 00000000000\end{array}$

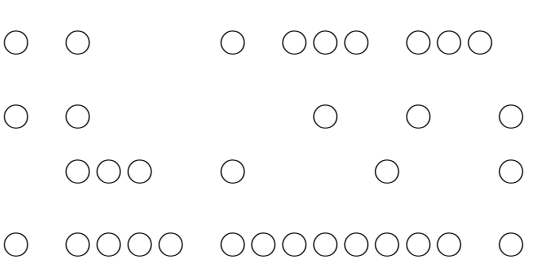

0000000000000<smiles>C1CC1</smiles><smiles>C1CO1</smiles>

○

$\bigcirc \bigcirc \bigcirc \bigcirc \bigcirc \bigcirc$

\begin{tabular}{lll}
0 & \\
0 & \\
\hline
\end{tabular} 
Appendix 1. Continued.

Taxa/Collection numbers (NIBRVP0000-)

\begin{tabular}{llllllll} 
Collection sites $^{\mathrm{a}}$ \\
\hline 12 & 345678 & 81011121314151617
\end{tabular}

Lotus corniculatus L. 서양벌노랑이; 456018, 456922

Lotus corniculatus var. japonicus Regel 벌노랑이; 308920, 364284, 456617, 457220, 470425, 479127, 479507, 479674, 489209

Medicago lupulina L. 잔개자리; 479508

Medicago sativa L. 자주개자리; 456918

Pueraria lobata (Willd.) Ohwi 칡; 399395, 456785, 457217, 457696, 488697, 488776, 488974, 489229

Robinia pseudoacacia L. 아까시나무; 399211, 410319, 437556, 456312, 456687, 456779, 456934, 488670, 488904

Sophora flavescens Aiton 고삼; 399603, 399643, 410525, 456596, 457690

Thermopsis lupinoides (L.) Link 갯활량나물; 437530

Trifolium hybridum L. 선토끼풀; 456960

Trifolium pratense L. 붉은토끼풀; 437803, 456021, 456665, 457606, 487036

Trifolium repens L. 토끼풀; 364286, 364452, 410296, 437317, 437365, 437583, 437679, 437833, 456172, 456608, 456747, 456929, 479197, 488689

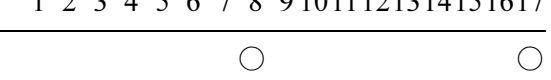

Vicia amoena Fisch. ex Ser. 갈퀴나물; 486816

Vicia amurensis Oett. 벌완두; 457356, 488501, 488782

Vicia angustifolia L. ex Reichard 가는살갈퀴; 364663, 410265, 456953, 479512, 479749

Vicia bungei Ohwi 들완두; 364423

Vicia tetrasperma (L.) Schreb. 얼치기완두; 364671, 456741, 456931, 479567

Vicia unijuga A. Braun 나비나물; 399536, 457593

Vigna minima (Roxb.) Ohwi \& H. Ohashi 좀돌팥; 399288, 399397, 410501, 457340, 457713, 474911, 488624, 488773, 488896, 489070

Wisteria floribunda (Willd.) DC. 등(식재); 437845

Haloragaceae 개미탑과

Haloragis micrantha (Thunb.) R. Br. 개미탑; 410602, 457311

Myriophyllum spicatum L. 이삭물수세미; 281546, 410335, 437441, 456188, 456863, 479191

Myriophyllum ussuriense (Regel) Maxim. 선물수세미; 399360, 399757, 456192, 456620

\section{Lythraceae 부처꽃과}

Lythrum salicaria L. 털부처꽃; 399204, 399308, 399390, 410471, 410640, 456577, 456819, 457140, 457322, 457601, 486961, 488679, 489197

Rotala indica (Willd.) Koehne 마디꽃; 291830, 399781, 457524, 489188

\section{Trapaceae 마름과}

Trapa incisa Siebold \& Zucc. 애기마름; 456153

Trapa japonica Flerow 마름; 308840, 399356, 399464, 456253, 456791, 457224, 488841, 489234

\section{Onagraceae 바늘꽃과}

Circaea mollis Siebold \& Zucc. 털이슬; 399653, 456357, 457628, 488589, 488916

Epilobium palustre L. 버들바늘꽃; 399492

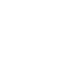
(n) 
Appendix 1. Continued.

Collection sites $^{\mathrm{a}}$

Taxa/Collection numbers (NIBRVP0000-)

122344556788991011121314151617

Ludwigia epilobioides Maxim. 여뀌바늘; 399190, 399465, 399775, 410554, 410760, 456997, 457544, 488865

Oenothera biennis L. 달맞이꽃; 399192, 399429, 456308, 456510, 456817, 457259, 488633, 488781, 489075, 489198, 489687

\section{Cornaceae 충충나무과}

Cornus controversa Hemsl 층층나무; 437482

Cornus walteri Wangerin 말채나무; 456908

Santalaceae 단향과

Thesium chinense Turcz. 제비꿀; 399405, 410281, 437711, 456672, 479271, 486727

Celastraceae 노박덩굴과

Celastrus flagellaris Rupr. 푼지나무; 437477

Celastrus orbiculatus Thunb. 노박덩굴; 364237, 410221, 410715, 437346, 437470, 456031, 456605,456906

Euonymus alatus (Thunb.) Siebold 화살나무; 479584

Euonymus japonicus Thunb. 사철나무; 427896, 488988, 489109

\section{Euphorbiaceae 대극과}

Acalypha australis L. 깨풀; 156265, 399380, 399483, 399773, 410578, 456373, 456426, 456763, 457022, 457473, 457674, 488716, 488784, 488927

0000000000000000

Euphorbia esula L. 흰대극; 427929

Euphorbia supina Raf. 애기땅빈대; 457607, 474910, 486842, 488656, 488762

Phyllanthus ussuriensis Rupr. \& Maxim. 여우주머니; 488863, 489036

Securinega suffruticosa (Pall.) Rehder 광대싸리; 489155

\section{Vitaceae 포도과}

Ampelopsis brevipedunculata (Maxim.) Trautv. 개머루; 399609, 456469, 457689, 488926

Parthenocissus tricuspidata (Siebold \& Zucc.) Planch. 담쟁이덩굴; 399557, 399701, 455997, 456137, 456283, 456685, 456868, 457724

\section{Staphyleaceae 고추나무과}

Staphylea bumalda DC. 고추나무; 474868

\section{Aceraceae 단풍나무과}

Acer negundo L. 네군도단풍(식재); 457619

Acer tataricum ssp. ginnala (Maxim.) Wesm. 신나무; 364255, 410232, 437467, 437719, 456059, 456140, 456604, 456705, 457250, 462991

\section{Anacardiaceae 옻나무과}

Rhus javanica L. 붉나무; 399423, 410538, 457208, 486714, 488967

Toxicodendron trichocarpum (Miq.) Kuntze 개옻나무; 364235, 410672, 437288, 437713, 456033, 456202

\section{Simaroubaceae 소태나무과}

Ailanthus altissima (Mill.) Swingle 가중나무; 399463, 410539, 456648, 457643, 489110

\section{Rutaceae 운향과}

Zanthoxylum piperitum DC. 초피나무; 437475, 486836

$\bigcirc \bigcirc \quad \bigcirc \bigcirc \bigcirc \quad \bigcirc 0$

$\bigcirc 000000000000000$

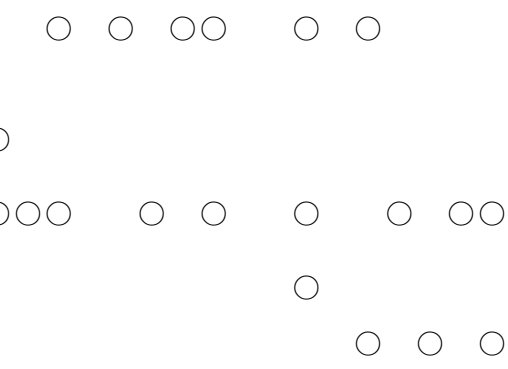<smiles>O=C(O)O</smiles> 
Appendix 1. Continued.

Taxa/Collection numbers (NIBRVP0000-)

Collection sites $^{\mathrm{a}}$

Zanthoxylum schinifolium Siebold \& Zucc. 산초나무; 308989, 399602, 399696, 410670, 456211, 456291, 457633, 474876

12234456678891011121314151617

Oxalidaceae 괭이밥과

Oxalis corniculata L. 괭이밥; 399201, 399340, 399456

Oxalis dillenii Jacq. 들괭이밥; 479562, 479397

Oxalis stricta L. 선괭이밥; 410739, 456309, 456585, 479480, 479563, 479649, 479686, 489063, 489152, 489908

\section{Geraniaceae 쥐손이풀과}

Geranium sibiricum L. 쥐손이풀; 156352, 399264, 399409, 399562, 456520, 456854, 489785

Balsaminaceae 봉선화과

Impatiens textori Miq. 물봉선; 410508, 457882, 489637

\section{Araliaceae 두릅나무과}

Aralia cordata var. continentalis (Kitag.) Y. C. Chu 독활; 437531, 488799, 488936, 489560 Aralia elata (Miq.) Seem. 두릅나무; 437487, 456273

Eleutherococcus divaricatus (Siebold \& Zucc.) S. Y. Hu 개가시오갈피나무(털오갈피나무); 410267

\section{Apiaceae 미나리과}

Angelica dahurica (Fisch. ex Hoffm.) Benth. \& Hook. f. ex Franch. \& Sav. 구릿대;457756, 488735,489050

Angelica decursiva (Miq.) Franch. \& Sav. 바디나물; 410511, 457029, 457233, 457755

Cnidium japonicum Miq. 갯사상자; 399304, 474863

Glehnia littoralis F. Schmidt 갯 방풍; 479522, 490017

Ligusticum hultenii Fernald 기름당귀; 465440

Oenanthe javanica (Blume) DC. 미나리; 399335, 399421, 399733, 456331, 456478, 457561, 462989, 488609, 488739, 489243

Ostericum grosseserratum (Maxim.) Kitag. 신감채; 457637

Sium suave Walter 개발나물; 156191, 399249, 399761, 410490, 456258, 456428, 457274, 457634, 487019, 488795

Torilis japonica (Houtt.) DC. 사상자; 399197, 486957

Loganiaceae 마전과

Mitrasacme alsinoides R. Br. 벼룩아재비; 410419, 457114

Gentianaceae 용담과

Gentiana zollgeri Fawc. 큰구슬붕이; 478789

\section{Menyanthaceae 조름나물과}

Menyanthes trifoliata L. 조름나물; 208698, 364607

Nymphoides peltata (S. G. Gmel.) Kuntze 노랑어리연; 457430

Nymphoides coreana (H. Lév.) H. Hara 애기어리연(좀어리연꽃); 399765, 457419, 486792

Asclepiadaceae 박주가리과

Cynanchum nipponicum Matsum. 덩굴박주가리; 480261

Cynanchum paniculatum (Bunge) Kitag. 산해박; 479608

00

000

. 
Appendix 1. Continued.

Collection sites ${ }^{\mathrm{a}}$

Taxa/Collection numbers (NIBRVP0000-)

12234456678891011121314151617

Metaplexis japonica (Thunb.) Makino 박주가리; 457244, 457700, 486891, 486954, 488625,

488747, 489877

$\bigcirc \bigcirc$

$\bigcirc \bigcirc \bigcirc \bigcirc \bigcirc \bigcirc \bigcirc$

Solanaceae 가지과

Datura tatula L. 독말풀; 488723, 488961

Lycium chinense Mill. 구기자나무; 488714

Physalis wrightii A. Gray 노란꽃땅꽈리; 457536

Solanum americanum Mill. 미국까마중; 457508

Solanum nigrum L. 까마중; 156295, 399693, 456492, 456830, 457129, 457513, 457659, 462970, 488728, 489008, 489659, 489850

$00000 \bigcirc 0000 \bigcirc 0$

\section{Convolvulaceae 메꽃과}

Calystegia hederacea Wall. 애기메꽃; 456179, 456894, 488713

Calystegia sepium var. japonica (Choisy) Makino 메꽃; 399279, 456561, 457467, 457614, 479307, 486878, 488711, 488756, 489247

Calystegia soldanella (L.) Roem. \& Schult. 갯메꽃; 399819, 456014, 456624, 456942, 457608, 479118, 479152, 479173, 479256,486889

Cuscuta japonica Choisy. 새삼; 156156, 399354, 399428, 489064, 489105

Cuscuta pentagona Engelm. 미국실새삼; 399298, 399439, 399471, 410574, 456162, 456315, $456481,457246,488691$

Ipomoea hederacea Jacq. 미국나팔꽃; 399243, 410663, 456793, 457052

Ipomoea hederacea var. integriuscula A. Gray 둥근잎미국나팔꽃; 488996, 489561

Ipomoea purpurea (L.) Roth 둥근잎나팔꽃; 457540, 489535, 489704

\section{Boraginaceae 지치과}

Argusia sibirica (L.) Dandy 모래지치; 479125

Bothriospermum tenellum (Hornem.) Fisch. \& C. A. Mey. 꽃받이; 364669, 410252, 456164, 456631

Trigonotis peduncularis (Trevis.) Benth. ex Baker \& S. Moore 꽃마리; 364426, 364617 , 410295, 427943, 437298, 437371, 437700, 437810, 437878, 456170, 456589, 456749, 456911, 478795

\section{Verbenaceae 마편초과}

Callicarpa dichotoma (Lour.) K. Koch 좀작살나무(식재); 489756

Callicarpa japonica Thunb. 작살나무; 457708, 479629

Clerodendrum trichotomum Thunb. 누리장나무; 156193, 457749, 488595

\section{Phrymaceae 파리풀과}

Phryma leptostachya var. oblongifolia (Koidz.) Honda 파리풀; 399462, 456292, 457433, 457627, 486638, 488922, 489164

\section{Lamiaceae 꿀풀과}

Agastache rugosa (Fisch. \& C. A. Mey.) Kuntze 배초향; 156189, 399553, 456224

Clinopodium chinense (Benth.) Kuntze 층층이꽃; 399240, 399434, 457560

Clinopodium micranthum (Regel) H. Hara 두메층층이; 457872, 488588

Elsholtzia ciliata (Thunb.) H. Hyl. 향유; 399639, 399713, 410517, 410681, 410743, 456266, $456378,456500,457482,457820,489546,489926,489973,490052$

Isodon excisus (Maxim.) Kudô 오리방풀; 456385, 489527

Isodon inflexus (Thunb.) Kudô 산박하; 399661, 410794, 456360, 457894, 489515, 489648

$\bigcirc \bigcirc \quad \bigcirc \bigcirc \bigcirc \bigcirc$

$\bigcirc \bigcirc \bigcirc$

$\bigcirc$<smiles>COc1ccccc1</smiles>

○०

000000

\section{$\bigcirc \bigcirc \bigcirc$}

$\bigcirc \bigcirc$

0000<smiles>CCC</smiles> 
Appendix 1. Continued.

Leonurus japonicus Houtt. 익모초; 399196, 399432, 410654, 456836, 488744, 488971, 489095

Lycopus lucidus Turcz. ex Benth. 쉽싸리; 399565, 399753, 410532, 410732, 456565, 457215, 457562, 462951, 486834, 488606, 488880, 489104

$\bigcirc \bigcirc \bigcirc \bigcirc$

Lycopus lucidus var. hirtus Regel 큰쉽싸리; 456574, 457769, 462949, 486949, 487040, 488601, 489068

Lycopus maackianus (Maxim. ex Heder) Makino 애기쉽싸리; 399359, 410567, 456581, 457020, 457533, 457792

Lycopus ramosissimus (Makino) Makino 개쉽싸리; 399486, 410702, 456802, 457230, 457819, 488853

Lycopus uniflorus Michx. 털쉽싸리; 399410, 399513, 399656, 410749, 456362

Mentha arvensis var. piperascens Malinv. ex Holmes 박하; 399265, 399529, 456230, 457063, 457704, 462988, 489059

Mosla dianthera (Buch.-Ham. ex Roxb.) Maxim. 쥐깨풀; 410460, 410692, 410808, 456229, 457345, 457826, 488660

Mosla punctulata (J. F. Gmel.) Nakai 들깨풀; 399478, 399528, 410381, 410609, 410731, 456352, 457281, 457845, 489415, 489580, 489609, 489719

Prunella asiatica Nakai 꿀풀; 410289, 456320, 456590, 486864, 486982

Scutellaria dependens Maxim. 애기골무꽃; 399532, 456282, 479499, 486860, 493299

Scutellaria strigillosa Hemsl. 참골무꽃; 281544, 399217, 399344, 410548, 486665

Stachys japonica Miq. 석잠풀; 399200, 399319, 410699, 488608

\section{Callitrichaceae 별이끼과}

Callitriche palustris L. 물별이끼; 3644570

\section{Plantaginaceae 질경이과}

Plantago asiatica L. 질경이; 364688, 410312, 410659, 410754, 437311, 437375, 456012, 456563, 456784, 457235, 479131, 479598, 486833, 486979

Plantago camtschatica Cham. ex Link 개질경이; 364283, 456016, 456709, 456870, 479117

Plantago depressa Willd. 털질경이; 437715, 479135, 479384, 479764

Plantago lanceolata L. 창질경이; 456006

Plantago major var. japonica (Franch. \& Sav.) Miyabe 왕질경이; 399244, 457671, 486801, 488640

\section{Oleaceae 물푸레나무과}

Forsythia koreana (Rehder) Nakai 개나리(식재); 427909, 437896, 489587, 489789

Fraxinus rhynchophylla Hance 물푸레나무; 399422, 456030

Ligustrum obtusifolium Siebold \& Zucc. 쥐똥나무; 410341, 456060, 456149, 456384, 456470, 456606, 457887, 479283, 479336

\section{Scrophulariaceae 현삼과}

Deinostema violaceum (Maxim.) T. Yamaz. 진땅고추풀; 399584, 410454, 457231, 462922

Limnophila sessiliflora (Vahl) Blume 구와말; 456990

Linaria japonica Miq. 해란초; 410413, 462924, 479143, 479172, 488509, 489999

Lindernia dubia (L.) Pennell 미국외풀; 489624

Lindernia micrantha D. Don 논뚝외풀; 399350, 399467, 456803, 457306

\section{(1)}

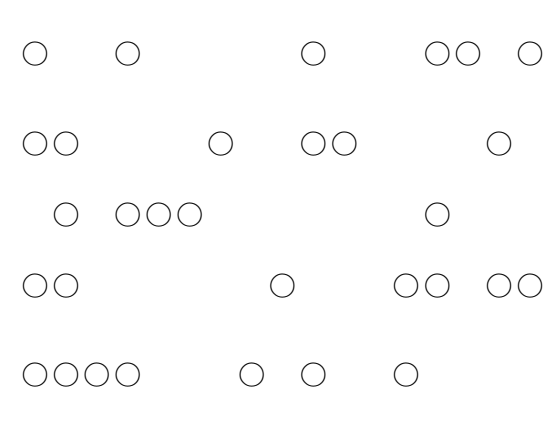

$0000 \bigcirc 0000 \quad 000$

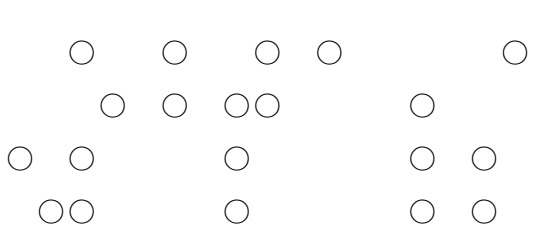


Appendix 1. Continued.

Collection sites $^{\mathrm{a}}$

Taxa/Collection numbers (NIBRVP0000-)

12234556778991011121314151617

Lindernia procumbens (Krock.) Borbás 밭뚝외풀; 309286, 399349, 399596, 410786, 456832, 456993, 457498, 488870

Mazus pumilu (Burm. f.) Steenis 주름잎; 364430, 364670, 410256, 437492, 437744, 456669, 478793, 478821, 479719, 489180

Melampyrum roseum Maxim. 꽃며느리밥풀; 292179

Melampyrum setaceum (Maxim. ex Palib.) Nakai 애기며느리밥풀; 410533, 457417

Paulownia tomentosa (Thunb.) Steud. 참오동나무; 489934

Phtheirospermum japonicum (Thunb.) Kanitz 나도송이풀; 410717, 456414, 489619

Scrophularia kakudensis Franch. 큰개현삼; 399638, 457896

Veronica arvensis L. 선개불알풀; 364259, 364447, 364673, 437426, 437705, 456628, 456719, 456876, 478804

Veronica peregrina L. 문모초; 437740, 456666, 456978, 479202

Veronica persica Poir. 큰개불알풀; 427869, 427892, 456977, 479744

Veronica polita ssp. lilacina (H. Hara ex T. Yamaz.) T. Yamaz. 개불알풀; 456874

\section{Acanthaceae 쥐꼬리망초과}

Justicia procumbens L. 쥐꼬리망초; 489874

\section{Lentibulariaceae 통발과}

Utricularia australis R. Brown 통발; 399328, 410559, 410712, 456124, 457375, 462964, 479011, 489237

Utricularia pilosa (Makino) Makino 들통발; 399563, 399590, 410558, 457377

Campanulaceae 초롱꽃과

Adenophora divaricata Franch. \& Sav. 넓은잔대; 457394

Codonopsis lanceolata (Siebold \& Zucc.) Trautv. 더덕; 457897, 486890

Lobelia chinensis Lour. 수염가래꽃; 399228, 399334, 410735, 457273, 479582

\section{Rubiaceae 꼭두선이과}

Diodia teres Walter 백령풀; 399681, 399776, 456267, 456768, 489653

Galium gracilens (A. Gray) Makino 좀네 잎갈퀴; 489088

Galium spurium var. echinospermum (Wallr.) Hayek 갈퀴덩굴; 364446, 364625, 364665 , $410301,437324,437358,437596,437672,437815,456173,456699,456955,479194$, 479457,486758

Galium trifidum L. 가는네잎갈퀴; 399365, 399748, 399783,456197, 462963, 479581

Galium verum var. asiaticum Nakai 솔나물; 410411, 486813

Hedyotis diffusa Willd. 백 운풀; 399600, 488658

Paederia scandens (Lour.) Merr. 계요등; 474912, 488998

Rubia akane Nakai 꼭두선이; 410848

\section{Diervillaceae 병꽃나무과}

Weigela florida (Bunge) A. DC. 붉은병꽃나무; 437524, 437756, 479436

Caprifoliaceae 인동과

Lonicera japonica Thunb. 인동; 410334, 410364, 410721, 456027, 456319, 456777, 457864, 479343, 479751

$\bigcirc \bigcirc$

$\bigcirc \bigcirc$<smiles>C1CCCOCC1</smiles>

0<smiles>OCCOCCO</smiles>

$\bigcirc$

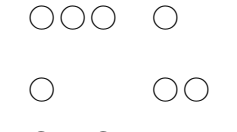<smiles>O=CO</smiles>

Viburnaceae 산분쫓나무과 
Appendix 1. Continued.

Taxa/Collection numbers (NIBRVP0000-)

Collection sites $^{\mathrm{a}}$

123455678991011121314151617

Bidens biternata (Lour.) Merr. \& Sherff 털도깨비바늘; 399194, 399545, 399774, 410385, 410756, 456432, 457431, 456240, 457046, 488607

Bidens frondosa L. 미국가막사리; 156259, 399616, 399664, 410400, 410701, 456234, 456383, 456505, 457136, 457484, 457972, 474871, 489592, 489742, 489974

Bidens pilosa L. 울산도깨비바늘; 399601, 400782, 456239, 457045, 539707

Bidens radiata var. pinnatifida (Turcz. ex DC.) Kitam. 구와가막사리; 486929

Bidens tripartita L. 가막사리; 309332, 399655, 399704, 399734, 410470, 410782, 456374 , 456464, 456998, 457837, 489511, 489634

Breea segeta (Bunge) Kitam. 조뱅이; 479679

Carpesium abrotanoides L. 담배풀; 457895

Carpesium cernuum L. 좀담배풀; 48989

Centaurea cyanus L. 수레국화; 456924

Centipeda minima (L.) A. Braun \& Aschers. 중대가리풀; 399236, 399366, 399406, 410499, 456517, 456840, 457091, 457550, 457682, 486930, 488655, 488764, 489038

Chrysanthemum leucanthemum L. 불란서국화; 487032

Cirsium pendulum Fisch. ex DC. 큰엉겅퀴; 457347, 489221, 489600

Conyza bonariensis (L.) Cronquist 실망초; 487029

Conyza canadensis (L.) Cronquist 망초; 399246, 399431, 399778, 410616, 410728, 456512, 456792, 457054, 457209, 457647, 474858, 488797, 488901, 489056

Coreopsis lanceolata L. 큰금계국; 456603, 456831, 456875, 479174, 479193, 479322, 479344, 486874, 490015

Cosmos bipinnatus Cav. 코스모스; 399642, 457265, 486920, 489228, 489618

Cosmos sulphureus Cav. 노랑코스모스; 489171

Crepidiastrum denticulatum (Houtt.) J. H. Pak \& Kawano 이고들빼기; 156180, 399632, 399649, 456256, 457008, 457844, 489516

Crepidiastrum sonchifolium (Bunge) J. H. Pak \& Kawano 고들 빼기; 364290, 364428, 364608, 364675, 410264, 410361, 437363, 437737, 437784, 455984, 456112, 456518, 456636, 486873

Dendranthema boreale (Makino) Ling ex Kitam. 산국; 399636, 410516, 410656, 456226, 456410, 456991, 457177, 457801, 489951, 489982, 490022, 499035

Dendranthema zawadskii (Herbich) Tzvelev 산구절초; 399680, 410594

Dendranthema zawadskii var. latilobum (Maxim.) Kitam. 구절초; 399629, 399651, 410547, 457846, 462969

Eclipta prostrata (L.) L. 한련초; 292180, 399239, 399379, 456462, 456769, 457329, 457649, 488731

Erechtites hieracifolia (L.) Raf. ex DC. 붉은서나물; 399571, 399604, 399772, 410633 , 456242, 456434, 457499, 489093, 489411, 489639

Erigeron annuus (L.) Pers. 개망초; 410363, 456303, 456433, 456721, 456842, 457260, 457644, 479323, 479661, 486916, 488715, 489885

Erigeron strigosus Muhl. ex Willd. 주걱개망초; 455990, 456715, 457168

Euchiton japonicus (Thunb.) Holub 풀솜나물; 489084

Eupatorium japonicum Thunb. 등골나물; 399417, 399476, 410522, 410605, 410704, 456254, $456302,456586,457646,486701,486757$

Eupatorium lindleyanum DC. 골등골나물; 399728, 457893

$\bigcirc \bigcirc \bigcirc \quad \bigcirc \bigcirc 0 \bigcirc \quad \bigcirc 00 \bigcirc 00$

0000000000000000<smiles>OOO</smiles>

0

$0000000 \quad 0 \quad 000$

$\bigcirc$

$\bigcirc$

$\bigcirc$

00000000000000

0000000000000000

$\bigcirc \bigcirc \bigcirc \bigcirc \bigcirc \bigcirc \bigcirc \bigcirc$

$\bigcirc \quad \bigcirc \bigcirc \quad \bigcirc \bigcirc \quad \bigcirc$

$\bigcirc$

$\bigcirc \bigcirc \quad \bigcirc \quad \bigcirc \bigcirc \quad \bigcirc \bigcirc$

00000000000000

$0000 \quad 00000000$

$\bigcirc \bigcirc$

००

$\bigcirc \bigcirc$

$000 \quad 0 \quad 00 \quad 000$

$00 \quad 000000000$

0000000000000000

$\bigcirc \bigcirc \quad \bigcirc$

$\bigcirc$

00000000000 
Appendix 1. Continued.

Taxa/Collection numbers (NIBRVP0000-)

Collection sites $^{\mathrm{a}}$

(39)

Galinsoga ciliata (Raf.) S. F. Blake 털별꽃아재비; 156264, 399592, 456290, 456770, 457014, 457538, 457610, 462987, 488707, 489041

Galinsoga parviflora Cav. 별꽃아재비; 457968

Helianthus tuberosus L. 뚱딴지; 399546, 457005, 457358, 489712

Hemistepta lyrata Bunge 지칭개; 364442, 410258, 437718, 456106, 456653, 456964, 479206, 479411, 479758

Hieracium umbellata L. 조밥나물; 309436, 410394, 457393, 488695, 489536, 489681

Inula britannica var. japonica (Thunb.) Franch. \& Sav. 금불초; 399266, 399547, 399769, 410457, 456804, 457506, 457777, 488643, 488868, 488973, 489148

Ixeridium dentatum (Thunb.) Tzvelev 씀바귀; 410352, 479306, 486900

Ixeris chinensis (Thunb.) Kitag. 노랑선씀바귀; 456101,456972, 479615, 479727

Ixeris debilis (Thunb.) A. Gray 벋음씀바귀; 364257, 364437, 410231, 437366, 437590, 437860, 456007, 456663, 456930, 479707

Ixeris polycephala Cass. 벌씀바귀; 437822, 437449, 437770, 437310, 437646, 456190

Ixeris repens (L.) A. Gray 갯씀바귀; 457729, 479123, 479146, 479165, 488962

Ixeris stolonifera A. Gray 좀씀바귀; 437453, 479316

Lactuca indica var. laciniata (Kuntze) H. Hara 왕고들 빼기; 156200, 399544, 410784, 455973, 456436, 457880, 488769, 488933, 489049, 489193

Leibnitzia anandria (L.) Turcz. 솜나물; 364262, 410247

Matricaria matricarioides (Less.) Porter ex Britton 족제비쑥; 456712, 462905

Petasites japonicus (Siebold \& Zucc.) Maxim. 머위; 427826, 427877, 456553, 479667

Pseudognaphalium affine (D. Don) Anderb. 떡쑥; 456935, 457117, 479423, 498669

Rudbeckia laciniata var. hortensia L. H. Bailey 겹삼잎국화; 488890

Senecio vulgaris L. 개쑥갓; 456004, 456952, 479249, 479309, 479680

Serratula coronata ssp. insularis (Iljin) Kitam. 산비장이; 457876

Sigesbeckia glabrescens Makino 진득찰; 456228, 457866

Sigesbeckia pubescens Makino 털진득찰; 399694, 457539, 457645

Solidago gigantea ssp. serotina (Aiton) McNeill 미국미역취; 456364

Solidago virgaurea ssp. asiatica Kitam. ex H. Hara 미역취; 399621, 399671, 399710, 410521, $410678,456262,456381,456485,488584$

Sonchus asper (L.) Hill 큰방가지똥; 455982, 486876, 456227, 456573, 456968

Sonchus brachyotus DC. 사데풀; 457609

Sonchus oleraceus L. 방가지똥; 474899, 479518, 489089

Syneilesis palmata (Thunb.) Maxim. 우산나물; 457635

Tagetes minuta L. 만수국아재비; 457968

Taraxacum coreanum Nakai 흰민들레; 437486

Taraxacum laevigatum (Willd.) DC. 붉은씨서양민들레; 427854, 479685

Taraxacum officinale F. H. Wigg. 서양민들레; 156201, 364453, 410720, 427878, 427902, $427927,437285,456682,456748,456970,478784$

1233456678991011121314151617

$\bigcirc \bigcirc \bigcirc 0000$

$\bigcirc \bigcirc$

$\bigcirc$

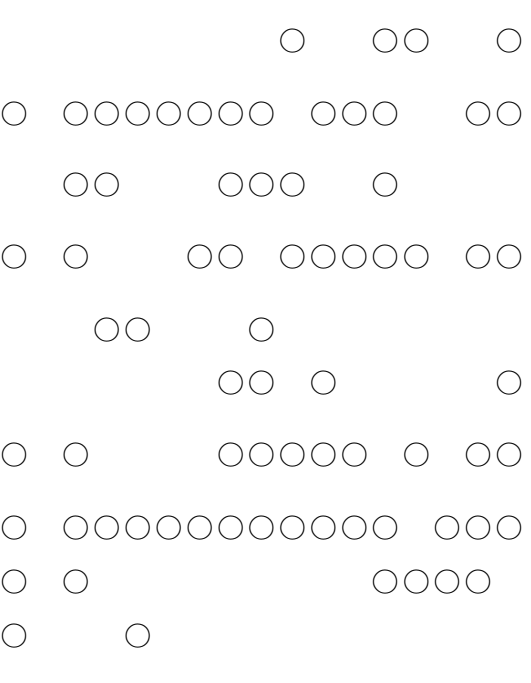

$\bigcirc \circ \quad 000000000$

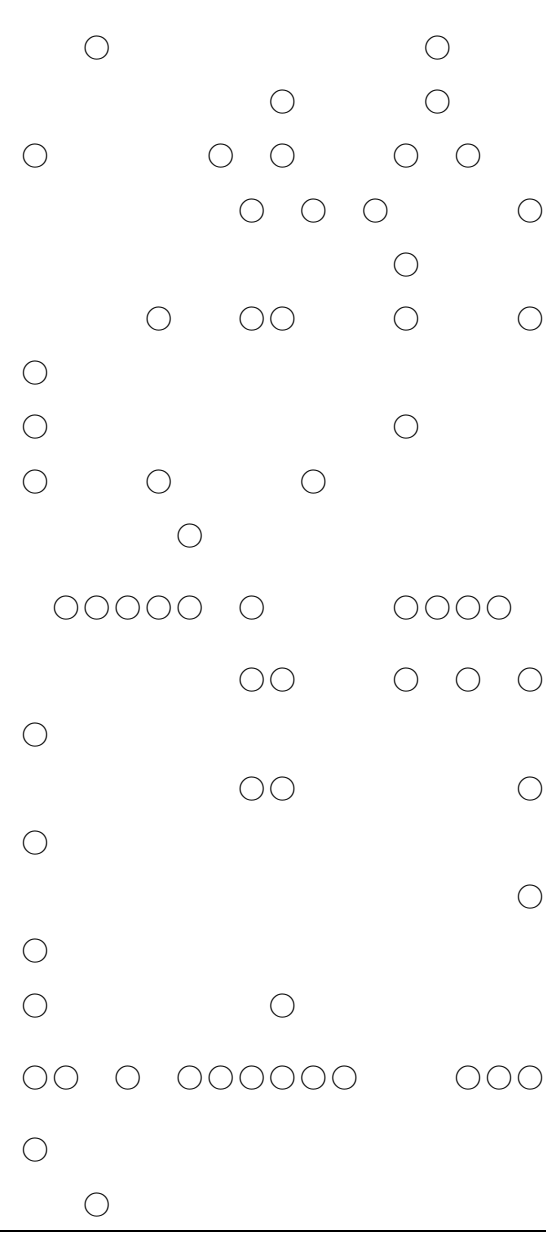

Tephroseris pseudosonchus (Vaniot) C. Jeffrey \& Y. L. Chen 물솜방망이; 493282 
Appendix 1. Continued.

Collection sites ${ }^{\mathrm{a}}$

Taxa/Collection numbers (NIBRVP0000-)

12234556778991011121314151617

Xanthium strumarium L. 도꼬마리; 457542

Youngia japonica (L.) DC. 뽀리뱅이; 364288, 364440, 410234, 410357, 437297, 437369,

437576, 437666, 437793, 456093, 456642, 456736, 456895, 479216

$\bigcirc$

Alismataceae 택사과

Alisma canaliculatum A. Braun \& C. D. Bouché 택사; 399362, 399392, 399500, 399718, 410730, 457575, 462925

Alisma orientale (Sam.) Juz. 질경이택사; 399212, 489201

Sagittaria aginashi Makino 보풀; 213409, 330928, 409303, 399371, 399717, 410707, 456477, $456849,457800,457569,486805,489244$

\section{Hydrocharitaceae 자라풀과}

Blyxa japonica (Miq.) Maxim. ex Asch. \& Gürke 올챙 이솔; 399579, 410842

Hydrilla verticillata (L. f.) Royle 검정 말; 489235

Ottelia alismoides (L.) Pers. 물질경이; 292187, 410744, 457827, 489627

Juncaginaceae 지채과

Triglochin maritimum L. 지채; 462681

Potamogetonaceae 가래과

Potamogeton crispus L. 말즘; 213335, 364289, 410240, 437808, 456122, 456927, 479295, 479627

Potamogeton cristatus Regel \& Maack 가는가래; 456912

Potamogeton distinctus A. Benn. 가래; 399206, 399523, 410740, 456857, 457015, 457576, 479228,479628

Potamogeton natans L. 큰가래; 399506, 410843

Potamogeton octandrus Poir. 애기가래; 213339, 213410

Potamogeton pectinatus L. 솔잎가래; 479184

Potamogeton pusillus L. 실말; 291831, 399222, 399320, 410837, 456928, 457093, 486773, 486917

\section{Ruppiaceae 줄말과}

Ruppia maritima L. 줄말; 281538, 410387, 213415, 457212, 457134, 479233, 486996

Najadaceae 나자스말과

Najas graminea Delile 나자스말; 213487, 399210, 399522, 399564, 410838, 457592

Najas marina L. 민나자스말; 399329

\section{Zosteraceae 거머리말과}

Zostera japonica Asch. \& Graebn. 애기거머리말; 308891, 410380

Zostera marina L. 거머리말; 489479, 479126

\section{Araceae 천남성과}

Pinellia ternata (Thunb.) Ten. ex Breitenb. 반하; 364438, 410228, 456039

Symplocarpus nipponicus Makino 애기앉은부채; 427865

\section{Lemnaceae 개구리밥과}

Lemna perpusilla Torr. 좀개구리밥; 399224, 456215, 456856, 457525, 488877

Spirodela polyrhiza (L.) Schleid. 개구리밥; 399225, 399436, 456460, 456921, 457222

Commelinaceae 닭의장풀과 
Appendix 1. Continued.

Taxa/Collection numbers (NIBRVP0000-)

Collection sites $^{\mathrm{a}}$

Commelina communis L. 닭의장풀; 399199, 399369, 399459, 410487, 410703, 456297, 456509, 456838, 488618, 488771, 488887, 489246, 489584

Murdannia keisak (Hassk.) Hand.-Mazz. 사마귀풀; 399470, 399507, 399524, 410777, 456390, 457707, 488814, 489200

\section{Eriocaulaceae 곡정초과}

Eriocaulon decemflorum Maxim. 좀개수염; 399575, 410601

Eriocaulon miquelianum Körn. 개수염; 457786, 457391, 462918, 462966

Eriocaulon robustius (Maxim.) Makino 넓은잎개수염; 399582, 399726, 399767, 410452, 410845

\section{Juncaceae 골풀과}

Juncus bufonius L. 애기비녀골풀; 410307

Juncus diastrophanthus Buchenau 별날개골풀; 399267, 410475, 410582, 410755, 456294, 456848, 457570, 462926, 486809, 486956, 489184, 489525

Juncus effusus var. decipiens Buchenau 골풀; 156292, 364689, 399302, 410344, 437577. $437906,456028,456325,456399,456538,456725,456835,457558,479653,489255$

\section{0}

Juncus fauriei H. Lév. \& Vaniot 검정납작골풀; 479188

Juncus gracillimus (Buchenau) V. I. Krecz. \& Gontsch. 물골풀; 399346, 410336, 456023, 457675,479221

Juncus krameri Franch. \& Sav. 비녀골풀; 410611, 457266, 462921

Juncus papillosus Franch. \& Sav. 청비녀골풀; 399347, 399495, 399583, 399760, 410553, 410590, 456994, 457426, 457573, 486905

Juncus tenuis Willd. 길골풀; 410305, 437789, 456095, 456829, 456879, 457225, 479725

Luzula capitata (Miq.) Miq. ex Kom. 뀡의밥; 364256, 410279, 427832, 437701, 456667, 456867, 479443, 479694

Luzula multiflora (Ehrh.) Lej. 산꿩의밥; 427856

\section{Cyperaceae 사초과}

Bolboschoenus fluviatilis (Torr.) Soják 큰매자기; 328381, 437747, 456017, 456521, 456640, 456926, 486922

Bolboschoenus planiculmis (F. Schmidt) T. V. Egorova 새섬매자기; 364306, 410309, 437502, 437675, 437799, 456661, 456983, 479528

Bulbostylis barbata (Rottb.) C. B. Clarke 모기골; 399768, 410414, 457403, 488965

Bulbostylis densa (Wall.) Hand.-Mazz. 꽃하늘지기; 399779, 456487, 489029

Carex arenicola F. Schmidt 진퍼리사초; 364302, 364698, 410306, 410324, 437602, 437691, 455992, 456113, 479208

Carex bostrichostigma Maxim. 길뚝사초; 437489

Carex breviculmis R. Br. 청사초; 364226, 364460, 364693, 410219, 427950, 437360, 437707, 456109, 456633, 456716, 456878, 478790, 479168

Carex cinerascens Kük. 회색사초; 437629, 456118, 479626

Carex dickinsii Franch. \& Sav. 도깨비사초; 364696, 399221, 410366, 456295, 457564

Carex dimorpholepis Steud. 이삭사초; 479339

Carex dispalata Boott ex A. Gray 삿갓사초; 364422, 410356, 437720, 479550

Carex forficula Franch. \& Sav. 산뚝사초; 437432, 479710

Carex glabrescens (Kük.) Ohwi 곱슬사초; 410246, 437250, 437775, 456110

12234456678991011121314151617

000,000000000000

$\circ \circ \bigcirc \circ \quad \bigcirc \circ \bigcirc \bigcirc 0$

$\circ \bigcirc \quad \circ \quad$

$\circ \circ \bigcirc$
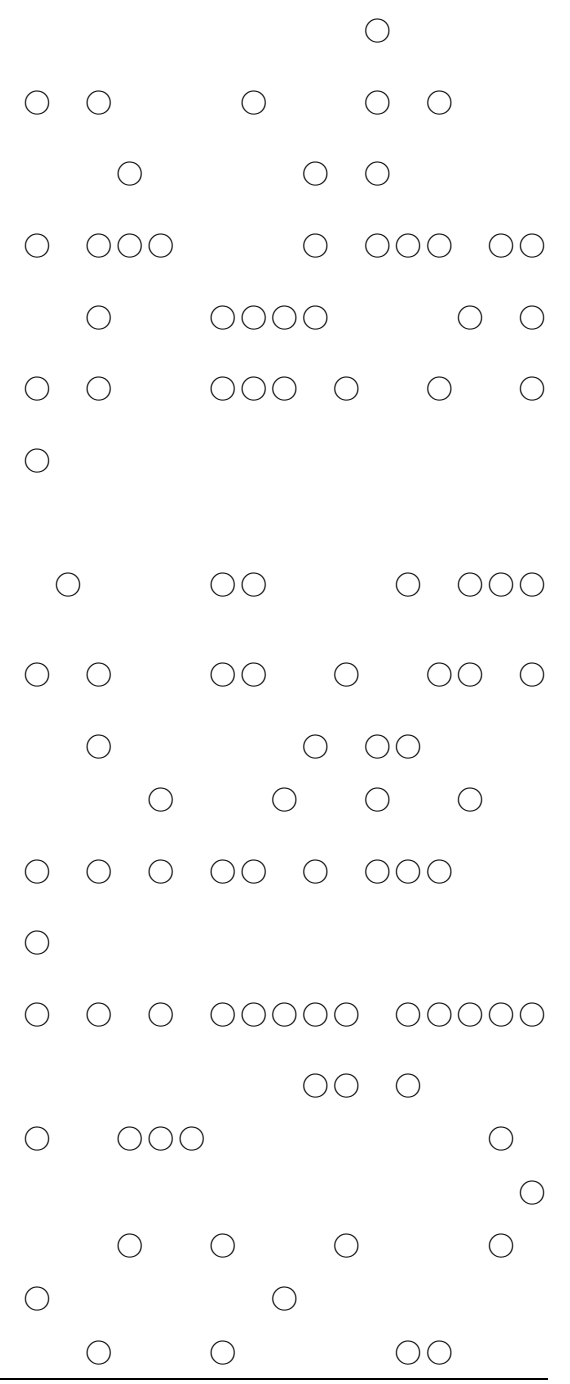
Appendix 1. Continued.

Taxa/Collection numbers (NIBRVP0000-)

Collection sites $^{\mathrm{a}}$

12234556778091011121314151617

Carex heterolepis Bunge 산비늘사초; 364627, 400863, 410365, 437315, 437439, 456674

$\bigcirc \bigcirc \bigcirc \bigcirc \bigcirc$

$\bigcirc$

Carex humbertiana Ohwi 큰뚝사초; 364305, 364692, 365384, 410320, 410345, 437438, 437608, 437687, 437829, 456119, 456592, 456873, 479204, 479479

Carex humilis var. nana (H. Lév. \& Vaniot) Ohwi 가는잎그늘사초; 410302, 427864, 437636, 456128, 456397, 456612

Carex japonica Thunb. 개찌버리사초; 437416, 456744

Carex kobomugi Ohwi 통보리사초; 410323, 458578, 479120, 488980

Carex laevissima Nakai 애괭이사초; 364296, 364613, 410304, 410346, 437451, 437709, 437831, 437879, 456654, 479730

Carex lanceolata Boott 그늘사초; 410254, 427837, 456005, 478812

Carex leiorhyncha C. A. Mey. 산갱이사초; 308872,456182

Carex maackii Maxim. 타래사초; 364265, 437732

Carex maximowiczii Miq. 왕비늘사초; 364661, 410374, 410714, 437434, 456205, 486736

Carex mitrata var. aristata Ohwi 까락겨사초; 486754

Carex miyabei Franch. 융단사초; 437551, 456180

Carex neurocarpa Maxim. 괭이사초; 364683, 456659, 456897, 457268, 486838

Carex pallida C. A. Mey. 까락사초(경성사초); 437632

Carex polyschoena H. Lév. \& Vaniot 가지청사초; 427836, 437847

Carex pumila Thunb. 모래사초(좀보리사초); 364224, 410313, 437616, 437695, 437861, 456087, 456143, 479176

Carex rugulosa Kük. 큰천일사초; 364225, 410255, 437400, 437846

Carex scabrifolia Steud. 천일사초; 410269, 437403, 437858, 456723, 479153

Carex vesicaria L. 새방울사초; 437633

Cyperus amuricus Maxim. 방동산이; 399785, 457432, 488809

Cyperus difformis L. 알방동산이; 399193, 399791, 410458, 410566, 410747, 457359, 457969, 489752

Cyperus globosus Forssk. 드렁방동산이; 457141

Cyperus glomeratus L. 물방동산이; 457013

Cyperus hakonensis Franch. \& Sav. 병아리방동산이; 399473, 399759, 410467, 410709, 457509

Cyperus haspan L. 모기방동산이; 399574, 410468, 410624, 410738, 457299

Cyperus iria L. 참방동산이; 156284, 308369, 308442, 457075, 457343, 488673, 489249, 489534

Cyperus microiria Steud. 금방동산이; 456453, 457611, 457366, 457102, 456225

Cyperus nipponicus Franch. \& Sav. 푸른방동산이; 457436

Cyperus orthostachyus Franch. \& Sav. 쇠방동산이; 399496, 399515, 399540, 399700, 410537, 410763, 456345, 457165, 489760

Cyperus polystachyos Rottb. 중방동산이(갯방동사니); 399530, 399762, 410536, 456522, 457442, 457656, 474906, 488644, 488861, 488981, 489533

Cyperus sanguinolentus Vahl 방동산이대가리; 399711, 399724, 410465, 410665, 410761, 456261, 457365, 457788, 488833, 489191, 498902

\section{O}<smiles>[CH]</smiles>

$\bigcirc 0$

0000

O<smiles>O[Hg]</smiles><smiles>CCC</smiles>

$\bigcirc \bigcirc \bigcirc \bigcirc$

0

$\bigcirc$

$\begin{array}{ll}0 & 0 \\ 0 & 0\end{array}$

$\bigcirc \bigcirc$

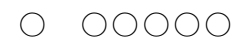

.

$\bigcirc \bigcirc \bigcirc 0$

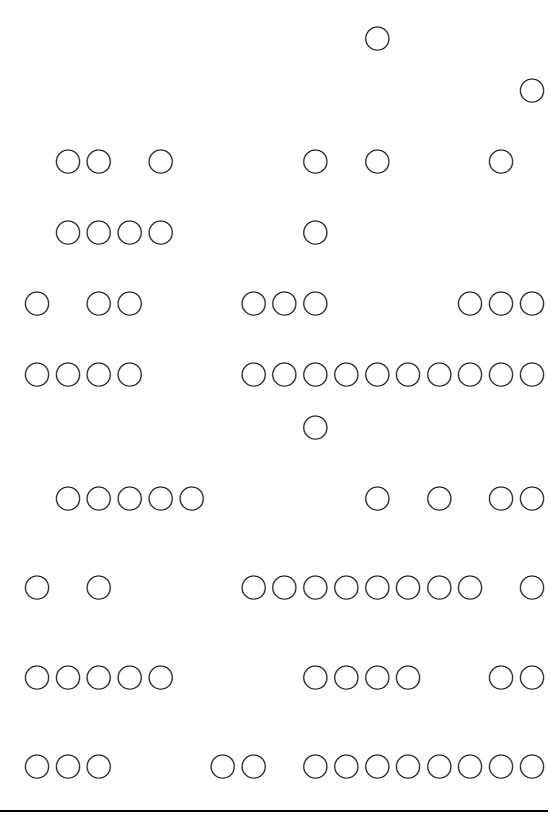

Cyperus serotinus Rottb. 꽃방동산이(너도방동사니); 156093, 399538, 399749, 399777, $410492,456435,456765,457481,457598,488636,488732,488982,489241$ 
Appendix 1. Continued.

Taxa/Collection numbers (NIBRVP0000-)

Collection sites $^{\mathrm{a}}$

Eleocharis acicularis (L.) Roem. \& Schult. 쇠털골; 399271, 399326, 456986

1223456678991011121314151617

Eleocharis congesta ssp. japonica (Miq.) T. Koyama 바늘골; 399272, 399415, 399512, 399797, 410766, 456286, 457386, 457572

Eleocharis kamtschatica (C. A. Mey.) Kom. 올방개아재비; 364307, 364427, 364619, 364697, 410308, 410327, 437689, 437817, 437890, 455995, 456104, 456618, 456883, 479281

Eleocharis kuroguwai Ohwi 올방개; 399742, 410675, 456859, 489242, 489633

Eleocharis ussuriensis G. Zinserl. 물꼬챙이꼴; 364424, 410354, 410844, 437664, 456622

Eleocharis valleculosa var. setosa Ohwi 까락골; 437303, 437670

Eleocharis wichurae Boeck. 좀네모골; 399413, 399511, 457579

Fimbristylis autumnalis (L.) Roem. \& Schult. 애기하늘지기; 399577, 399720, 489540

Fimbristylis dichotoma (L.) Vahl 하늘지기; 462929, 488493

Fimbristylis subbispicata Ness \& Meyen 꼴하늘지기; 399233, 399438, 399795, 410451, 488522

Fimbristylis squarrosa Vahl 민하늘지기; 399407, 399488, 399766, 410469, 410586, 410736, 456330, 456834, 457448, 457962, 486735, 486931, 488851

Kyllinga brevifolia Rottb. 가시파대가리; 399450, 399752, 410476, 410638, 410803, 456346, 456452, 457149, 457371, 457790, 488492, 488745, 489016, 489214

Lipocarpha microcephala (R. Br.) Kunth 세 대가리; 457443, 462930

Schoenoplectiella hotarui (Ohwi) J. Jung \& H.-K. Choi 좀올챙 이골; 399510, 399573

Schoenoplectiella juncoides (Roxb.) Lye 올챙이고랭이; 399509, 399580, 399732, 410812, 457223, 457582, 486803

Schoenoplectiella nipponicus (Makino) Soják 물고랭이; 399508

Schoenoplectiella tabernaemontani (C. C. Gmel.) Palla 큰고랭이; 364295, 364461, 399393 , 410239, 437437, 437648, 437834, 437899, 456193, 456623, 456820, 456982

Schoenoplectiella $\times$ trapezoidea (Koidz.) J. Jung \& H.-K. Choi 나도송이고랭이; 410688

Schoenoplectiella triangulata (Roxb.) J. Jung \& H.-K. Choi 송이고랭이; 399263, 399332, 399388, 410561, 410725, 456332, 457272, 457588, 486948, 489260

Schoenoplectiella triqueter (L.) Palla 세모고랭이; 309317, 399333, 399391, 399721

Scirpus karuizawensis Makino 솔방울고랭이; 399490, 399514, 399572, 457849

Scirpus radicans Schkuhr 도루박이; 399420

Scirpus wichurae Boeck. 방울고랭이; 399284, 410597, 456279, 456788, 457077, 457303, 457603, 486906, 489226, 456176, 457793, 462952

Scleria parvula Steud. 너도고랭이; 457387

\section{Poaceae 화본과}

Agropyron ciliare (Trin.) Franch. 속털개밀; 156092, 364687, 410332, 456139, 456598, 456751, 456887, 479149

Agropyron repens (L.) P. Beauv. 구주개밀; 486895, 487013

Agropyron tsukushiense var. transiens (Hack.) Ohwi 개밀; 307257, 410353, 455983, 456600, 456724, 479224, 489240

Agrostis alba L. 흰겨이삭; 291819, 486625

Agrostis clavata var. nukabo Ohwi 겨이삭; 410342, 456083, 456151, 456526, 456756, 456901, 479132, 479218, 479293, 479544

Agrostis hyemalis (Walter) Britton, Sterns \& Poggenb. 긴겨이삭; 410367

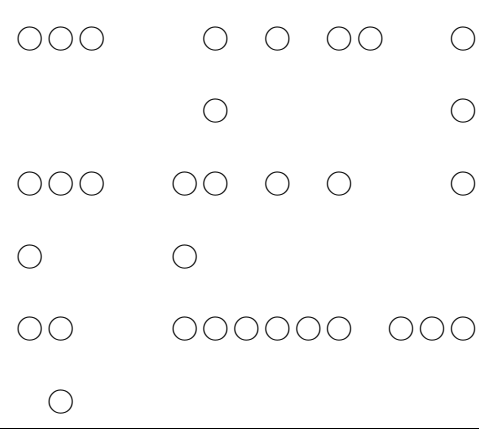


Appendix 1. Continued.

Alopecurus aequalis Sobol. 뚝새풀; 364250, 364431, 364622, 364674, 410278, 410371, 437296, 437350, 437589, 437680, 437832, 456114, 456626, 456981, 479203, 479275, 479469. 479753

Arthraxon hispidus (Thunb.) Makino 조개풀; 399641, 399679, 399727, 410564, 410733, $456355,457824,489543,489735$

Arundinella hirta (Thunb.) Tanaka 새; 399352, 399408, 410391, 410619, 456246, 457042, 457298, 488477, 488742

Beckmannia syzigachne (Steud.) Fernald 개피; 399202, 456662, 456786, 456871, 479759, 486734

Bromus japonicus Thunb. 참새귀리; 364465, 410262, 410362, 437368, 437660, 437881, 456057, 456116, 456696, 456951, 479151, 479300, 486775

Bromus pauciflorus Hack. 꼬리새; 486880

Bromus tectorum L. 털빕새귀리; 437463, 456174, 456957, 479160, 479760

Bromus unioloides Kunth 큰이삭풀; 489136

Calamagrostis arundinacea (L.) Roth 실새풀; 399675, 399690, 410386, 410753, 456339, $456441,457847,488545,489684$

Calamagrostis epigeios (L.) Roth 산조풀; 213391, 399260, 399300, 399449, 410505, 456281, 456524, 456807, 457270, 457557, 486618, 486762, 486871, 486942, 487012

Cymbopogon tortilis ssp. goeringii (Steud.) T. Koyama 개솔새; 399703, 410544, 410612, $410758,456272,456420,457395,488687,488818$

Dactylis glomerata L. 오리새; 364301, 364435, 364626, 410238, 437292, 437380, 437592, 437699, 437849, 456065, 456136, 456700, 456880, 479551

Digitaria sanguinalis (L.) Scop. 바랭이; 399401, 399561, 410396, 410833, 456263, 456287, 456450, 456800, 457346, 457733, 488623, 488786, 489044, 489245

Digitaria violascens Link 민바랭이; 410660, 410757, 456458, 489022, 489607, 489671

Dimeria ornithopoda Trin. 잔디바랭이; 399578

Echinochloa crus-galli (L.) P. Beauv. 돌피; 156095, 399324, 399725, 399794, 410563, 456232, 456376, 456413, 456780, 457521, 457664, 488757, 489042, 489916, 490053

Echinochloa crus-galli var. echinatum (Willd.) Honda 물피; 399216, 399468, 399556, 410407, 410806, 488719, 488746, 488913, 489744

Eleusine indica (L.) Gaertn. 왕바랭이; 156099, 399381, 456482, 456761, 457548, 457726, 486875, 486963, 488721, 489181, 539712

Elymus mollis Trin. 갯그령; 479134, 479148, 479159, 488975

Eragrostis cilianensis (All.) Vignolo ex Janch. 참새그령; 457732

Eragrostis curvula (Schrad.) Nees 능수참새그령; 456138, 486674

Eragrostis ferruginea (Thunb.) P. Beauv. 그령; 399238, 399548, 399585, 410661, 410727 , 456338, 456447, 456823, 457059, 457131, 457321, 457765, 488615, 488765, 488911, 489097

Eragrostis multicaulis Steud. 비노리; 291820, 486901, 488628, 489182

Eragrostis poaeoides P. Beauv. 좀새그령; 489026, 489143, 489466

Festuca arundinacea Schreb. 큰김의털; 364303, 410283, 437422, 437622, 437850, 456040, $456141,456641,456722,456976,479179$

Festuca myuros L. 들묵새; 410343, 455986, 456632, 456692, 456937, 479247, 479311

Festuca ovina L. 김의털; 437395, 437693, 437586,437871, 456200

Festuca parvigluma Steud. 김의털아재비; $364464,364624,410227,410369,437286,437418$, 437618, 437764, 456045, 456107, 456679, 456892, 479768

$\bigcirc \bigcirc \quad \bigcirc \quad \bigcirc \bigcirc$

$\bigcirc 000 \bigcirc \bigcirc \bigcirc \bigcirc$

$0 \bigcirc 0 \bigcirc \quad 00$

$\bigcirc 00 \quad 00000000 \bigcirc 0$

$0 \quad \bigcirc \quad 00 \bigcirc \bigcirc$

$\bigcirc$

$000 \bigcirc \bigcirc \quad 000$

- 000000000000000

$0000 \bigcirc 0000$

00000000000000

00000000000000000

$\bigcirc \bigcirc$

$\circ \bigcirc \bigcirc 0$

$\bigcirc$

0000000000000000

$\bigcirc \bigcirc \bigcirc \bigcirc \bigcirc \bigcirc \bigcirc$

$000 \quad 000000000$

$0 \bigcirc 00$

$\bigcirc$<smiles>O</smiles>

0000000000000000

$0 \quad 00 \quad 0$

$\bigcirc \bigcirc$

0000000000

$\circ \bigcirc 00000$

$000 \quad 0 \bigcirc \quad 00000$

$00000000000 \quad 00$ 
Appendix 1. Continued.

1233455678891011121314151617

Hemarthria compressa var. japonica Hack. 쇠치기풀; 399737, 457600, 488494, 489060

Glyceria leptolepis Ohwi 왕미꾸리광이; 488872

Hierochloe odorata (L.) P. Beauv. 향모; 364297, 410291, 427820, 427876, 427895, 427926, 437891, 456209, 456639, 478783

Imperata cylindrica var. koenigii (Retz.) Benth. ex Pilg. 띠; 364294, 364458, 410248, 437442, 437787, 456142, 479199, 479290, 479546, 489788

○

$\bigcirc \bigcirc$

○

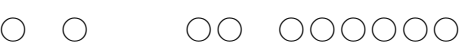

$\bigcirc$

$\bigcirc \bigcirc 000 \bigcirc \bigcirc 0$

Isachne globosa (Thunb.) Kuntze 기장대풀; 399358, 399414, 399799, 410455, 410620, 410737, 456813, 457018, 457275, 457604, 486761, 488536, 488882

00000000000000

Ischaemum crassipes (Steud.) Thell. 쇠보리; 410523, 457115, 457297, 457766, 486624, 489002

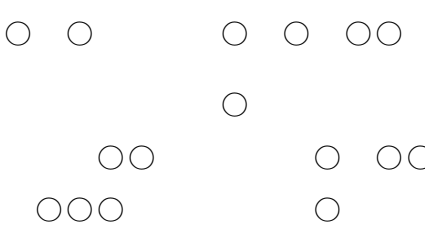

Leptochloa malabarica (L.) Veldkamp 갯드렁새; 399378

Lolium multiflorum Lam. 쥐보리; 486977

Lolium perenne L. 호밀풀; 455987, 478771

Microstegium vimineum (Trin.) A. Camus 애기나도바랭이새; 399667, 399685, 410549, 410587, 410781, 456248, 456349, 456489, 457816, 489445, 489597, 489776

Miscanthus sacchariflorus (Maxim.) Hack. 물억새; 410557, 410795, 489553, 489748

Miscanthus sinensis Andersson 억새; 399313, 399586, 399618, 399787, 410546, 410635, 410742, 456379, 456443, 457019, 457411, 457835, 488684, 488740, 489010, 489021

Moliniopsis japonica (Hack.) Hayata 진퍼리새; 399505, 399568, 399660, 457305

Muhlenbergia japonica Steud. 쥐꼬리새; 410696, 457867

Oplismenus undulatifolius (Ard.) Roem. \& Schult. 주름조개풀; 399460, 456235, 457743, 474867

Panicum bisulcatum Thunb. 개기장; 399472, 399549, 399695, 410644, 410776, 456342, 456421, 456421, 457031, 457492, 457848, 488534, 489004, 489660

Panicum dichotomiflorum Michx. 미국개기장; 399627, 399666, 400761, 410463, 410585, 410764, 456457, 457517, 457974, 488645, 488987, 489202, 489603, 489943

Paspalum thunbergii Kunth ex Steud. 참새피; 399441, 399537, 399755, 399790, 410493, 410627, 410718, 456528, 456822, 457264, 457594, 488616, 488783, 489185, 489564

Pennisetum alopecuroides (L.) Spreng. 수크령; 399245, 399400, 399535, 410662, 410752, $456335,456818,457035,457155,457475,457762,488648,488802$

Phalaris arundinacea L. 갈풀; 399351, 456048, 456645, 456890, 479739

Phragmites communis Trin. 갈대; 399567, 399617, 399640, 399786, 410421, 410565, 410711, 456250, 456380, 456498, 456767, 457512, 457807, 488598, 488741, 489055, 489231

Phragmites japonica Steud. 달뿌리풀; 399705, 410648, 410814, 488859

Poa acroleuca Steud. 실포아풀; 399677, 479757

Poa annua L. 새포아풀; 364618, 410534, 410668, 427894, 437302, 437373, 437682, 456044, 456178, 456597, 456753, 456949, 479220, 479276

Poa nipponica Koidz. 큰꾸러미풀; 456156, 456657, 479468

Poa pratensis L. 왕포아풀; 364300, 364459, 364686, 410245, 437348, 437355, 437597, 437657, 437816, 437894, 456046, 456727, 456948, 479636

Poa sphondylodes Trin. 포아풀; 410266, 437614, 437751, 437796, 456973, 479406, 479587
00000000

00000<smiles>O=CO</smiles>

$\bigcirc \bigcirc \bigcirc \bigcirc \bigcirc \bigcirc \bigcirc \bigcirc \bigcirc$

$\bigcirc \bigcirc$

$\bigcirc \quad 0$

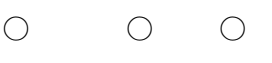

$\bigcirc \bigcirc 0 \bigcirc \bigcirc \bigcirc \bigcirc \bigcirc \bigcirc 000 \bigcirc 0$ $\bigcirc \bigcirc 0000 \bigcirc \bigcirc \bigcirc 0$

000000000000000

$\bigcirc \bigcirc 0 \bigcirc \bigcirc \bigcirc \bigcirc \quad \bigcirc \bigcirc \bigcirc \bigcirc \bigcirc$<smiles>OC1OCO1</smiles>

00000000000000000

$\bigcirc \bigcirc \bigcirc$<smiles>[Co]</smiles>

$\bigcirc$

$\bigcirc 0000000 \bigcirc 00$ 0000<smiles>OC1CO1</smiles>

○ 0000000000000 $\circ \quad 0000 \quad 0 \quad 0$ $\bigcirc \bigcirc 0 \bigcirc \bigcirc \bigcirc 0$ 
Appendix 1. Continued.

Collection sites $^{\mathrm{a}}$

Taxa/Collection numbers (NIBRVP0000-)

122354566778991011121314151617

Puccinellia distans (Jacq.) Parl. 처진미꾸리광이; 479373

Puccinellia kurilensis (Takeda) Honda 천도미꾸리광이; 467788

Sacciolepis indica (L.) Chase 좀물뚝새; 399576, 399792, 410472, 410631, 457381, 457785, 488678

Sasa japonica (Siebold \& Zucc. ex Steud.) Makino 이대; 427637, 427847, 488698, 488995

Setaria faberi R. A. W. Herrm. 가을강아지풀; 486944

Setaria glauca (L.) P. Beauv. 금강아지풀; 399559, 399722, 399796, 410420, 410589, 410745,

456222, 456431, 457468, 457734, 488507, 488738, 489069, 489207

Setaria viridis (L.) P. Beauv. 강아지풀; 156359, 399293, 410562, 456525, 456809, 457051, 457307, 457612, 486705, 486965, 488775, 489962

Spodipogon sibiricus Trin. 큰기름새; 156184, 410503, 456341, 457832, 488579, 488875

Sporobolus elongatus R. Br. 쥐꼬리새풀; 489770

Sporobolus japonicus (Steud.) Maxim. \& Rendle 나도잔디; 410613

Stipa pekinensis Hance 나래새; 410719, 457742

Themeda triandra ssp. japonica (Willd.) T. Koyama 솔새; 156256, 399697, 456351, 457401, 462961, 474870, 488820

Trisetum bifidum (Thunb.) Ohwi 잠자리피; 291823, 456038, 456678, 456745, 457597, 479260, 479310, 479338

Zizania caduciflora (Turcz. ex Trin.) Hand.-Mazz. 줄; 399497, 410575, 410773, 456862, 486768, 488548, 489211

Zoysia japonica Steud. 잔디; 364280, 364679, 410303, 410373, 437690, 437867, 455988, 456609, 456718, 456971

Zoysia macrostachya Franch. \& Sav. 왕잔디; 410321, 479128

Zoysia sinica Hance 갯잔디; 410397, 479175

\section{Sparganiaceae 흑삼룽과}

Sparganium erectum L. 흑삼릉; 399321, 479236, 486826

Sparganium japonicum Rothert 긴흑삼릉; 399504, 456366

\section{Typhaceae 부들과}

Typha angustifolia L. 애기부들; 212539, 213386, 399234, 399310, 399469, 410461, 456264, 456323, 456560, 456855, 457437, 486721, 486786, 489208

Typha latifolia L. 큰잎부들; 399275, 456322, 456483

Typha orientalis C. Presl. 부들; 156356, 292175, 457568, 486820, 486947, 488685, 489196

\section{Pontederiaceae 물옥잠과}

Monochoria korsakowii Regel \& Maack 물옥잠; 212538, 399337, 399491, 410768, 456860, 488862, 489199

Monochoria vaginalis var. plantaginea (Roxb.) Solms 물달개비; 399251, 399357, 410496, 410710, 457829

\section{Liliaceae 백합과}

Allium deltoidefistulosum S. O. Yu, S. T. Lee \& W. T. Lee 세모부추; 456237, 457494

Allium macrostemon Bunge 산달래; 437404, 479226

Allium sacculiferum Maxim. 참산부추; 399622, 399686, 410527, 410680, 457434, 490010

Allium tuberosum Rottler ex Spreng. 부추; 488726

0000

0000

0000000000

$\bigcirc$

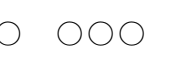

O

\section{$000000 \bigcirc \quad \bigcirc$}

(1)

$\bigcirc$

$\bigcirc \bigcirc \bigcirc \bigcirc \bigcirc \bigcirc$

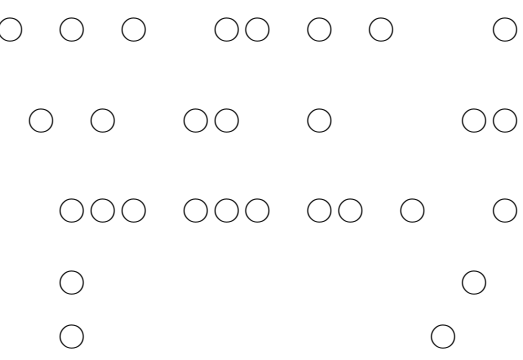

$\bigcirc \bigcirc \bigcirc$

$\bigcirc$

00000000000000

$\bigcirc \quad \bigcirc \bigcirc$

$000 \quad 0 \quad 00$

$\bigcirc \bigcirc \quad \bigcirc \quad \bigcirc \quad \bigcirc 0$

$\bigcirc \bigcirc \bigcirc+\bigcirc$

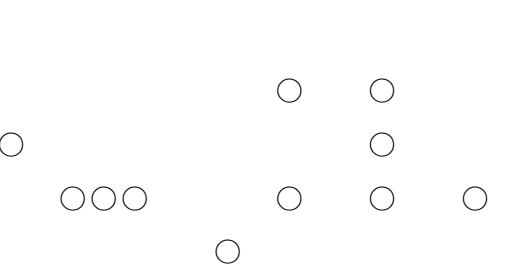


Appendix 1. Continued.

Taxa/Collection numbers (NIBRVP0000-)

Collection sites $^{\mathrm{a}}$

Asparagus oligoclonos Maxim. 방울비짜루; 364239, 410226

Convallaria keiskei Miq. 은방울꽃; 364251, 437460

Disporum smilacinum A. Gray 애기나리; 437714

Disporum viridescens (Maxim.) Nakai 큰애기나리; 364253, 410593

Lilium lancifolium Thunb. 참나리; 456861, 457640

Liriope spicata (Thunb.) Lour. 개맥문동; 488489

Polygonatum humile Fisch. ex Maxim. 각시둥굴레; 364246, 410326, 437284

Polygonatum odoratum var. pluriflorum (Miq.) Ohwi 둥굴레; 410230, 437314, 437481

Scilla scilloides (Lindl.) Druce 무릇; 399343, 488680, 489012

\section{Iridaceae 붓꽃과}

Iris ensata var. spontanea (Makino) Nakai 꽃창포; 213390, 457287, 489668

Iris laevigata Fisch. ex Fisch. \& C. A. Mey. 제비붓꽃; 410713, 417569

Iris pseudoacorus L. 노랑꽃창포; 456910, 462906, 462910, 479705

Iris rossii Baker 각시붓꽃; 437338

Iris sanguinea Donn ex Hornem. 붓꽃; 479500

Iris setosa Pall. ex Link 부채붓꽃; 399525, 410251, 437377, 437621, 437686, 437806, 456002,462915

\section{Smilacaceae 청미래덩굴과}

Smilax china L. 청미래덩굴; 156159, 399669, 410556, 410671, 437295, 437415, 437659, $456131,456471,457503,479554,489530$

Smilax sieboldii Miq. 청가시덩굴; 364247,437390

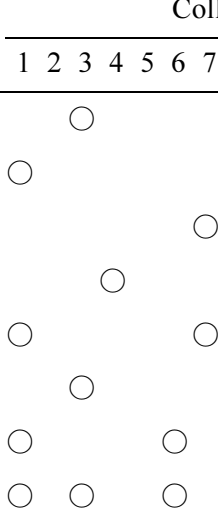

$\bigcirc \bigcirc$

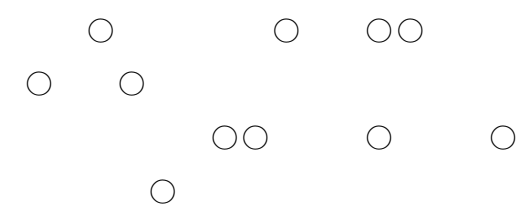

$\bigcirc \bigcirc \quad \bigcirc 0 \quad 00 \quad \bigcirc 0$

\section{Dioscoreaceae 마과}

Dioscorea oppositifolia L. 마; 410543, 410579, 410800, 457666, 488692, 488794, 488929, 489582

\section{Orchidaceae 난초과}

Liparis makinoana Schltr. 나리난초; 457898

Oreorchis patens (Lindl.) Lindl. 감자난초; 427845

Spiranthes sinensis (Pers.) Ames 타래난초; 414463, 486750, 486845

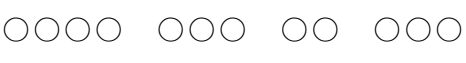

$\bigcirc \bigcirc$

$\bigcirc$

${ }^{\mathrm{a} C o l l e c t i o n ~ s i t e s: ~ 1, ~ H w a j i n p o h o ; ~ 2, ~ S o e n y u d a m ; ~ 3, ~ S o n g j i h o ; ~ 4, ~ C h e o n j i n h o ; ~ 5, ~ B o n g p o h o ; ~ 6, ~ B o n g p o s e u p j i ; ~ 7, ~ G w a n g p o h o ; ~ 8, ~ Y e o n g l a n g h o ; ~}$ 9. Cheongchoho; 10, Gapyeongriseupji; 11, Ssangho; 12, Yeomgaeho; 13, Gungaeho; 14, Pomaeho; 15, Hyangho; 16, Sunpoho; 17, Kyeongpoho. 